NATIONAL WATER-QUALITY ASSESSMENT PROGRAM NATIONAL SYNTHESIS ON VOLATILE ORGANIC COMPOUNDS

\title{
Occurrence and Temporal Variability of Methyl tert-Butyl Ether (MTBE) and Other Volatile Organic Compounds in Select Sources of Drinking Water: Results of the Focused Survey
}

Water-Resources Investigations Report 02-4084

Prepared in cooperation with the Metropolitan Water District of Southern California, Oregon Health \& Science University, and the American Water Works Association Research Foundation 


\section{Occurrence and Temporal Variability of Methyl tert-Butyl Ether (MTBE) and Other Volatile Organic Compounds in Select Sources of Drinking Water: Results of the Focused Survey}

By Gregory C. Delzer and Tamara Ivahnenko

Water-Resources Investigations Report 02-4084

Prepared in cooperation with the Metropolitan Water District of Southern California, Oregon Health \& Science University, and the

American Water Works Association Research Foundation 


\title{
U.S. Department of the Interior
}

GALE A. NORTON, Secretary

\author{
U.S. Geological Survey \\ Charles G. Groat, Director
}

The use of firm, trade, and brand names in this report is for identification purposes only and does not constitute endorsement by the U.S. Government.

Rapid City, South Dakota: 2003

For additional information write to:

\section{District Chief}

U.S. Geological Survey

1608 Mt. View Road

Rapid City, SD 57702

Copies of this report can be purchased from:

\section{U.S. Geological Survey \\ Information Services \\ Building 810 \\ Box 25286, Federal Center \\ Denver, CO 80225-0286}




\section{FOREWORD}

The U.S. Geological Survey (USGS) is committed to providing the Nation with accurate and timely scientific information that helps enhance and protect the overall quality of life and that facilitates effective management of water, biological, energy, and mineral resources (http://www.usgs.gov/). Information on the quality of the Nation's water resources is critical to assuring the long-term availability of water that is safe for drinking and recreation and suitable for industry, irrigation, and habitat for fish and wildlife.

Population growth and increasing demands for multiple water uses make water availability, now measured in terms of quantity and quality, even more essential to the long-term sustainability of our communities and ecosystems.

The USGS implemented the National WaterQuality Assessment (NAWQA) Program in 1991 to support national, regional, and local information needs and decisions related to water-quality management and policy (http://water.usgs.gov/nawqa). Shaped by and coordinated with ongoing efforts of other Federal, State, and local agencies, the NAWQA Program is designed to answer: What is the condition of our Nation's streams and ground water? How are the conditions changing over time? How do natural features and human activities affect the quality of streams and ground water, and where are those effects most pronounced? By combining information on water chemistry, physical characteristics, stream habitat, and aquatic life, the NAWQA Program aims to provide science-based insights for current and emerging water issues and priorities.

From 1991-2001, the NAWQA Program completed interdisciplinary assessments in 51 of the Nation's major river basins and aquifer systems, referred to as Study Units (http://water.usgs.gov/ nawqa/studyu.html). Baseline conditions were established for comparison to future assessments, and long-term monitoring was initiated in many of the basins. During the next decade, 42 of the 51 Study
Units will be reassessed so that 10 years of comparable monitoring data will be available to determine trends at many of the Nation's streams and aquifers. The next 10 years of study also will fill in critical gaps in characterizing water-quality conditions, enhance understanding of factors that affect water quality, and establish links between sources of contaminants, the transport of those contaminants through the hydrologic system, and the potential effects of contaminants on humans and aquatic ecosystems.

The USGS aims to disseminate credible, timely, and relevant science information to inform practical and effective water-resource management and strategies that protect and restore water quality. We hope this NAWQA publication will provide you with insights and information to meet your needs, and will foster increased citizen awareness and involvement in the protection and restoration of our Nation's waters.

The USGS recognizes that a national assessment by a single program cannot address all water-resource issues of interest. External coordination at all levels is critical for a fully integrated understanding of watersheds and for costeffective management, regulation, and conservation of our Nation's water resources. The NAWQA Program, therefore, depends on advice and information from other agencies-Federal, State, interstate, Tribal, and local-as well as nongovernmental organizations, industry, academia, and other stakeholder groups. Your assistance and suggestions are greatly appreciated.
Robert M. Hirsch

Associate Director for Water 



\section{CONTENTS}

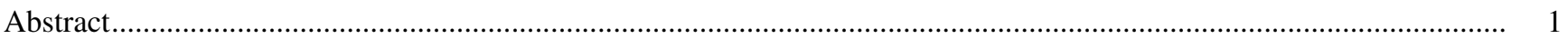

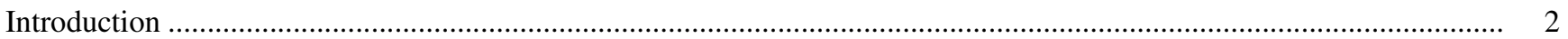

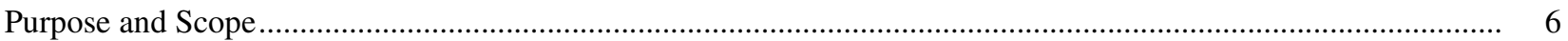

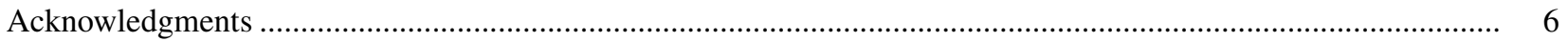

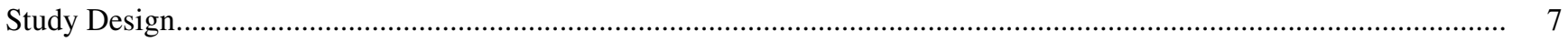

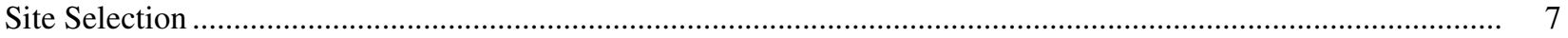

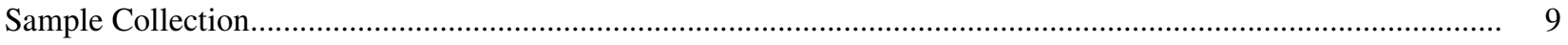

Occurrence and Temporal Variability of Volatile Organic Compounds ....................................................................... 10

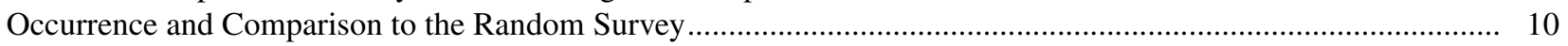

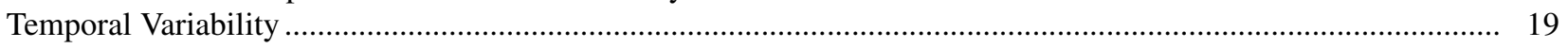

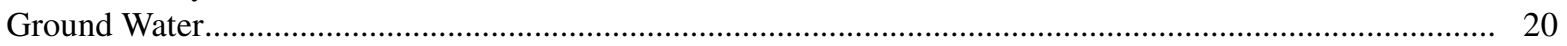

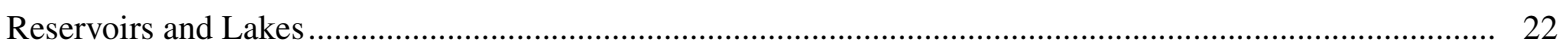

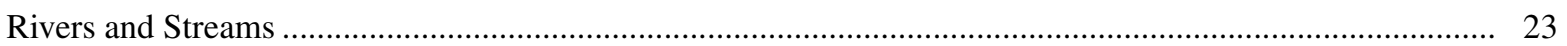

Anthropogenic Factors Associated with MTBE, Gasoline Oxygenates, and Trihalomethanes ...................................... 25

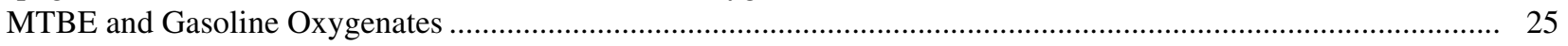

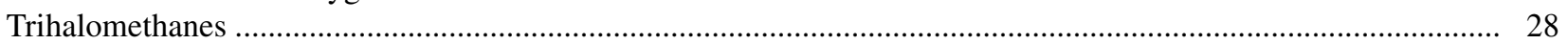

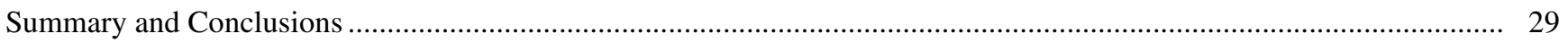

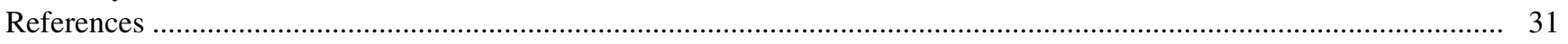

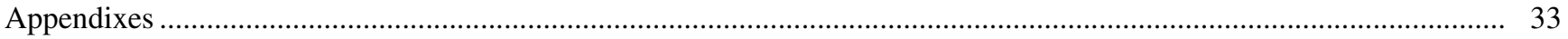

A. Number of community water system sources sampled per State ................................................................. 35

B. Detailed review of field quality-control data ............................................................................................... 39

C. Data acceptance criteria using quality-control data .................................................................................... 53

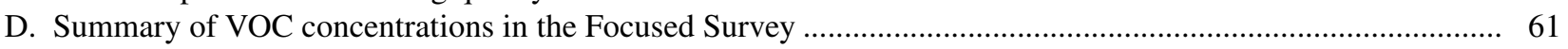

\section{FIGURES}

1. Map showing methyl tert-butyl ether (MTBE) high-use areas and location of source waters sampled in the Focused Survey

2-8. Graphs showing:

2. Detection frequency at or above the minimum reporting level of individual volatile organic compounds in source waters sampled in the Focused Survey versus the Random Survey.

3. Detection frequency at or above the minimum reporting level of volatile organic compound subgroups in community water system source waters sampled in the Focused Survey and the Random Survey .......

4. Detection frequency at or above the minimum reporting level of any volatile organic compound (VOC) and subgroup of VOCs in ground-water sources sampled in the Focused Survey and Random Survey by size of community water system.

5. Detection frequency at or above the minimum reporting level of any volatile organic compound (VOC) and subgroup of VOCs in surface-water sources sampled in the Focused Survey and Random Survey by size of community water system.

6. Number of surface-water samples collected by source type and season

7. Detection frequency at or above the minimum reporting level of any volatile organic compound (VOC) and by subgroup of VOCs in community water system source waters by source type.

8. Comparison of the detection frequency of at least one volatile organic compound (VOC) at or above the method detection limit by subgroup of VOCs in the first and second sampling of ground-water source water. 


\section{FIGURES-Continued}

9. Boxplots of detected concentrations of volatile organic compound subgroups in ground-water source water collected in the first and second samples

10. Graph showing detection frequency of at least one volatile organic compound (VOC) at or above the method detection limit by subgroup of VOCs in reservoir and lake source waters by season...

11. Boxplots of detected concentrations of volatile organic compound subgroups in reservoir and lake source waters by season

12. Graph showing detection frequency of at least one volatile organic compound (VOC) at or above the method detection limit by subgroup of VOCs in river and stream source waters by season.....

3. Boxplots of detected concentrations of volatile organic compound subgroups in river and stream source waters by season.....

14. Boxplots of detected concentrations of methyl tert-butyl ether (MTBE) in reservoir and lake source waters by location in MTBE low- and high-use areas

15. Boxplots of detected concentrations of methyl tert-butyl ether (MTBE) in river and stream source waters by location in MTBE low- and high-use areas ...

6. Graph showing average sum of gasoline oxygenate concentrations versus watercraft-use factor.......

17. Boxplots of average concentrations of gasoline oxygenates by watercraft-use quartiles

B1. Graph showing concentration of methyl tert-butyl ether in field duplicate and source-water samples.

\section{TABLES}

1. Volatile organic compounds (VOCs) analyzed as part of the Focused Survey and related information by subgroups of VOCs

2. Summary of number of source waters sampled, frequency of sample collection, and number of samples collected during the Focused Survey.....

3. Summary of the frequency and number of quality-control samples collected during the Focused Survey ...........

4. Summary of detection frequencies of any volatile organic compound (VOC), any subgroup of VOCs, and individual VOCs in source waters sampled in the Focused and Random Surveys...

. Distribution of source waters sampled in the Focused and Random Surveys by source-type and size of community water system based on population served

A1. Number of Community Water System source waters sampled that were suspected of having concentrations of methyl tert-butyl ether, by State and source-size category ....

A2. Number of Community Water System source waters sampled with known concentrations of methyl tert-butyl ether, by State and source-size category

A3. Number of Community Water System source waters sampled as control sites where methyl tert-butyl ether would likely not be present, by State and source-size category

B1. Summary of volatile organic compounds detected in field-equipment blanks, field-reagent blanks, and trip-reagent blanks

B2. Relation between concentrations of volatile organic compounds in 292 companion field blank samples and trip blank samples .....

B3. Relation between concentrations of volatile organic compounds in 27 companion field equipment blank samples and field reagent blank samples

4. Relation between concentrations of volatile organic compounds in 27 companion field equipment

B5. Statistical comparison of concentrations of volatile organic compounds in source-water and

C1. Schematic diagram for adjusting the frequency of detection of volatile organic compounds in

C2. Number of source-water samples that meet specified conditions at the method detection limit, with respect to the possibility of random contamination.

C3. Detection frequency of volatile organic compounds detected at or above the method detection level in source water before and after applying the quality-control screening process.

C4. Schematic diagram for adjusting the frequency of detection of methyl tert-butyl ether in source-water samples to reflect possible random sample contamination.

D1. Statistical summary of volatile organic compounds in source-water samples in the Focused Survey........ 


\title{
Occurrence and Temporal Variability of Methyl tert-Butyl Ether (MTBE) and Other Volatile Organic Compounds in Select Sources of Drinking Water: Results of the Focused Survey
}

\author{
By Gregory C. Delzer and Tamara Ivahnenko
}

\section{ABSTRACT}

The large-scale use of the gasoline oxygenate methyl tert-butyl ether (MTBE), and its high solubility, low soil adsorption, and low biodegradability, has resulted in its detection in ground water and surface water in many places throughout the United States. Studies by numerous researchers, as well as many State and local environmental agencies, have discovered high levels of MTBE in soils and ground water at leaking underground gasoline-storage-tank sites and frequent occurrence of low to intermediate levels of MTBE in reservoirs used for both public water supply and recreational boating.

In response to these findings, the American Water Works Association Research Foundation sponsored an investigation of MTBE and other volatile organic compounds (VOCs) in the Nation's sources of drinking water. The goal of the investigation was to provide additional information on the frequency of occurrence, concentration, and temporal variability of MTBE and other VOCs in source water used by community water systems (CWSs). The investigation was completed in two stages: (1) reviews of available literature and (2) the collection of new data. Two surveys were associated with the collection of new data. The first, termed the Random Survey, employed a statistically stratified design for sampling source water from 954 randomly selected CWSs. The second, which is the focus of this report, is termed the Focused Survey, which included samples collected from 134 CWS source waters, including ground water, reservoirs, lakes, rivers, and streams, that were suspected or known to contain MTBE. The general intent of the Focused Survey was to compare results with the Random Survey and provide an improved understanding of the occurrence, concentration, temporal variability, and anthropogenic factors associated with frequently detected VOCs.

Each sample collected was analyzed for 66 VOCs, including MTBE and three other ether gasoline oxygenates (hereafter termed gasoline oxygenates). As part of the Focused Survey, 451 source-water samples and 744 field qualitycontrol (QC) samples were collected from 78 ground-water, 39 reservoir and (or) lake, and 17 river and (or) stream source waters at fixed intervals for a period of 1 year.

Using a common assessment level of $0.2 \mu \mathrm{g} / \mathrm{L}$ (micrograms per liter) $(2.0 \mu \mathrm{g} / \mathrm{L}$ for methyl ethyl ketone), 37 of the 66 VOCs analyzed were detected in both surveys. However, VOCs, especially MTBE and other gasoline oxygenates, were detected more frequently in the Focused Survey than in the Random Survey. MTBE was detected in 55.5 percent of the CWSs sampled in the Focused Survey and in 8.7 percent of those sampled in the Random Survey. Little difference in occurrence, however, was observed for trihalomethanes (THMs), which were detected in 16.4 and 14.8 percent of Focused Survey and 
Random Survey CWSs, respectively. This may indicate a pervasive occurrence of THMs in several source-water types, regardless of CWS size or geographic location.

Using data at or above the method detection limit to assess temporal variability and anthropogenic factors associated with frequent detection of select VOCs, concentrations in the Focused Survey in ground-water, reservoir, and river source waters were typically less than $1 \mu \mathrm{g} / \mathrm{L}$. Also, at a 95-percent confidence interval, no statistically significant differences were observed in comparing concentrations in the first and second groundwater sample. A weak seasonal pattern was observed in samples collected from reservoirs and lakes where gasoline oxygenates and other gasoline compounds were detected more frequently during spring and summer, presumedly a result of increased use of motorized watercraft during these seasons. In contrast, seasonal patterns were not observed in samples collected from rivers and streams. The lack of seasonal differences in river and stream source waters sampled may indicate a common and continuous source of contamination.

The most frequently detected VOC (MTBE) and the two most frequently occurring subgroups of VOCs (gasoline oxygenates and THMs) detected in CWS source waters were further characterized to evaluate some anthropogenic factors that may better explain their frequent occurrence. Gasoline oxygenates were detected in 73.9 percent of all CWSs sampled. The concentration of gasoline oxygenates was slightly correlated with watercraft use on reservoirs inside MTBE high-use areas $\left(\mathrm{r}^{2}=0.3783\right)$ but not outside of these areas $\left(r^{2}=0.0242\right)$. In general, the concentration of gasoline oxygenates increased as watercraft use increased. THMs were detected in 47.8 percent of the CWSs supplied by surface water. The frequent occurrence of THMs in reservoir source waters was determined to be an artifact of disinfection and the recycling of chlorinated water to these reservoirs. All CWSs with frequent occurrence of THMs served by a reservoir indicated that chlorine was added to waters for various reasons and that the chlorinated water was then released back to, or upstream of, the reservoir or lake that was sampled.

\section{INTRODUCTION}

The gasoline oxygenate methyl tert-butyl ether (MTBE) has been added to gasoline to enhance octane levels since the late 1970's, and in 1990, the Clean Air Act (CAA) Amendments mandated seasonal or yearround use of oxygenated compounds (oxygenates) in gasoline in specific parts of the United States. Oxygenates are added to gasoline to increase the oxygen content, which enhances combustion and decreases vehicular carbon monoxide emissions. Oxygenates also reduce the need for benzene and other ozoneforming, aromatic compounds in gasoline. MTBE is the most commonly used oxygenate, followed by ethanol.

Oxygenates are added to gasoline during the winter months in areas where winter concentrations of carbon monoxide exceed established air-quality standards. This gasoline is called oxygenated (OXY) gasoline, which contains oxygenates at 2.7 percent by weight (15 percent by volume for MTBE) (U.S. Environmental Protection Agency, 1999b). In select areas, oxygenates are added to gasoline year round to abate ozone pollution during the summer months and carbon monoxide pollution during the winter months (U.S. Environmental Protection Agency, 1999a). This gasoline is called reformulated gasoline (RFG), which contains oxygenates at 2 percent by weight (11 percent by volume for MTBE).

The implementation of the CAA Amendments resulted in a substantial increase in the production and use of MTBE during the 1990's. For example, MTBE went from the 39th highest produced organic chemical in the United States in 1970 to the fourth highest in 1998 (Johnson and others, 2000). During that period, the aggregate production of MTBE was 60 million metric tons. In 1998, 39.7 million liters per day were used in the United States, 40 percent of which was used in California alone. Most of MTBE use is associated with RFG. MTBE is used in only about 3 percent of OXY gasoline, whereas MTBE is used in about 85 percent of all RFG (Wigglesworth, 1999).

MTBE is a possible human carcinogen. The U.S. Environmental Protection Agency (USEPA) has issued a taste and odor drinking water advisory of concentrations in the range of 20 to $40 \mu \mathrm{g} / \mathrm{L}$ (micrograms per liter) to avert unpleasant taste and odor effects in drinking water causing it to become non-potable (U.S. Environmental Protection Agency, 1997). The chemical properties of MTBE, such as high solubility in water, low soil-sorption properties, and low biodegradability in ground water may result in contamination of 
some private and public source waters, and some cities have lost substantial amounts of drinking-water supplies to MTBE contamination. For example, in Santa Monica, California, 75 percent of the drinking-water wells are now unusable due to MTBE; in South Lake Tahoe, California, one-third of the city's 34 drinkingwater wells have been shut down because of MTBE contamination; in Windham, Maine, wells have been taken offline; and Los Angeles, San Francisco, Santa Clara Valley, and Sacramento in California all have wells affected by MTBE (Bourelle, 1998; State of Maine, 1998; City of Santa Monica, 1999; California Department of Health Services, 2001). La Crosse, Kansas, also has had wells affected by MTBE; however, officials there have taken steps to remediate the problem and to treat the water rather than to remove the wells from service (Hattan, 2000).

Although isolated instances of MTBE contamination have been observed, the overall extent of MTBE occurrence in the Nation's drinking-water supplies has not been fully evaluated. The Interagency Assessment of Oxygenated Fuels (Zogorski and others, 1997) attempted to address the national occurrence of MTBE in drinking-water supplies, but was unable to do so due to insufficient data. As a result, additional assessments were recommended.

One such assessment, the focus of this report, was sponsored by the American Water Works Association Research Foundation (AWWARF), an organization that sponsors numerous research studies for the benefit of the drinking-water community. This assessment of MTBE in the Nation's drinking-water supplies was completed by the Metropolitan Water District of Southern California (MWDSC), the U.S. Geological Survey (USGS) National Water-Quality Assessment (NAWQA) Program, and the Oregon Health \& Science University (OHSU). This assessment studied not only MTBE but also 65 other volatile organic compounds (VOCs), including other ether gasoline oxygenates (hereafter termed gasoline oxygenates) in drinkingwater supplies (table 1), and tert-butyl alcohol (TBA) - a degradation by-product of MTBE. However, TBA results are not presented herein.

Drinking-water supplies studied were specifically termed source waters. Source water is defined by the American Water Works Association as "the supply of water for a water utility [that] is usually treated before distribution to consumers." A source water can be a river, brook, stream, lake, reservoir, impoundment, spring, or aquifer from which a supply of water is obtained. As such, the assessment did not study any waters that are within a distribution line or after treatment processes have been applied to the water.

The complete list of compounds included in this assessment also included 13 VOCs that are on the USEPA's Contaminant Candidate List (CCL) (U.S. Environmental Protection Agency, 1998). The CCL is a list of contaminants not currently regulated by a National Primary Drinking Water Standard. Additional data on these compounds are needed before a regulatory determination can be made. This national assessment of MTBE and other VOCs began in September 1998.

The national assessment of MTBE and other VOCs in source-water supplies was accomplished by a two-phase approach: (1) reviews of available literature, and (2) the collection of new drinking-waterquality data. The literature review was conducted in two phases. One review focused on MTBE taste and odor threshold concentrations and their relevance to aesthetic effects and possible water-treatment requirements. The second review concentrated on the occurrence of MTBE in public and domestic drinking-water supplies reported by national, regional, or statewide assessments (Delzer and Ivahnenko, 2003).

Two surveys were associated with the collection of new drinking-water data. The first survey, termed the Random Source-Water Survey (hereafter termed Random Survey), employed a statistically stratified design for sampling source water from 954 community water systems (CWSs) randomly selected on the basis of the total number of systems within five population served-size categories, source-water type, and the total number of people served by each of the source-size categories used within the United States. Findings of the Random Survey are reported elsewhere (Rowe and others, 2001; Grady, 2003). The second survey, which is the focus of this report, is termed the Focused Source-Water Survey (hereafter termed Focused Survey). The Focused Survey included samples collected from CWS source waters that were selected on the basis of factors that appear to be or are known to be related to the frequent detection of MTBE in water. The Focused Survey provides an improved understanding of the occurrence, concentration, temporal variability, and anthropogenic factors associated with the detection of MTBE and other frequently identified VOCs. It is important to note, for both the Random Survey and the Focused Survey, that CWSs were promised anonymity in presenting results. Specific information on the design of the Random and Focused Surveys is detailed in Ivahnenko and others (2001). 
Table 1. Volatile organic compounds (VOCs) analyzed as part of the Focused Survey and related information by subgroups of VOCs

[IUPAC, International Union of Pure and Applied Chemistry; --, none; CCL, compound is listed on the U.S. Environmental Protection Agency's Contaminant Candidate List]

\begin{tabular}{|c|c|c|c|c|}
\hline $\begin{array}{l}\text { Compound name (used } \\
\text { throughout report) }\end{array}$ & $\begin{array}{c}\text { Chemical } \\
\text { abstract service } \\
\text { number }\end{array}$ & IUPAC name & Other common names & $\begin{array}{l}\text { Chemical } \\
\text { formula }\end{array}$ \\
\hline \multicolumn{5}{|c|}{ Gasoline Oxygenates } \\
\hline tert-Amyl methyl ether (TAME) & $994-05-8$ & 2-Methoxy-2-methylbutane & -- & $\mathrm{C}_{6} \mathrm{H}_{14} \mathrm{O}$ \\
\hline Diisopropyl ether (DIPE) & $108-20-3$ & $2,2^{\prime}$-oxybis[propane] & -- & $\mathrm{C}_{6} \mathrm{H}_{14} \mathrm{O}$ \\
\hline Ethyl tert-butyl ether (ETBE) & $637-92-3$ & 2-Ethoxy-2-methylpropane & -- & $\mathrm{C}_{6} \mathrm{H}_{14} \mathrm{O}$ \\
\hline Methyl tert-butyl ether (MTBE) ${ }^{\mathrm{CCL}}$ & $1634-04-4$ & 2-Methoxy-2-methylpropane & -- & $\mathrm{C}_{5} \mathrm{H}_{12} \mathrm{O}$ \\
\hline \multicolumn{5}{|c|}{ Other Gasoline Compounds } \\
\hline Benzene & $71-43-2$ & Benzene & -- & $\mathrm{C}_{6} \mathrm{H}_{6}$ \\
\hline$n$-Butylbenzene & $104-51-8$ & $n$-Butylbenzene & 1-Phenylbutane & $\mathrm{C}_{10} \mathrm{H}_{14}$ \\
\hline sec-Butylbenzene & $135-98-8$ & (1-Methylpropyl)benzene & -- & $\mathrm{C}_{10} \mathrm{H}_{14}$ \\
\hline tert-Butylbenzene & $98-06-6$ & (1,1-Dimethylethyl)benzene & -- & $\mathrm{C}_{10} \mathrm{H}_{14}$ \\
\hline Ethylbenzene & $100-41-4$ & Ethylbenzene & Phenylethane & $\mathrm{C}_{8} \mathrm{H}_{10}$ \\
\hline Naphthalene $\mathrm{CCL}^{\mathrm{CL}}$ & $91-20-3$ & Naphthalene & -- & $\mathrm{C}_{10} \mathrm{H}_{8}$ \\
\hline Toluene & $108-88-3$ & Methylbenzene & -- & $\mathrm{C}_{7} \mathrm{H}_{8}$ \\
\hline 1,3,5-Trimethylbenzene & $108-67-8$ & 1,3,5-Trimethylbenzene & Mesitylene & $\mathrm{C}_{9} \mathrm{H}_{12}$ \\
\hline$m, p$-Xylene & $\begin{array}{r}108-38-3 / \\
106-42-3\end{array}$ & $\begin{array}{l}\text { 1,3-Dimethylbenzene and } \\
\text { 1,4-Dimethylbenzene }\end{array}$ & $m$-Xylene, $p$-Xylene & $\mathrm{C}_{8} \mathrm{H}_{10}$ \\
\hline$o$-Xylene & $95-47-6$ & 1,2-Dimethylbenzene & -- & $\mathrm{C}_{8} \mathrm{H}_{10}$ \\
\hline \multicolumn{5}{|c|}{ Trihalomethanes } \\
\hline Bromodichloromethane & $75-27-4$ & Bromodichloromethane & Dichlorobromomethane & $\mathrm{CHBrCl}_{2}$ \\
\hline Bromoform & $75-25-2$ & Tribromomethane & -- & $\mathrm{CHBr}_{3}$ \\
\hline Chlorodibromomethane & $124-48-1$ & Chlorodibromomethane & Dibromochloromethane & $\mathrm{CHBr}_{2} \mathrm{Cl}$ \\
\hline Chloroform & $67-66-3$ & Trichloromethane & -- & $\mathrm{CHCl}_{3}$ \\
\hline \multicolumn{5}{|c|}{ Solvents } \\
\hline Bromobenzene $e^{\mathrm{CCL}}$ & $108-86-1$ & Bromobenzene & Phenyl bromide & $\mathrm{C}_{6} \mathrm{H}_{5} \mathrm{Br}$ \\
\hline Carbon tetrachloride & $56-23-5$ & Tetrachloromethane & -- & $\mathrm{CCl}_{4}$ \\
\hline Chlorobenzene & $108-90-7$ & Chlorobenzene & Monochlorobenzene & $\mathrm{C}_{6} \mathrm{H}_{5} \mathrm{Cl}$ \\
\hline Chloroethane & $75-00-3$ & Chloroethane & Ethyl chloride & $\mathrm{C}_{2} \mathrm{H}_{5} \mathrm{Cl}$ \\
\hline 2-Chlorotoluene & $95-49-8$ & 1-Chloro-2-methylbenzene & $o$-chlorotoluene & $\mathrm{C}_{7} \mathrm{H}_{7} \mathrm{Cl}$ \\
\hline 4-Chlorotoluene & $106-43-4$ & 1-Chloro-4-methylbenzene & $p$-chlorotoluene & $\mathrm{C}_{7} \mathrm{H}_{7} \mathrm{Cl}$ \\
\hline Dibromomethane & $74-95-3$ & Dibromomethane & Methylene bromide & $\mathrm{CH}_{2} \mathrm{Br}_{2}$ \\
\hline 1,2-Dichlorobenzene & $95-50-1$ & 1,2-Dichlorobenzene & $o$-Dichlorobenzene & $\mathrm{C}_{6} \mathrm{H}_{4} \mathrm{Cl}_{2}$ \\
\hline 1,3-Dichlorobenzene & $541-73-1$ & 1,3-Dichlorobenzene & $m$-dichlorobenzene & $\mathrm{C}_{6} \mathrm{H}_{4} \mathrm{Cl}_{2}$ \\
\hline 1,1-Dichloroethane $\mathrm{CCL}^{\mathrm{CL}}$ & $75-34-3$ & 1,1-Dichloroethane & Ethylidene chloride & $\mathrm{C}_{2} \mathrm{H}_{4} \mathrm{Cl}_{2}$ \\
\hline
\end{tabular}


Table 1. Volatile organic compounds (VOCs) analyzed as part of the Focused Survey and related information by subgroups of VOCs-Continued

[IUPAC, International Union of Pure and Applied Chemistry; --, none; CCL, compound is listed on the U.S. Environmental Protection Agency's Contaminant Candidate List]

\begin{tabular}{|c|c|c|c|c|}
\hline $\begin{array}{l}\text { Compound name (used } \\
\text { throughout report) }\end{array}$ & $\begin{array}{c}\text { Chemical } \\
\text { abstract service } \\
\text { number }\end{array}$ & IUPAC name & Other common names & $\begin{array}{c}\text { Chemical } \\
\text { formula }\end{array}$ \\
\hline \multicolumn{5}{|c|}{ Solvents-Continued } \\
\hline 1,2-Dichloroethane & $107-06-2$ & 1,2-Dichloroethane & Ethylene dichloride & $\mathrm{C}_{2} \mathrm{H}_{4} \mathrm{Cl}_{2}$ \\
\hline 1,1-Dichloroethene & $75-35-4$ & 1,1-Dichloroethene & Vinylidene chloride & $\mathrm{C}_{2} \mathrm{H}_{2} \mathrm{Cl}_{2}$ \\
\hline cis-1,2-Dichloroethene & $156-59-2$ & cis-1,2-Dichloroethene & (Z)-1,2-dichloroethene & $\mathrm{C}_{2} \mathrm{H}_{2} \mathrm{Cl}_{2}$ \\
\hline trans-1,2-Dichloroethene & $156-60-5$ & trans-1,2-Dichloroethene & (E)-1,2-dichloroethene & $\mathrm{C}_{2} \mathrm{H}_{2} \mathrm{Cl}_{2}$ \\
\hline 1,2-Dichloropropane & $78-87-5$ & 1,2-Dichloropropane & Propylene dichloride & $\mathrm{C}_{3} \mathrm{H}_{6} \mathrm{Cl}_{2}$ \\
\hline Hexachloroethane & $67-72-1$ & 1,1,1,2,2,2-Hexachloroethane & Carbon hexachloride & $\mathrm{C}_{2} \mathrm{Cl}_{6}$ \\
\hline Methylene chloride & $75-09-2$ & Dichloromethane & -- & $\mathrm{CH}_{2} \mathrm{Cl}_{2}$ \\
\hline Methyl ethyl ketone (MEK) & $78-93-3$ & 2-Butanone & -- & $\mathrm{C}_{4} \mathrm{H}_{8} \mathrm{O}$ \\
\hline$n$-Propylbenzene & $103-65-1$ & $n$-Propylbenzene & 1-Phenylpropane & $\mathrm{C}_{9} \mathrm{H}_{12}$ \\
\hline 1,1,1,2-Tetrachloroethane & $630-20-6$ & 1,1,1,2-Tetrachloroethane & -- & $\mathrm{C}_{2} \mathrm{H}_{2} \mathrm{Cl}_{4}$ \\
\hline 1,1,2,2-Tetrachloroethane $\mathrm{CCL}^{\mathrm{CL}}$ & $79-34-5$ & 1,1,2,2-Tetrachloroethane & -- & $\mathrm{C}_{2} \mathrm{H}_{2} \mathrm{Cl}_{4}$ \\
\hline Tetrachloroethene & $127-18-4$ & Tetrachloroethene & Perchloroethene, PCE & $\mathrm{C}_{2} \mathrm{Cl}_{4}$ \\
\hline 1,2,4-Trichlorobenzene & $120-82-1$ & 1,2,4-Trichlorobenzene & -- & $\mathrm{C}_{6} \mathrm{H}_{3} \mathrm{Cl}_{3}$ \\
\hline 1,1,1-Trichloroethane & $71-55-6$ & 1,1,1-Trichloroethane & Methyl chloroform & $\mathrm{C}_{2} \mathrm{H}_{3} \mathrm{Cl}_{3}$ \\
\hline 1,1,2-Trichloroethane & $79-00-5$ & 1,1,2-Trichloroethane & Vinyl trichloride & $\mathrm{C}_{2} \mathrm{H}_{3} \mathrm{Cl}_{3}$ \\
\hline Trichloroethene (TCE) & $79-01-6$ & Trichloroethene & Trichloroethylene & $\mathrm{C}_{2} \mathrm{HCl}_{3}$ \\
\hline 1,2,3-Trichloropropane & $96-18-4$ & 1,2,3-Trichloropropane & Allyl trichloride & $\mathrm{C}_{3} \mathrm{H}_{5} \mathrm{Cl}_{3}$ \\
\hline \multicolumn{5}{|c|}{ Organic Synthesis } \\
\hline Acrylonitrile & $107-13-1$ & 2-Propenenitrile & -- & $\mathrm{C}_{3} \mathrm{H}_{3} \mathrm{~N}$ \\
\hline Bromochloromethane & $74-97-5$ & Bromochloromethane & Methylene chlorobromide & $\mathrm{CH}_{2} \mathrm{BrCl}$ \\
\hline 1,3-Dichloropropane ${ }^{\mathrm{CCL}}$ & $142-28-9$ & 1,3-Dichloropropane & Trimethylene dichloride & $\mathrm{C}_{3} \mathrm{H}_{6} \mathrm{Cl}_{2}$ \\
\hline 2,2-Dichloropropane $\mathrm{CCL}^{\mathrm{CL}}$ & $594-20-7$ & 2,2-Dichloropropane & -- & $\mathrm{C}_{3} \mathrm{H}_{6} \mathrm{Cl}_{2}$ \\
\hline 1,1-Dichloropropene ${ }^{\mathrm{CCL}}$ & $563-58-6$ & 1,1-Dichloropropene & -- & $\mathrm{C}_{3} \mathrm{H}_{4} \mathrm{Cl}_{2}$ \\
\hline Hexachlorobutadiene ${ }^{\mathrm{CCL}}$ & $87-68-3$ & 1,1,2,3,4,4-Hexachloro-1,3-butadiene & -- & $\mathrm{C}_{4} \mathrm{Cl}_{6}$ \\
\hline Isopropylbenzene & $98-82-8$ & (1-Methylethyl)benzene & Cumene & $\mathrm{C}_{9} \mathrm{H}_{12}$ \\
\hline$p$-Isopropyltoluene $\mathrm{CCL}^{\mathrm{CL}}$ & $99-87-6$ & 1-Isopropyl-4-methylbenzene & -- & $\mathrm{C}_{10} \mathrm{H}_{14}$ \\
\hline Styrene & $100-42-5$ & Ethenylbenzene & Vinyl benzene & $\mathrm{C}_{8} \mathrm{H}_{8}$ \\
\hline 1,2,3-Trichlorobenzene & $87-61-6$ & 1,2,3-Trichlorobenzene & -- & $\mathrm{C}_{6} \mathrm{H}_{3} \mathrm{Cl}_{3}$ \\
\hline 1,2,4-Trimethylbenzene ${ }^{\mathrm{CCL}}$ & $95-63-6$ & 1,2,4-Trimethylbenzene & Pseudocumene & $\mathrm{C}_{9} \mathrm{H}_{12}$ \\
\hline Vinyl bromide & $593-60-2$ & Bromoethene & -- & $\mathrm{C}_{2} \mathrm{H}_{3} \mathrm{Br}$ \\
\hline Vinyl chloride & $75-01-4$ & Chloroethene & -- & $\mathrm{C}_{2} \mathrm{H}_{3} \mathrm{Cl}$ \\
\hline
\end{tabular}


Table 1. Volatile organic compounds (VOCs) analyzed as part of the Focused Survey and related information by subgroups of VOCs-Continued

[IUPAC, International Union of Pure and Applied Chemistry; --, none; CCL, compound is listed on the U.S. Environmental Protection Agency's Contaminant Candidate List]

\begin{tabular}{|c|c|c|c|c|}
\hline $\begin{array}{l}\text { Compound name (used } \\
\text { throughout report) }\end{array}$ & $\begin{array}{c}\text { Chemical } \\
\text { abstract service } \\
\text { number }\end{array}$ & IUPAC name & Other common names & $\begin{array}{l}\text { Chemical } \\
\text { formula }\end{array}$ \\
\hline \multicolumn{5}{|c|}{ Fumigants } \\
\hline Bromomethane $\mathrm{CCL}^{\mathrm{CL}}$ & $74-83-9$ & Bromomethane & Methyl bromide & $\mathrm{CH}_{3} \mathrm{Br}$ \\
\hline 1,4-Dichlorobenzene & $106-46-7$ & 1,4-Dichlorobenzene & $p$-Dichlorobenzene & $\mathrm{C}_{6} \mathrm{H}_{4} \mathrm{Cl}_{2}$ \\
\hline cis-1,3-Dichloropropene $\mathrm{CCL}^{\mathrm{CC}, 1}$ & $10061-01-5$ & cis-1,3-Dichloropropene & (Z)-1,3-Dichloropropene & $\mathrm{C}_{3} \mathrm{H}_{4} \mathrm{Cl}_{2}$ \\
\hline trans-1,3-Dichloropropene $\mathrm{CCL}^{\mathrm{CL}} 1$ & $10061-02-6$ & trans-1,3-Dichloropropene & (E)-1,3-Dichloropropene & $\mathrm{C}_{3} \mathrm{H}_{4} \mathrm{Cl}_{2}$ \\
\hline \multicolumn{5}{|c|}{ Refrigerants } \\
\hline Chloromethane & $74-87-3$ & Chloromethane & Methyl chloride & $\mathrm{CH}_{3} \mathrm{Cl}$ \\
\hline Dichlorodifluoromethane & $75-71-8$ & Dichlorodifluoromethane & CFC 12, Freon 12 & $\mathrm{CCl}_{2} \mathrm{~F}_{2}$ \\
\hline Trichlorofluoromethane & $75-69-4$ & Trichlorofluoromethane & CFC 11, Freon 11 & $\mathrm{CCl}_{3} \mathrm{~F}$ \\
\hline $\begin{array}{l}\text { 1,1,2-Trichloro-1,2,2-trifluoro- } \\
\text { ethane }\end{array}$ & $76-13-1$ & 1,1,2-Trichloro-1,2,2-trifluoroethane & CFC 113, Freon 113 & $\mathrm{C}_{2} \mathrm{Cl}_{3} \mathrm{~F}_{3}$ \\
\hline
\end{tabular}

\footnotetext{
${ }^{1}$ The CCL lists only 1,3-dichloropropene. The two isomers, cis- and trans-, are measured separately in the analytical method used in this study.
}

\section{Purpose and Scope}

This report describes the occurrence and temporal variability of MTBE and other VOCs in CWS source water suspected or known to contain MTBE as part of the Focused Survey. In addition, comparisons between results of the Focused and Random Surveys on the occurrence of MTBE and other VOCs are summarized. This report also analyzes anthropogenic factors associated with the frequent occurrence of MTBE, other gasoline oxygenates, and trihalomethanes (THMs).

The 451 samples were collected at fixed intervals from 78 ground-water, 39 reservoir and (or) lake, and 17 river and (or) stream source waters in selected areas of the Nation. In addition, 744 field quality-control (QC) samples were collected, including trip-reagent blanks, field-reagent blanks, field-equipment blanks, and duplicate samples. All data underwent a thorough quality-control review process to accept or reject source-water data for inclusion in the Focused Survey. The resulting source-water data set included VOC concentrations greater than the method detection limit (MDL). However, an assessment level equal to the minimum reporting level (MRL) was used for comparing Focused Survey and Random Survey results.
Temporal variability of subgroups of VOCs was characterized for CWSs supplied by surface water by examining the frequency of occurrence and detected concentrations by season of the year. VOC subgroups include gasoline oxygenates, other gasoline compounds (excluding gasoline oxygenates), THMs, solvents, organic synthesis compounds, fumigants, and refrigerants.

Anthropogenic factors and their relation to concentrations of MTBE and two frequently occurring subgroups of VOCs-gasoline oxygenates and THMs - were examined. These factors include MTBE high-use areas, watercraft density, and ancillary information obtained from CWS personnel. These factors were characterized to determine their potential significance with respect to MTBE, gasoline oxygenates, and THM contamination.

\section{Acknowledgments}

The authors would like to thank the AWWARF and Kenan Ozekin for their support and oversight of this study. Also, the AWWARF project advisory committee, consisting of Homer C. Emery of the San Antonio Water System, David Lipsky of the New York 
City Department of Environmental Protection, and Howard Weinberg of the University of North Carolina, are recognized for their technical advice. Importantly, this assessment would not have been possible without the cooperation and assistance of the owners, operators, and staff of the CWSs that allowed access to sample their source waters.

The cooperation and assistance of the 31 USGS District offices that collected samples and worked directly with CWSs is greatly appreciated. All chemical analyses for volatile organic compounds in sourcewater samples were conducted at the MWDSC laboratory in LaVerne, California, under the direction of Bart Koch and Melissa Dale. The authors would like to thank John Zogorski, Stephen Grady, Rick Clawges, and Barbara Rowe of the USGS, Bart Koch of the MWDSC, and Paul Tratnyek of the Oregon Health \& Science University for their technical questions, comments, and suggestions during the design and implementation of this study.

Bart Koch of the MWDSC and Ryan Thompson and Stephen Grady of the USGS are thanked for providing thorough technical review and insight to this report. Finally, Janet Carter, Ella Decker, Connie Ross, and Chester Zenone of the USGS provided valuable editorial review and assistance in completing this report.

\section{STUDY DESIGN}

The Focused Survey was designed to sample source waters suspected or known to be contaminated with MTBE. An equal number of samples was intended to be collected from ground-water, reservoir and (or) lake, and river and (or) stream source waters. Furthermore, a fixed-interval sampling was followed in order to better understand temporal variability. Groundwater, reservoir and (or) lake, and river and (or) stream source waters were sampled biannually, quarterly, and eight times per year for one year, respectively. Finally, a rigorous field QC sampling regime and data interpretation process was followed in order to ensure that the samples collected were representative of the source water being sampled. Data from these field QC samples were used to accept or reject source-water data from the analyses presented in this report.

\section{Site Selection}

The original design of the Focused Survey called for 480 samples to be collected at fixed intervals from 140 CWS source waters. Specifically, 80 ground-water, 40 reservoir and (or) lake, and 20 river and (or) stream source waters were to be sampled. CWS source waters were selected for sampling if MTBE was suspected or known to occur in the source water. Source waters suspected to be contaminated with MTBE included those in highly urbanized, high population-density settings, usually in MTBE highuse areas. Occasionally, a source water was suspected to be contaminated with MTBE for other reasons. For example, reservoirs near MTBE high-use areas that allowed the use of motorized watercraft were suspected to be contaminated with MTBE. Source waters known to contain MTBE were identified on the basis of recently completed reports (Delzer and Ivahnenko, 2003) and discussions with local, State, or other Federal agency personnel. In addition, source waters analyzed as part of the Random Survey of this study in which concentrations of MTBE were greater than $0.5 \mu \mathrm{g} / \mathrm{L}$ also were selected for sampling. Further information on site selection and the design of the Focused Survey is presented in Ivahnenko and others (2001).

The final selection resulted in 134 CWS source waters sampled. The geographic distribution of the 134 source waters sampled in the Focused Survey with respect to the location of MTBE high-use areas, is shown in figure 1. MTBE high-use areas were defined as areas within the RFG Program that use MTBE in gasoline (U.S. Environmental Protection Agency, 1999a). Areas designated as "high use" had a median content of MTBE in gasoline greater than 9 percent by volume in at least one year or season from 1995 through 1999. Medians of MTBE content by volume in gasoline were determined from yearly data from the Reformulated Gasoline Survey (Stuart Romanow, U.S. Environmental Protection Agency, written commun., 1999) and seasonal (winter and summer) data from Motor Gasoline surveys conducted by the National Institute for Petroleum and Energy Research (Cheryl Dickson, TRW Systems \& Information Technology Group, written commun., 2001). All areas currently (2002) in the Federal RFG Program were considered MTBE high-use areas, with the exception of the Chicago and Milwaukee metropolitan areas, which use ethanol in gasoline to meet Federal oxygenate requirements. Two areas that were previously 


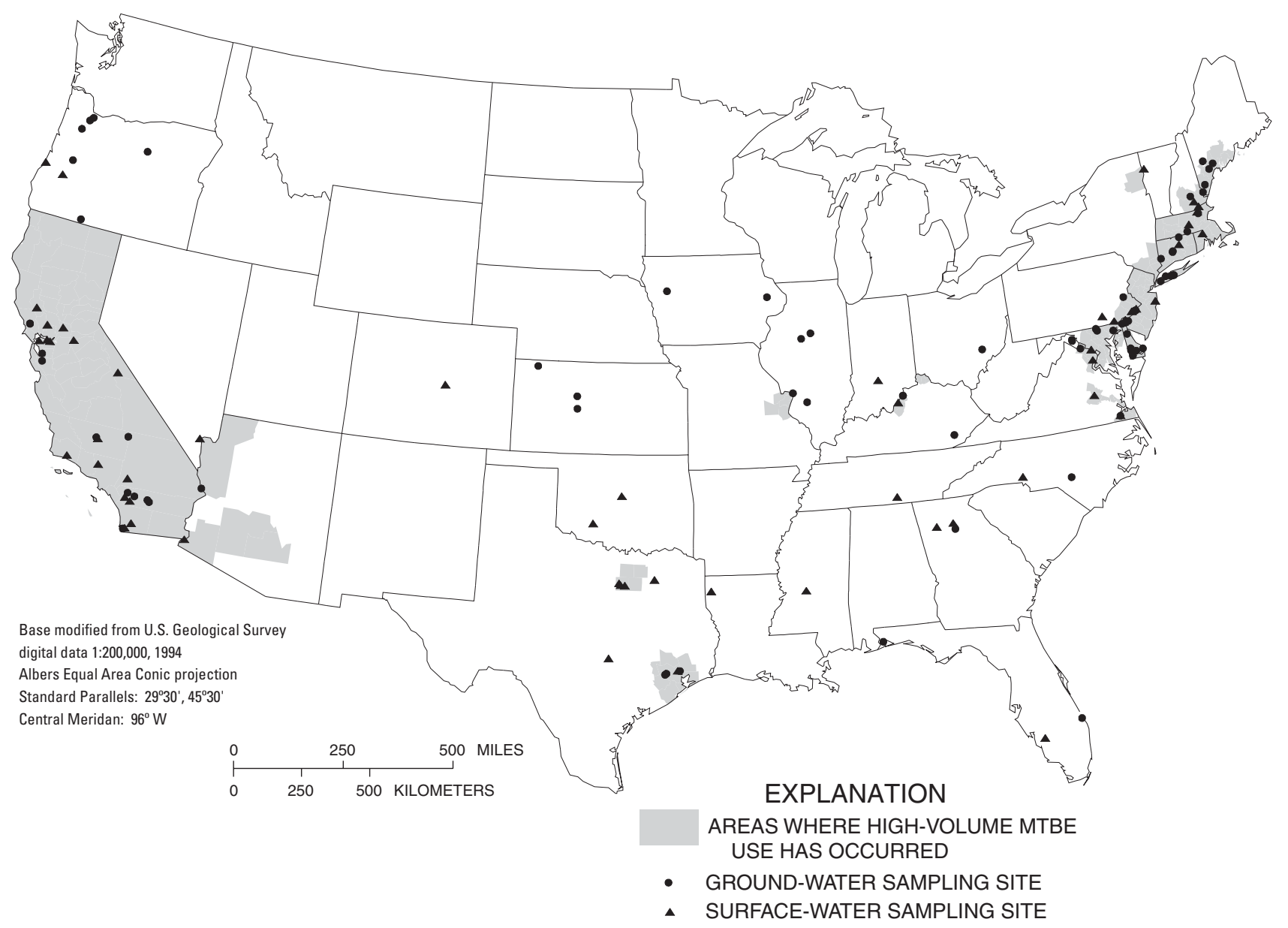

Figure 1. Methyl tert-butyl ether (MTBE) high-use areas and location of source waters sampled in the Focused Survey.

in the Federal RFG Program also were considered MTBE high-use areas for this analysis. Areas of southern Maine voluntarily entered (opted into) the RFG Program in 1995 and opted out in 1999. Phoenix, Arizona, voluntarily entered the RFG Program in 1997 and opted out in June 1998. Both of these areas have shown significant MTBE use (greater than 9 percent by volume) during the period 1995-99.

Two other areas also were considered MTBE high-use areas for this analysis. All areas in the State of California, including those outside Federal RFG Program areas, are considered to be MTBE high-use areas because of documented statewide MTBE highuse in state wintertime oxygenate and (or) California Cleaner Gasoline requirements (California Environmental Protection Agency, 1997; California Senate, 1998). Additionally, Yuma and Mohave Counties in Arizona are considered MTBE high-use areas because they likely receive gasoline containing high volumes of MTBE from California distribution sources (Arizona Department of Environmental Quality, 1999).

Seventy-seven source waters selected were suspected to contain MTBE. Of these, about 50 percent were ground-water source waters and 50 percent were surface-water source waters. Fifty-seven source waters selected were known to contain MTBE. Of these, 67 percent were ground-water source waters and 33 percent were surface-water source waters. In addition to the $134 \mathrm{CWS}$ sources sampled, four source waters (two wells, one reservoir, and one river) were selected as control sites where MTBE was not suspected to be present. A summary of source waters sampled in each State by size of CWS is presented in Appendix A. Excluding the control sites, the 78 ground-water, 39 reservoir and (or) lake, and 17 river and (or) stream source waters were selected for participation in the Focused Survey. 


\section{Sample Collection}

Sample collection and analysis began in September 1999 and was completed in April 2001. Samples were collected by USGS personnel using USGS protocols prior to any water treatment. Groundwater samples were collected from water-supply wells as described by Koterba and others (1995). Surfacewater samples were collected as close to the intake as was reasonable and safe within 5 feet of the surface using a VOC hand-sampler as described by Shelton (1997) and Halde and others (1998).

The 451 samples were collected and analyzed from the 134 source waters selected-160 groundwater samples, 155 reservoir and (or) lake samples, and 136 river and (or) stream samples (table 2). The scheduled number of samples was collected from most of the sites. However, 2 samples collected from reservoirs were lost in shipment, 5 (instead of 4) samples were collected from one reservoir, and 3 (instead of 2) samples were collected from three wells over the sampling period.

Table 2. Summary of number of source waters sampled, frequency of sample collection, and number of samples collected during the Focused Survey

[CWS, community water system; --, not applicable]

\begin{tabular}{lccc}
\hline $\begin{array}{c}\text { Source-water } \\
\text { type }\end{array}$ & $\begin{array}{c}\text { Number of } \\
\text { cWS } \\
\text { sources } \\
\text { sampled }\end{array}$ & $\begin{array}{c}\text { Frequency } \\
\text { of sample } \\
\text { collection } \\
\text { (number } \\
\text { per year) }\end{array}$ & $\begin{array}{c}\text { Total } \\
\text { number of } \\
\text { samples } \\
\text { collected }\end{array}$ \\
\hline Ground water & 78 & 2 & 160 \\
Reservoir and (or) lake & 39 & 4 & 155 \\
River and (or) stream & 17 & 8 & 136 \\
\cline { 2 - 4 } Total & 134 & -- & 451 \\
\hline
\end{tabular}

The 744 field QC samples were collected as part of the Focused Survey (table 3). One hundred percent of source-water samples were collected in association with a trip-reagent blank (TRB). TRB samples were prepared at the MWDSC laboratory by filling sampling vials with VOC-free water and sending them to the field office that would conduct the sampling. TRB samples were never opened to the atmosphere and traveled with all other samples from the field site to the laboratory for analysis. TRB samples were intended to document if VOC contamination of the source-water samples could have occurred in transit and, thus, were analyzed only if VOCs were detected in the corresponding sourcewater sample. As such, 304 TRB samples were analyzed.

Table 3. Summary of the frequency and number of quality-control samples collected during the Focused Survey

[--, not applicable]

\begin{tabular}{lcc}
\hline $\begin{array}{c}\text { Quality-control } \\
\text { sample type }\end{array}$ & $\begin{array}{c}\text { Frequency of } \\
\text { quality-control } \\
\text { sample collection } \\
\text { (percent) }\end{array}$ & $\begin{array}{c}\text { Number of } \\
\text { quality-control } \\
\text { samples } \\
\text { analyzed }\end{array}$ \\
\hline Trip-reagent blank & 100 & 304 \\
Field-reagent blank & 1100 & 321 \\
Field-equipment blank & 15 & 50 \\
$\begin{array}{c}\text { Duplicate source-water } \\
\text { samples }\end{array}$ & 15 & 69 \\
\cline { 2 - 3 } Total & -- & 744 \\
\hline $\begin{array}{c}1 \\
\text { Sample frequency was 15 percent during the first three months of }\end{array}$ \\
sample collection and 100 percent thereafter.
\end{tabular}

Field-reagent blank (FRB) samples also were collected in association with 100 percent of sourcewater samples during most of the study. However, FRB samples were collected only in association with about 15 percent of source-water samples during the first three months of sampling. The 321 FRB samples were prepared by pouring VOC-free water into a sampling vial at the field site and were sent to the laboratory for analyses. These blank samples were intended to document all aspects of contamination including sample collection, processing, shipment, and analyses.

Field-equipment blank (FEB) samples and duplicate source-water samples were prepared in association with 15 percent of source-water samples collected. Fifty FEB samples were collected at surfacewater sites as described by Shelton (1997) by passing VOC-free water through the USGS VOC hand sampler and filling the vials accordingly. FEB samples were not collected at ground-water sites because the supply wells sampled had dedicated, submersible pumps. Finally, 69 duplicate samples were collected and analyzed. Ground-water duplicates were collected sequentially, and surface-water duplicates were collected concurrently. 
Review of the QC data indicates no systematic contamination of samples. Detected VOC concentrations in blank samples typically were less than $0.2 \mu \mathrm{g} / \mathrm{L}$, and very little variability was associated with the sample collection, transportation, and analytical processes for the majority of VOCs included in this study. A detailed review of these QC data is presented in Appendix B.

\section{OCCURRENCE AND TEMPORAL VARIABILITY OF VOLATILE ORGANIC COMPOUNDS}

The results of the chemical analyses of sourcewater samples collected for the Focused Survey were evaluated for the occurrence and temporal variability of individual VOCs and subgroups of VOCs (table 1). VOC subgroups examined include gasoline oxygenates, other gasoline related compounds (excluding the oxygenates), THMs, solvents, organic synthesis compounds, fumigants, and refrigerants. All source-water data used in these analyses have undergone an extensive QC screening procedure. This systematic procedure compares source-water data with respective FRB samples to ultimately accept or reject the source-water data. Thus, only those source-water data that met dataquality criteria were accepted and included in these analyses. Details of this screening procedure are presented in Appendix C.

Detection frequencies resulting from the QC screening process for each VOC detected in the Focused Survey also are presented in Appendix C. The detection frequencies in Appendix $C$ are for all 467 samples collected from the three source-water types (includes data from four control sites). It is important to note, however, that the analytical method reports all detections above the MDL. Thus, the detection frequencies in Appendix $\mathrm{C}$ were calculated using data that were not censored to a statistically determined MRL. The MDL concentrations typically were less than $0.05 \mu \mathrm{g} / \mathrm{L}$ and ranged from $0.014 \mu \mathrm{g} / \mathrm{L}$ for $1,1,2-$ trichloroethane to $0.645 \mu \mathrm{g} / \mathrm{L}$ for methyl ethyl ketone (MEK) (Ivahnenko and others, 2001). The MRL was $0.2 \mu \mathrm{g} / \mathrm{L}$ for all compounds except MEK, which had a MRL of $2.0 \mu \mathrm{g} / \mathrm{L}$.

Concentrations of VOCs detected in the Focused Survey generally were less than $1 \mu \mathrm{g} / \mathrm{L}$ (Appendix D); however, the concentrations of benzene, tetrachloroethene, and trichloroethene in some samples exceeded the USEPA Maximum Contaminant Levels (MCLs) set for those compounds. It is important to note that MCLs are established for finished drinking water and not for source water. MCLs for benzene, tetrachloroethene, and trichloroethene have been set at $5 \mu \mathrm{g} / \mathrm{L}$ for each compound (U.S. Environmental Protection Agency, 2001). Benzene concentrations exceeded the MCL in 4 samples, tetrachloroethene in 13 samples, and trichloroethene in 7 samples. Concentrations of MTBE detected in the Focused Survey exceeded the lower limit of the USEPA Drinking Water Advisory of 20 to $40 \mu \mathrm{g} / \mathrm{L}$ (U.S. Environmental Protection Agency, 1997) in 12 samples. All samples in which concentrations exceeded MCLs or the Drinking Water Advisory for MTBE were collected from ground-water source waters. Of the 4 control sites-2 wells, 1 reservoir, 1 river-that were selected because MTBE was not suspected to be detected, MTBE was detected only in 1 ground-water sample at a concentration of $0.05 \mu \mathrm{g} / \mathrm{L}$. Control site data are not included in table 4.

\section{Occurrence and Comparison to the Random Survey}

One objective of the Random Survey was to provide a statistically representative assessment of the quality of the source water of the Nation's public drinking-water supplies with respect to the occurrence of MTBE and other VOCs. This objective differs markedly from that of the Focused Survey, which intentionally sampled source waters suspected or known to be contaminated with MTBE. Some comparisons between the two surveys, however, may augment conclusions drawn from both surveys.

Results from the Random Survey (Rowe and others, 2001; Grady, 2003) were based on the analyses of source water obtained from 954 randomly selected CWSs sampled between May 3, 1999, and October 23, 2000. The Random Survey data underwent the same QC screening process that was applied to data from the Focused Survey. VOC concentrations detected during the Random Survey, however, were only reported at or above the MRL. As such, any meaningful comparisons between the two surveys had to be conducted with a common assessment level. Thus, the Focused Survey data were also censored at the MRL in order to make comparisons with the Random Survey.

Additional adjustments to Focused Survey data were needed in order to compare findings between the two surveys. Results from the Random Survey were commonly presented such that reservoir, lake, river, and stream source waters were combined into one 
surface-water category. Thus, all Focused Survey surface-water data were combined into one category. Finally, in the Random Survey one sample was collected from each CWS source water, whereas in the Focused Survey multiple samples were collected from the same CWS source water. Because concentrations may change from one sample to the next at the same site, one sample was randomly selected from each source water sampled as part of the Focused Survey and used for comparing results with the Random Survey.

As expected, most VOCs were detected more frequently in the Focused Survey than in the Random Survey (fig. 2). The Focused Survey sampled source waters suspected or known to contain MTBE whereas the Random Survey did not. Thus, MTBE was detected much more frequently at sites sampled in the Focused Survey than in the Random Survey. MTBE was detected in 60 and 49.1 percent of CWSs supplied by ground and surface water, respectively, in the Focused Survey and in 5.4 and 13.8 percent of CWSs supplied by ground and surface water, respectively, in the Random Survey. MTBE was detected in 55.5 percent of the 134 CWSs sampled in the Focused Survey and in 8.7 percent of 954 CWSs sampled in the Random Survey (table 4).
In addition to MTBE, numerous other VOCs were detected more frequently in the Focused Survey than in the Random Survey (fig. 2). This may be explained by population density in areas sampled in the Focused Survey. High-population density, which was one factor associated with the selection of a site to be sampled as part of the Focused Survey, has been shown to be related to increased VOC detection frequencies (Reiser and O'Brien, 1998; Squillace and others, 1999; Bush and others, 2000; Lopes and Furlong, 2001). Similarly, results from the Random Survey concluded that the occurrence of VOCs was greatest in the largest ground-water CWSs serving populations greater than 50,000 people and medium-sized surface-water CWSs serving populations of 3,001 to 10,000 people.

Individual VOC detection frequencies in CWSs sampled as part of the Focused and Random Surveys are presented in table 4 . Detection frequencies are presented for data at or above the MRL for both surveys and also at or above the MDL for the Focused Survey. Detection frequencies are lower when using data at or above the MRL because detections of VOCs at or above the MDL, yet below the MRL, were not included in the calculation (Appendix C).

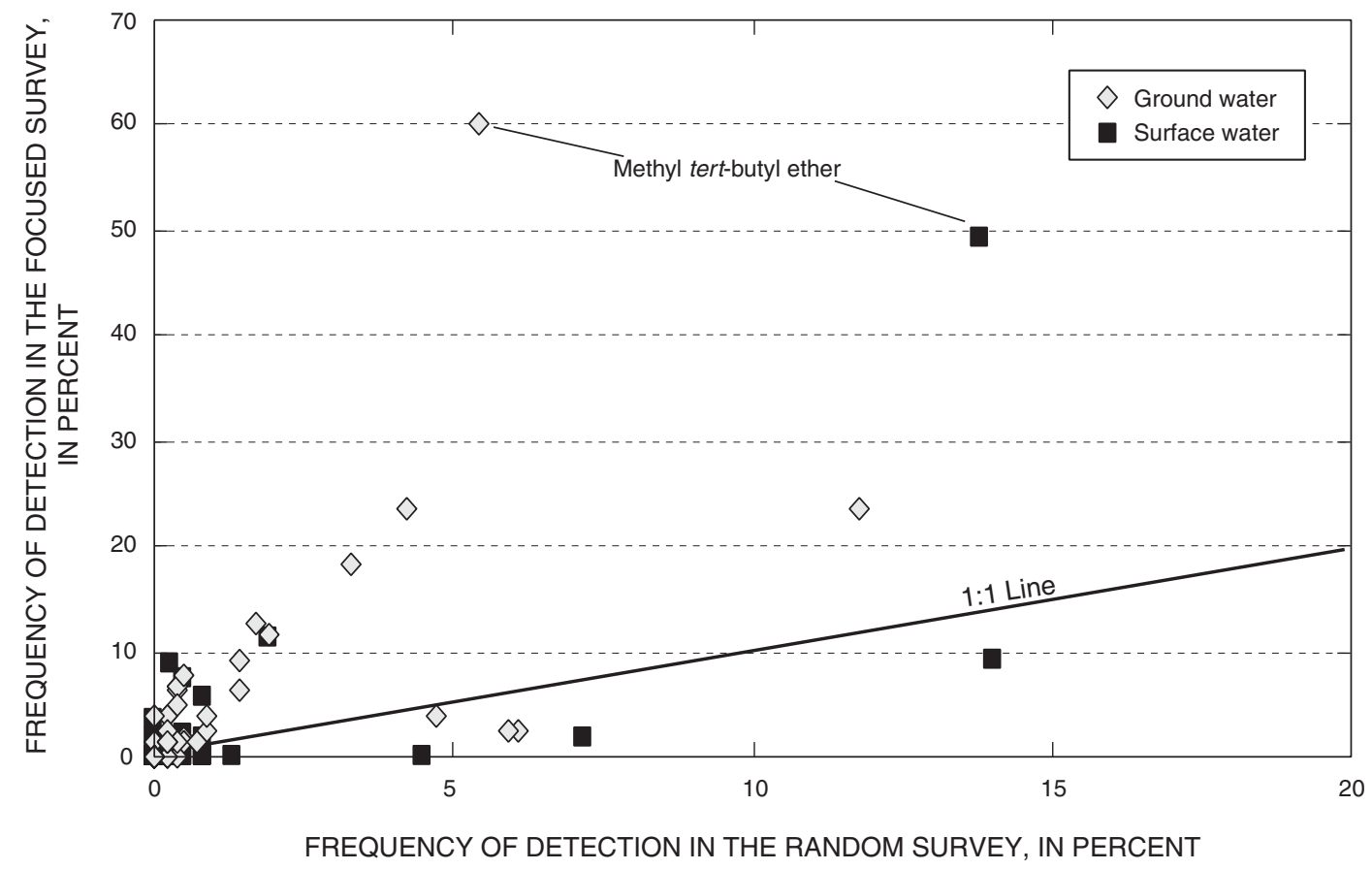

Figure 2. Detection frequency at or above the minimum reporting level of individual volatile organic compounds in source waters sampled in the Focused Survey versus the Random Survey. 
Table 4. Summary of detection frequencies of any volatile organic compound (VOC), any subgroup of VOCs, and individual VOCs in source waters sampled in the Focused and Random Surveys

[VOC, volatile organic compound; CWS, community water system; n, number of samples]

\begin{tabular}{|c|c|c|c|c|c|c|c|c|c|}
\hline \multirow{3}{*}{$\begin{array}{l}\text { Volatile organic } \\
\text { compound subgroup } \\
\text { and individual } \\
\text { compound name }\end{array}$} & \multicolumn{6}{|c|}{ Focused Survey } & \multirow{2}{*}{\multicolumn{3}{|c|}{$\begin{array}{c}\text { Random Survey } \\
\begin{array}{c}\text { Detection frequency at or above } \\
\text { the MRL (percent) }\end{array}\end{array}$}} \\
\hline & \multicolumn{3}{|c|}{$\begin{array}{l}\text { Detection frequency at or above } \\
\text { the MDL (percent) }\end{array}$} & \multicolumn{3}{|c|}{$\begin{array}{c}\text { Detection frequency at or above } \\
\text { the MRL (percent) }\end{array}$} & & & \\
\hline & $\begin{array}{c}\text { All CWSs } \\
(n=134)\end{array}$ & $\begin{array}{l}\text { Ground } \\
\text { water } \\
(n=78)\end{array}$ & $\begin{array}{l}\text { Surface } \\
\text { water } \\
(n=56)\end{array}$ & $\begin{array}{c}\text { All CWSs } \\
(n=134)\end{array}$ & $\begin{array}{l}\text { Ground } \\
\text { water } \\
(n=78)\end{array}$ & $\begin{array}{l}\text { Surface } \\
\text { water } \\
(n=56)\end{array}$ & $\begin{array}{c}\text { All CWSs } \\
(n=954)\end{array}$ & $\begin{array}{l}\text { Ground } \\
\text { water } \\
(n=579)\end{array}$ & $\begin{array}{l}\text { Surface } \\
\text { water } \\
(n=375)\end{array}$ \\
\hline Any VOC & 92.5 & 92.3 & 92.9 & 61.2 & 66.7 & 53.6 & 26.9 & 25.2 & 29.6 \\
\hline \multicolumn{10}{|c|}{ Gasoline Oxygenates } \\
\hline tert-Amyl methyl ether & 20.3 & 20.8 & 19.6 & 4.5 & 6.5 & 1.8 & 0.2 & 0.4 & 0.0 \\
\hline Diisopropyl ether & 6.0 & 10.3 & 0.0 & 3.0 & 5.1 & 0.0 & 0.2 & 0.4 & 0.0 \\
\hline Ethyl tert-butyl ether & 1.5 & 2.6 & 0.0 & 0.7 & 1.3 & 0.0 & 0.1 & 0.2 & 0.0 \\
\hline Methyl tert-butyl ether & 77.3 & 68.0 & 90.6 & 55.5 & 60.0 & 49.1 & 8.7 & 5.4 & 13.8 \\
\hline Any gasoline oxygenate & 73.9 & 65.4 & 85.7 & 53.7 & 59.0 & 46.4 & 8.5 & 5.3 & 13.3 \\
\hline \multicolumn{10}{|c|}{ Other Gasoline Compounds } \\
\hline Benzene & 22.0 & 15.8 & 30.4 & 7.6 & 6.6 & 8.9 & 0.3 & 0.4 & 0.3 \\
\hline$n$-Butylbenzene & 1.5 & 1.3 & 1.8 & 0.0 & 0.0 & 0.0 & 0.1 & 0.2 & 0.0 \\
\hline sec-Butylbenzene & 1.5 & 2.6 & 0.0 & 0.0 & 0.0 & 0.0 & 0.0 & 0.0 & 0.0 \\
\hline tert-Butylbenzene & 0.0 & 0.0 & 0.0 & 0.0 & 0.0 & 0.0 & 0.0 & 0.0 & 0.0 \\
\hline Ethylbenzene & 4.8 & 4.1 & 6.0 & 1.6 & 1.4 & 2.0 & 0.5 & 0.5 & 0.5 \\
\hline Naphthalene & 9.9 & 10.5 & 9.1 & 2.3 & 3.9 & 0.0 & 0.2 & 0.2 & 0.3 \\
\hline Toluene & 18.3 & 9.4 & 31.1 & 5.5 & 1.6 & 11.1 & 1.1 & 0.5 & 1.9 \\
\hline 1,3,5-Trimethylbenzene & 4.5 & 1.3 & 8.9 & 2.2 & 1.3 & 3.6 & 0.0 & 0.0 & 0.0 \\
\hline$m, p$-Xylene & 8.6 & 5.3 & 13.5 & 3.1 & 1.3 & 5.8 & 0.8 & 0.7 & 0.8 \\
\hline$o$-Xylene & 14.2 & 10.8 & 18.9 & 3.9 & 1.4 & 7.5 & 0.6 & 0.7 & 0.5 \\
\hline Any gasoline compound & 35.8 & 29.5 & 44.6 & 9.0 & 7.7 & 10.7 & 2.2 & 1.9 & 2.7 \\
\hline \multicolumn{10}{|c|}{ Trihalomethanes } \\
\hline Bromoform & 4.5 & 5.1 & 3.6 & 2.2 & 3.8 & 0.0 & 3.4 & 4.7 & 1.3 \\
\hline Bromodichloromethane & 20.9 & 15.4 & 28.6 & 2.2 & 2.6 & 1.8 & 6.4 & 5.9 & 7.2 \\
\hline Chlorodibromomethane & 12.7 & 10.3 & 16.1 & 1.5 & 2.6 & 0.0 & 5.5 & 6.1 & 4.5 \\
\hline Chloroform & 48.4 & 55.6 & 38.9 & 17.5 & 23.6 & 9.3 & 12.7 & 11.8 & 14.0 \\
\hline Any trihalomethane & 47.8 & 53.8 & 39.3 & 16.4 & 21.8 & 8.9 & 14.8 & 15.2 & 14.0 \\
\hline \multicolumn{10}{|c|}{ Solvents } \\
\hline Bromobenzene & 0.0 & 0.0 & 0.0 & 0.0 & 0.0 & 0.0 & 0.0 & 0.0 & 0.0 \\
\hline Carbon tetrachloride & 2.2 & 3.8 & 0.0 & 1.5 & 2.6 & 0.0 & 0.7 & 0.9 & 0.5 \\
\hline Chlorobenzene & 3.7 & 5.1 & 1.8 & 1.5 & 2.6 & 0.0 & 0.1 & 0.2 & 0.0 \\
\hline Chloroethane & 0.7 & 1.3 & 0.0 & 0.0 & 0.0 & 0.0 & 0.1 & 0.2 & 0.0 \\
\hline 2-Chlorotoluene & 0.0 & 0.0 & 0.0 & 0.0 & 0.0 & 0.0 & 0.0 & 0.0 & 0.0 \\
\hline 4-Chlorotoluene & 0.7 & 1.3 & 0.0 & 0.0 & 0.0 & 0.0 & 0.0 & 0.0 & 0.0 \\
\hline
\end{tabular}


Table 4. Summary of detection frequencies of any volatile organic compound (VOC), any subgroup of VOCs, and individual VOCs in source waters sampled in the Focused and Random Surveys-Continued

[VOC, volatile organic compound; CWS, community water system; n, number of samples]

\begin{tabular}{|c|c|c|c|c|c|c|c|c|c|}
\hline \multirow{3}{*}{$\begin{array}{l}\text { Volatile organic } \\
\text { compound subgroup } \\
\text { and individual } \\
\text { compound name }\end{array}$} & \multicolumn{6}{|c|}{ Focused Survey } & \multirow{2}{*}{\multicolumn{3}{|c|}{$\begin{array}{c}\text { Random Survey } \\
\begin{array}{c}\text { Detection frequency at or above } \\
\text { the MRL (percent) }\end{array}\end{array}$}} \\
\hline & \multicolumn{3}{|c|}{$\begin{array}{l}\text { Detection frequency at or above } \\
\text { the MDL (percent) }\end{array}$} & \multicolumn{3}{|c|}{$\begin{array}{l}\text { Detection frequency at or above } \\
\text { the MRL (percent) }\end{array}$} & & & \\
\hline & $\begin{array}{l}\text { All CWSs } \\
(n=134)\end{array}$ & $\begin{array}{l}\text { Ground } \\
\text { water } \\
(n=78)\end{array}$ & $\begin{array}{l}\text { Surface } \\
\text { water } \\
(n=56)\end{array}$ & $\begin{array}{l}\text { All CWSs } \\
(n=134)\end{array}$ & $\begin{array}{l}\text { Ground } \\
\text { water } \\
(n=78)\end{array}$ & $\begin{array}{l}\text { Surface } \\
\text { water } \\
(n=56)\end{array}$ & $\begin{array}{l}\text { All CWSs } \\
(n=954)\end{array}$ & $\begin{array}{c}\text { Ground } \\
\text { water } \\
(n=579)\end{array}$ & $\begin{array}{l}\text { Surface } \\
\text { water } \\
(n=375)\end{array}$ \\
\hline \multicolumn{10}{|c|}{ Solvents-Continued } \\
\hline Dibromomethane & 0.7 & 1.3 & 0.0 & 0.7 & 1.3 & 0.0 & 0.2 & 0.4 & 0.0 \\
\hline 1,2-Dichlorobenzene & 1.5 & 2.6 & 0.0 & 0.7 & 1.3 & 0.0 & 0.1 & 0.2 & 0.0 \\
\hline 1,3-Dichlorobenzene & 2.2 & 3.8 & 0.0 & 0.0 & 0.0 & 0.0 & 0.0 & 0.0 & 0.0 \\
\hline 1,1-Dichloroethane & 15.9 & 26.3 & 1.8 & 5.3 & 9.2 & 0.0 & 1.2 & 1.4 & 0.0 \\
\hline 1,2-Dichloroethane & 11.9 & 20.5 & 0.0 & 4.5 & 7.7 & 0.0 & 0.3 & 0.5 & 0.0 \\
\hline 1,1-Dichloroethene & 6.0 & 10.3 & 0.0 & 3.7 & 6.4 & 0.0 & 0.8 & 1.4 & 0.0 \\
\hline cis-1,2-Dichloroethene & 12.8 & 22.1 & 0.0 & 6.8 & 11.7 & 0.0 & 1.3 & 1.9 & 0.3 \\
\hline trans-1,2-Dichloroethene & 4.5 & 7.7 & 0.0 & 2.2 & 3.8 & 0.0 & 0.0 & 0.0 & 0.0 \\
\hline 1,2-Dichloropropane & 3.7 & 6.4 & 0.0 & 0.7 & 1.3 & 0.0 & 0.1 & 0.2 & 0.0 \\
\hline Hexachloroethane & 0.0 & 0.0 & 0.0 & 0.0 & 0.0 & 0.0 & 0.0 & 0.0 & 0.0 \\
\hline Methylene chloride & 0.8 & 1.4 & 0.0 & 0.8 & 1.4 & 0.0 & 0.2 & 0.2 & 0.3 \\
\hline Methyl ethyl ketone & 0.8 & 1.3 & 0.0 & 0.0 & 0.0 & 0.0 & 0.5 & 0.4 & 0.8 \\
\hline$n$-Propylbenzene & 3.0 & 1.3 & 5.4 & 0.8 & 1.3 & 0.0 & 0.1 & 0.0 & 0.3 \\
\hline 1,1,1,2-Tetrachloroethane & 1.5 & 2.6 & 0.0 & 0.0 & 0.0 & 0.0 & 0.0 & 0.0 & 0.0 \\
\hline Tetrachloroethene & 21.1 & 36.4 & 0.0 & 13.5 & 23.4 & 0.0 & 2.8 & 4.2 & 0.8 \\
\hline 1,1,2,2-Tetrachloroethane & 0.0 & 0.0 & 0.0 & 0.0 & 0.0 & 0.0 & 0.0 & 0.0 & 0.0 \\
\hline 1,2,4-Trichlorobenzene & 3.0 & 2.6 & 3.6 & 0.0 & 0.0 & 0.0 & 0.0 & 0.0 & 0.0 \\
\hline 1,1,1-Trichloroethane & 14.2 & 24.4 & 0.0 & 7.5 & 12.8 & 0.0 & 1.0 & 1.7 & 0.0 \\
\hline 1,1,2-Trichloroethane & 1.5 & 2.6 & 0.0 & 0.0 & 0.0 & 0.0 & 0.0 & 0.0 & 0.0 \\
\hline Trichloroethene & 17.3 & 29.9 & 0.0 & 10.5 & 18.2 & 0.0 & 2.3 & 3.3 & 0.8 \\
\hline 1,2,3-Trichloropropane & 3.8 & 3.8 & 3.7 & 0.0 & 0.0 & 0.0 & 0.1 & 0.2 & 0.0 \\
\hline Any solvent & 41.8 & 61.5 & 14.3 & 21.6 & 37.2 & 0.0 & 6.3 & 8.8 & 2.4 \\
\hline \multicolumn{10}{|c|}{ Organic Synthesis } \\
\hline Acrylonitrile & 0.7 & 1.3 & 0.0 & 0.7 & 1.3 & 0.0 & 0.0 & 0.0 & 0.0 \\
\hline Bromochloromethane & 3.7 & 5.1 & 1.8 & 0.0 & 0.0 & 0.0 & 0.0 & 0.0 & 0.0 \\
\hline 1,3-Dichloropropane & 3.0 & 2.6 & 3.6 & 0.7 & 1.3 & 0.0 & 0.0 & 0.0 & 0.0 \\
\hline 2,2-Dichloropropane & 0.0 & 0.0 & 0.0 & 0.0 & 0.0 & 0.0 & 0.0 & 0.0 & 0.0 \\
\hline 1,1-Dichloropropene & 0.0 & 0.0 & 0.0 & 0.0 & 0.0 & 0.0 & 0.0 & 0.0 & 0.0 \\
\hline Hexachlorobutadiene & 0.0 & 0.0 & 0.0 & 0.0 & 0.0 & 0.0 & 0.0 & 0.0 & 0.0 \\
\hline Isopropylbenzene & 3.8 & 5.2 & 1.8 & 0.8 & 1.3 & 0.0 & 0.2 & 0.2 & 0.3 \\
\hline$p$-Isopropyltoluene & 0.7 & 0.0 & 1.8 & 0.0 & 0.0 & 0.0 & 0.0 & 0.0 & 0.0 \\
\hline
\end{tabular}


Table 4. Summary of detection frequencies of any volatile organic compound (VOC), any subgroup of VOCs, and individual VOCs in source waters sampled in the Focused and Random Surveys-Continued

[VOC, volatile organic compound; CWS, community water system; n, number of samples]

\begin{tabular}{|c|c|c|c|c|c|c|c|c|c|}
\hline \multirow{3}{*}{$\begin{array}{l}\text { Volatile organic } \\
\text { compound subgroup } \\
\text { and individual } \\
\text { compound name }\end{array}$} & \multicolumn{6}{|c|}{ Focused Survey } & \multirow{2}{*}{\multicolumn{3}{|c|}{$\begin{array}{c}\text { Random Survey } \\
\begin{array}{c}\text { Detection frequency at or above } \\
\text { the MRL (percent) }\end{array}\end{array}$}} \\
\hline & \multicolumn{3}{|c|}{$\begin{array}{l}\text { Detection frequency at or above } \\
\text { the MDL (percent) }\end{array}$} & \multicolumn{3}{|c|}{$\begin{array}{l}\text { Detection frequency at or above } \\
\text { the MRL (percent) }\end{array}$} & & & \\
\hline & $\begin{array}{c}\text { All CWSs } \\
(n=134)\end{array}$ & $\begin{array}{l}\text { Ground } \\
\text { water } \\
(n=78)\end{array}$ & $\begin{array}{c}\text { Surface } \\
\text { water } \\
(n=56)\end{array}$ & $\begin{array}{l}\text { All CWSs } \\
(n=134)\end{array}$ & $\begin{array}{l}\text { Ground } \\
\text { water } \\
(n=78)\end{array}$ & $\begin{array}{c}\text { Surface } \\
\text { water } \\
(n=56)\end{array}$ & $\begin{array}{l}\text { All CWSs } \\
(n=954)\end{array}$ & $\begin{array}{l}\text { Ground } \\
\text { water } \\
(n=579)\end{array}$ & $\begin{array}{l}\text { Surface } \\
\text { water } \\
(n=375)\end{array}$ \\
\hline \multicolumn{10}{|c|}{ Organic Synthesis-Continued } \\
\hline Styrene & 16.3 & 21.3 & 9.3 & 3.8 & 6.6 & 0.0 & 0.5 & 0.4 & 0.8 \\
\hline 1,2,4-Trimethylbenzene & 7.6 & 1.3 & 16.7 & 1.5 & 1.3 & 1.9 & 0.4 & 0.2 & 0.8 \\
\hline 1,2,3-Trichlorobenzene & 5.2 & 6.4 & 3.6 & 0.0 & 0.0 & 0.0 & 0.0 & 0.0 & 0.0 \\
\hline Vinyl bromide & 0.0 & 0.0 & 0.0 & 0.0 & 0.0 & 0.0 & 0.0 & 0.0 & 0.0 \\
\hline Vinyl chloride & 2.2 & 3.8 & 0.0 & 2.2 & 3.8 & 0.0 & 0.1 & 0.2 & 0.0 \\
\hline Any organic synthesis & 32.8 & 33.3 & 32.1 & 7.5 & 11.5 & 1.8 & 1.0 & 0.7 & 1.6 \\
\hline \multicolumn{10}{|c|}{ Fumigants } \\
\hline Bromomethane & 3.0 & 3.8 & 1.8 & 0.0 & 0.0 & 0.0 & 0.2 & 0.2 & 0.3 \\
\hline 1,4-Dichlorobenzene & 4.5 & 6.5 & 1.8 & 0.8 & 1.3 & 0.0 & 0.3 & 0.2 & 0.5 \\
\hline cis-1,3-Dichloropropene & 0.0 & 0.0 & 0.0 & 0.0 & 0.0 & 0.0 & 0.0 & 0.0 & 0.0 \\
\hline trans-1,3-Dichloropropene & 0.0 & 0.0 & 0.0 & 0.0 & 0.0 & 0.0 & 0.0 & 0.0 & 0.0 \\
\hline Any fumigant & 7.5 & 10.3 & 3.6 & 0.7 & 1.3 & 0.0 & 0.5 & 0.4 & 0.8 \\
\hline \multicolumn{10}{|c|}{ Refrigerants } \\
\hline Chloromethane & 3.0 & 3.8 & 1.8 & 0.7 & 1.3 & 0.0 & 0.3 & 0.5 & 0.0 \\
\hline Dichlorodifluoromethane & 0.7 & 1.3 & 0.0 & 0.7 & 1.3 & 0.0 & 0.4 & 0.7 & 0.0 \\
\hline $\begin{array}{l}\text { 1,1,2-Trichloro- } \\
\text { 1,2,2-trifluoroethane }\end{array}$ & 0.7 & 1.3 & 0.0 & 0.7 & 1.3 & 0.0 & 0.1 & 0.2 & 0.0 \\
\hline Trichlorofluoromethane & 2.2 & 3.8 & 0.0 & 2.2 & 3.8 & 0.0 & 0.5 & 0.9 & 0.0 \\
\hline Any refrigerant & 5.2 & 7.7 & 1.8 & 3.0 & 5.1 & 0.0 & 1.0 & 1.7 & 0.0 \\
\hline
\end{tabular}

When considering data above the MDL and MRL as part of the Focused Survey, about 93 and 61 percent of all source waters sampled contained at least one of the $66 \mathrm{VOCs}$ analyzed, respectively. This compares to about 27 percent detected in source waters sampled as part of the Random Survey. Although detection frequencies were less in the Random Survey than in the Focused Survey, a similar number of VOCs were detected in both surveys. Fifty-eight and 41 VOCs were detected at least one time in the Focused Survey above the MDL and MRL, respectively, whereas, 42 were detected at levels above the MRL in the Random Survey. Thirty-seven of the 41 VOCs detected in the Focused Survey also were detected in the Random
Survey. Again, only the detection frequencies above the MRL should be used for comparison to the Random Survey. A summary of detected concentrations of VOCs collected as part of the Focused Survey is presented in Appendix D. Additional discussion of the occurrence of VOCs in the Focused Survey above the MDL is included in the next section-Temporal Variability.

Each subgroup of VOCs was detected at or above the MRL at a higher frequency in the Focused Survey than in the Random Survey (table 4, fig. 3). The largest difference in detection frequencies was found in the gasoline oxygenate subgroup, wherein these compounds were detected in 53.7 percent of CWSs sampled 
in the Focused Survey but in only 8.5 percent of CWSs sampled in the Random Survey. This difference is due to the intentional selection of sites with suspected or known occurrence of MTBE in the Focused Survey. A slightly higher detection frequency for gasoline oxygenates was found in ground-water source waters (59.0 percent) than in surface-water source waters (46.4 percent) in the Focused Survey. This pattern was reversed, however, for samples collected in the Random Survey, where gasoline oxygenates were detected in 5.3 and 13.3 percent of ground and surface water, respectively. MTBE was the most frequently detected gasoline oxygenate in source waters sampled in the Focused and Random Surveys, occurring in 55.5 and 8.7 percent, respectively.

A second large difference was found in the solvent subgroup, again with the larger detection frequency occurring in the Focused Survey. In both surveys, most of the solvent detections were in groundwater source waters (table 4). This may be due to solvents degrading slower in ground water than in surface water. The difference in detection frequency between the two surveys (fig. 3) may be due, in part, to intentionally sampling ground-water sites as part of the Focused Survey that were considered more vulnerable than other sites. That is, preference was given to sampling ground-water source waters withdrawn from shallow, unconsolidated, unconfined aquifers in urban areas serving large populations. The solvents detected most frequently in both surveys were tetrachloroethene and trichloroethene.

Interestingly, THMs were detected in the Focused and Random Surveys at approximately similar frequencies-16.4 and 14.8 percent of CWSs, respectively. Chloroform was the most frequently detected THM in both surveys. However, chloroform was detected more frequently in ground-water source waters in the Focused Survey (23.6 percent) than in the Random Survey (11.8 percent). Similar THM detection frequencies in both surveys indicates a pervasive occurrence of THMs in several source-water types regardless of CWS size or location.

Other gasoline compounds, organic synthesis compounds, fumigants, and refrigerants all were detected at or above the MRL in less than 10 percent of CWSs sampled in each survey. Although the gasoline oxygenate MTBE was detected frequently in the Focused Survey, VOCs in the other gasoline compound subgroup were detected in only 9 percent of CWS source waters. This may be due to these compounds

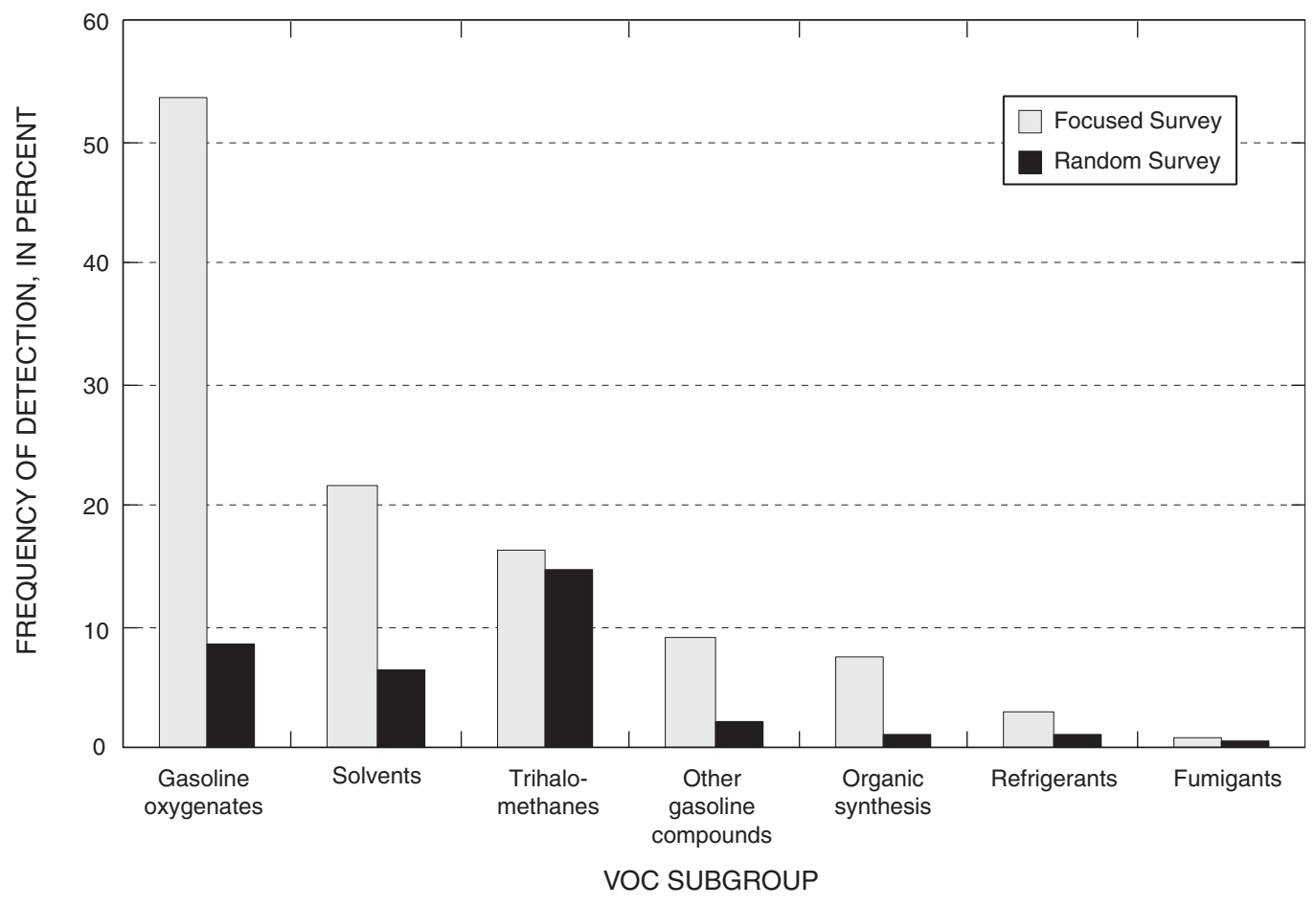

Figure 3. Detection frequency at or above the minimum reporting level of volatile organic compound subgroups in community water system source waters sampled in the Focused Survey and the Random Survey. 
degrading and (or) volatilizing more rapidly in ground and surface water in comparison to MTBE. Organic synthesis compounds also were detected more frequently in the Focused Survey (7.5 percent) than in the Random Survey (1.0 percent). The majority of detections in the Focused Survey were found in groundwater source waters (11.5 percent) rather than in surface-water source waters (1.8 percent). Again, this may be due to the Focused Survey's sampling urban ground-water source waters in shallow, unconsolidated, unconfined aquifers that may be susceptible to contamination. Very little difference in detection frequencies between either survey was observed for fumigants and refrigerants.

CWSs were subdivided into five size categories based on population served: (1) very small (serves 25 to 500 people); (2) small (serves 501 to 3,300 people); (3) medium (serves 3,301 to 10,000 people); (4) large (serves 10,001 to 50,000 people); and (5) very large (serves more than 50,000 people). Table 5 lists the relative percent of CWSs per size of system sampled in the Focused and Random Surveys. A summary of source waters sampled per State by size of CWS is presented in Appendix A.

A fairly equal distribution of ground-water CWS sizes was sampled in the Focused Survey-from 10.4 to 26 percent of each size category-whereas the majority of ground-water source waters sampled (50.4 percent) in the Random Survey were very small systems. The abundance of very small ground-water source waters in the Random Survey is due to the relative abundance of very small ground-water supplied CWSs on a national basis and reflects the random selection process used in the Random Survey. A disproportionate number of very large CWSs supplied by surface water were sampled (85.7 percent) in the Focused Survey. Similarly, the majority of CWSs supplied by surface water sampled (81.9 percent) as part of the Random Survey were large or very large CWSs. The abundance of large and very large surface-water systems sampled as part of the Random Survey was due to the cumulative population served, which was one weighting factor used in the design of that survey (Ivahnenko and others, 2001).

The highest VOC detection frequency in the Random Survey for each subgroup of VOCs (except THMs) was found in the very large CWSs supplied by ground water (fig. 4). THMs were detected slightly more often in the very small CWSs than in the very large CWSs. This likely reflects the fact that many more of the larger systems have source waters within high-population density, urban areas than do the smaller CWSs. This pattern was not evident in the Focused Survey for gasoline oxygenates, other gasoline compounds, solvents, and refrigerants (fig. 4). This is likely due to the fact that the source waters selected were considered more vulnerable to VOC contamination and MTBE was suspected or known to occur in the source, regardless of CWS size.

In the Random Survey, gasoline oxygenates and other gasoline compounds were detected more frequently in the very large CWSs supplied by surface water than in other size categories (fig. 5). This pattern was generally observed in the Focused Survey.

Although the Focused and Random Surveys each sampled disproportionately more large and very large CWSs than other size categories, gasoline oxygenates, other gasoline compounds, solvents, THMs, and organic synthesis compounds were detected in virtually every size category sampled in the Random Survey. This was not observed in the Focused Survey. Gasoline oxygenates primarily were detected in large and very large CWSs; however, solvents, THMs, and organic synthesis compounds were not detected at all or only detected in a few sizes of CWSs. The reason for this difference is not known.

Table 5. Distribution of source waters sampled in the Focused and Random Surveys by source-type and size of community water system based on population served

\begin{tabular}{lcc}
\hline Community water & \multicolumn{2}{c}{ System } \\
\cline { 2 - 3 } $\begin{array}{c}\text { system size (based } \\
\text { on population } \\
\text { served) }\end{array}$ & Percent of ground-water systems sampled \\
\hline \multirow{2}{*}{ Very small } & 10.4 & Random \\
Small & 16.8 & 50.4 \\
Medium & 20.8 & 20.9 \\
Large & 26.0 & 8.6 \\
Very large & 26.0 & 10.9 \\
Total & 100.0 & 9.2 \\
\cline { 2 - 3 } & Percent of surface-water systems sampled \\
Very small & 0.0 & 3.0 \\
Small & 7.1 & 6.9 \\
Medium & 1.8 & 8.0 \\
Large & 5.4 & 21.0 \\
Very large & 85.7 & 60.9 \\
Total & 100.0 & 100.0 \\
\hline
\end{tabular}



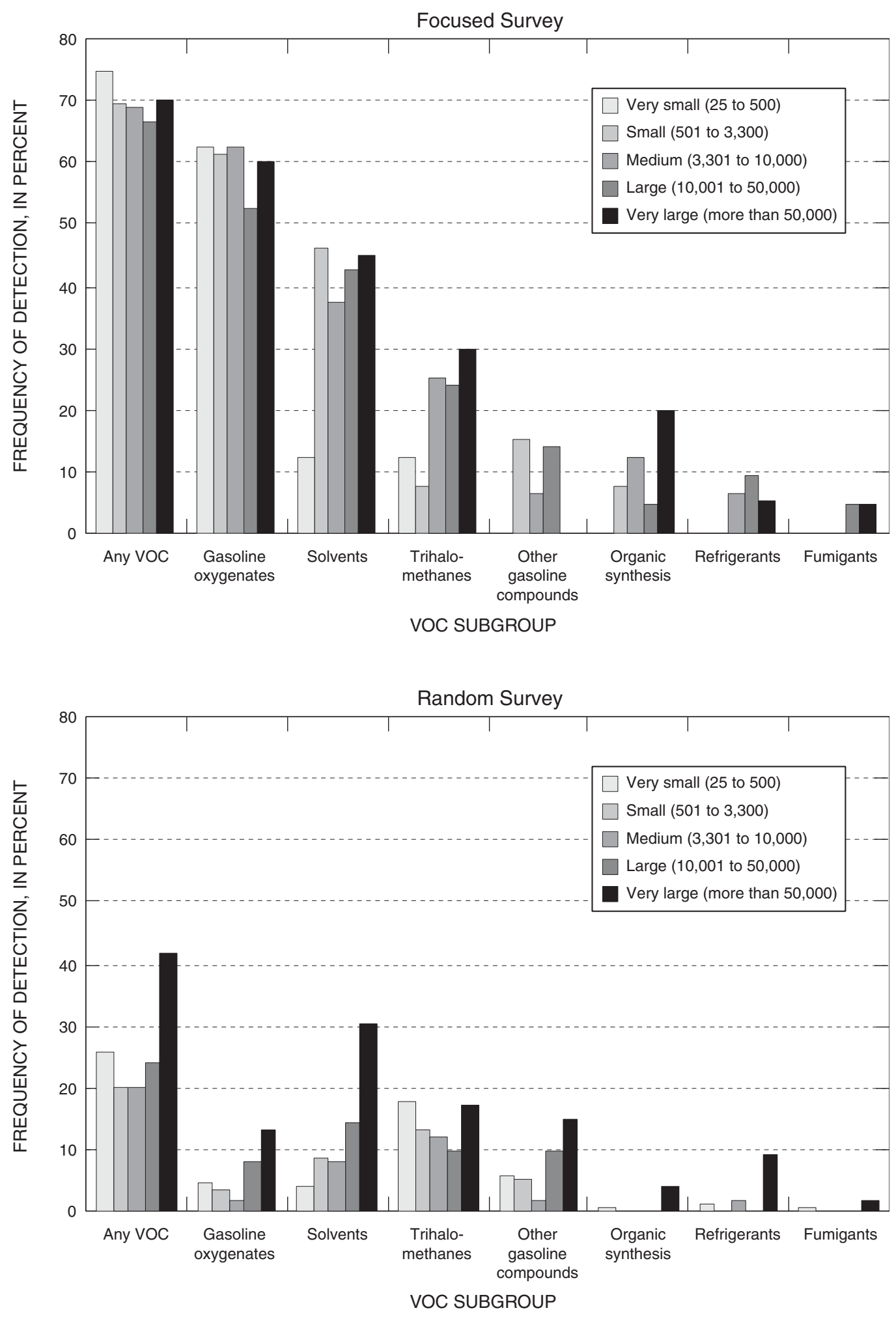

Figure 4. Detection frequency at or above the minimum reporting level of any volatile organic compound (VOC) and subgroup of VOCs in ground-water sources sampled in the Focused Survey and Random Survey by size of community water system. 

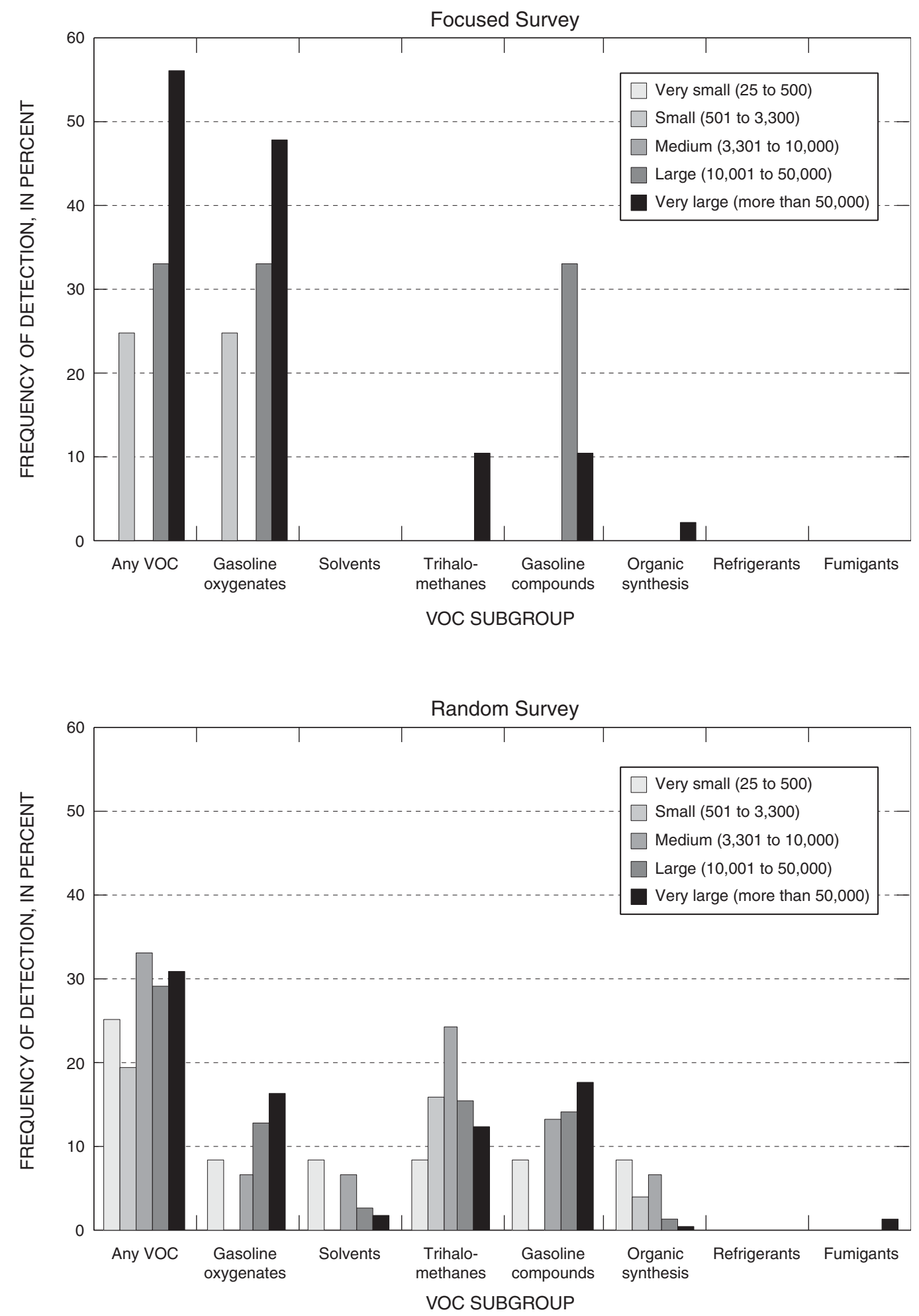

Figure 5. Detection frequency at or above the minimum reporting level of any volatile organic compound (VOC) and subgroup of VOCs in surface-water sources sampled in the Focused Survey and Random Survey by size of community water system. 


\section{Temporal Variability}

Samples were collected for one year at fixed intervals during the Focused Survey. Ground-water source waters were sampled biannually, reservoir and (or) lake source waters were sampled quarterly, and river and (or) stream source waters were sampled eight times per year (table 2). The intent of the fixed-interval sampling was to obtain sufficient data to evaluate temporal variability of VOCs in each source-water type. To do so, samples were collected more frequently in surface-water source waters than in ground-water source waters to account for likely changes in water quality caused by temperature and other seasonal affects.

The ground-water sampling design did not specifically distribute samples seasonally as was done for surface-water sampling. Ground-water samples were collected approximately six months apart and only two samples were collected from each well. Because of the slow movement of ground water, the elapsed time between samples was presumed insufficient to allow for significant changes in ground-water quality to occur. Thus, analyses of temporal variability in groundwater source waters in this report compare only the first sample to the second sample and do not evaluate seasonal patterns. In contrast, the analyses of temporal variability in surface-water source waters do evaluate seasonal patterns.

The four seasons considered in the temporal analyses were defined as spring (April-June), summer (July-September), fall (October-December), and winter (January-March). The number of reservoir and (or) lake source-water samples collected were distributed fairly evenly among the different seasons (fig. 6). The number of reservoir and lake samples collected ranged from 37 during winter to 46 in the spring. However, more samples were collected from river and (or) stream source waters during winter than in other seasons; about 30 river and (or) stream samples were collected during the spring, summer, and fall, and 52 samples were collected during the winter. Generally, this may result in an increase in VOC occurrence in rivers and streams during the winter months due to higher air-towater partitioning and decreased volatility of VOCs at winter temperatures.

Temporal analyses were performed to examine seasonal and concentration differences in those subgroups of VOCs that occur most frequently in CWS source water. It is important to note that all data above the MDL were used in the temporal analyses to maximize the number of VOC detections that are available for analyses. A summary of concentrations detected in source water is presented in Appendix D.

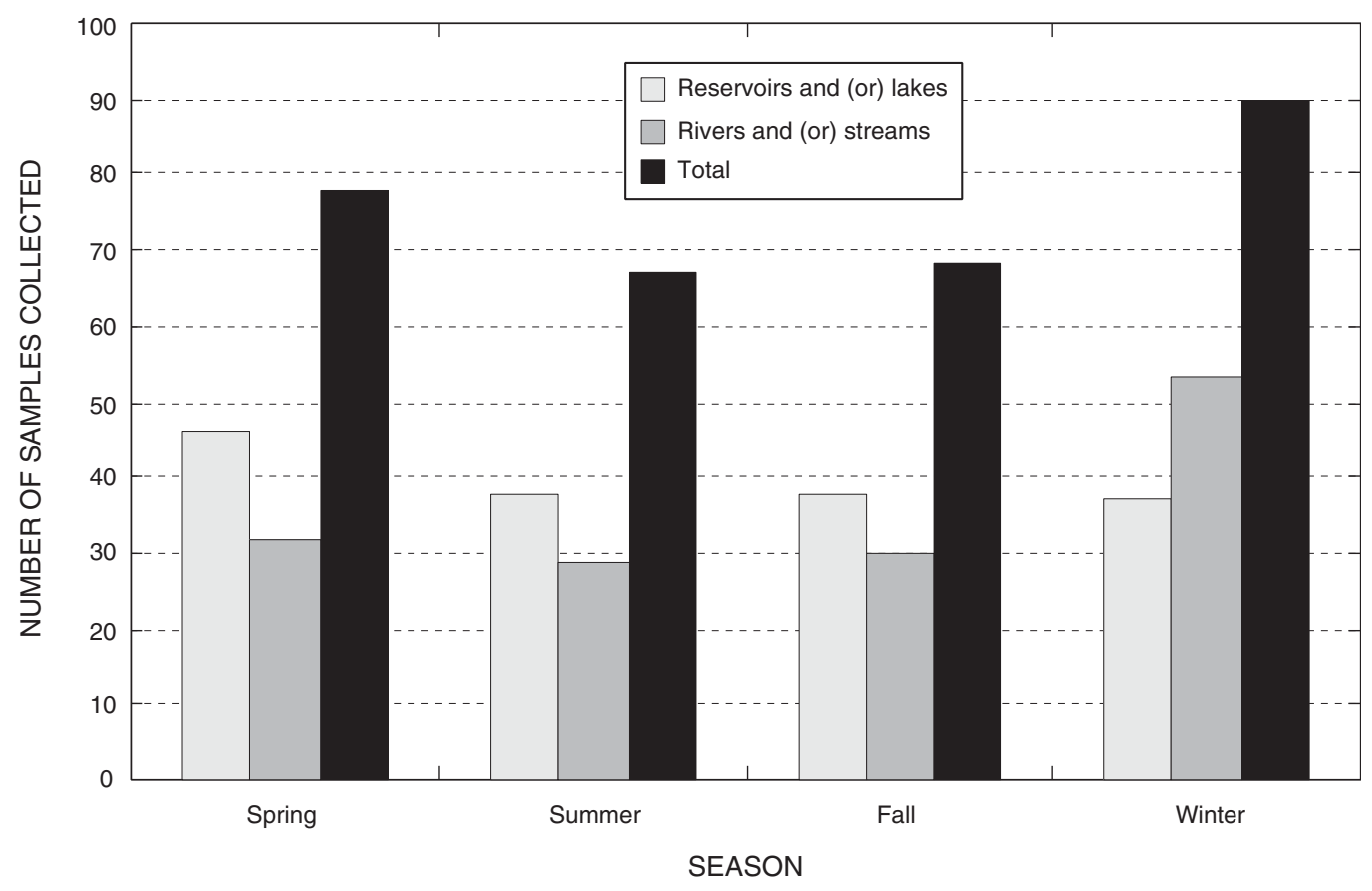

Figure 6. Number of surface-water samples collected by source type and season. 
Analyses of the data from the 134 CWS source waters previously used for comparing the Focused Survey to the Random Survey (table 4) showed that at least 1 of the 66 VOCs analyzed was detected in more than 90 percent of the source waters sampled as part of the Focused Survey (fig. 7). Each of the 17 CWSs supplied by rivers or streams contained at least one VOC, a result of the detection of a gasoline oxygenate in each of the $17 \mathrm{CWS}$ river and (or) stream source waters. In addition, gasoline oxygenates, other gasoline compounds, THMs, and organic synthesis compounds were detected more frequently in CWSs supplied by river source waters than in any other source water sampled. This may be due to the presence of point sources upstream from the sampling site that provide a fairly continuous source of contamination.

Gasoline oxygenates, other gasoline compounds, THMs, and organic synthesis compounds were detected in more than 25 percent of CWSs served by ground-water, reservoir and (or) lake, and river and (or) stream source waters (fig. 7). Therefore, these four subgroups of VOCs were used in subsequent temporal analyses. In addition, solvents were evaluated only in ground-water source waters because they were not detected frequently in surface-water source waters.
Fumigants and refrigerants were not analyzed for temporal variability due to their infrequent detection.

\section{Ground Water}

Analyses of data from all 78 ground-water source waters sampled biannually revealed that detection frequencies of VOC subgroups did not change significantly from the first sample collected to the second sample (fig. 8). Similarly, no statistically significant differences in detected concentrations of VOCs were found at the 95-percent confidence level using the Wilcoxon rank sum test (Helsel and Hirsch, 1992) (fig. 9). Because samples were collected approximately 6 months apart, it is presumed that an insufficient amount of time passed to show any significant changes in ground-water quality.

Although these subgroups of VOCs occur frequently in the source waters sampled, the concentrations detected were small, typically less than $1 \mu \mathrm{g} / \mathrm{L}$. However, some higher concentrations were observed-maximum concentrations of MTBE, tetrachloroethene, and trichloroethene in ground-water source waters were 924,290 , and $165 \mu \mathrm{g} / \mathrm{L}$, respectively.

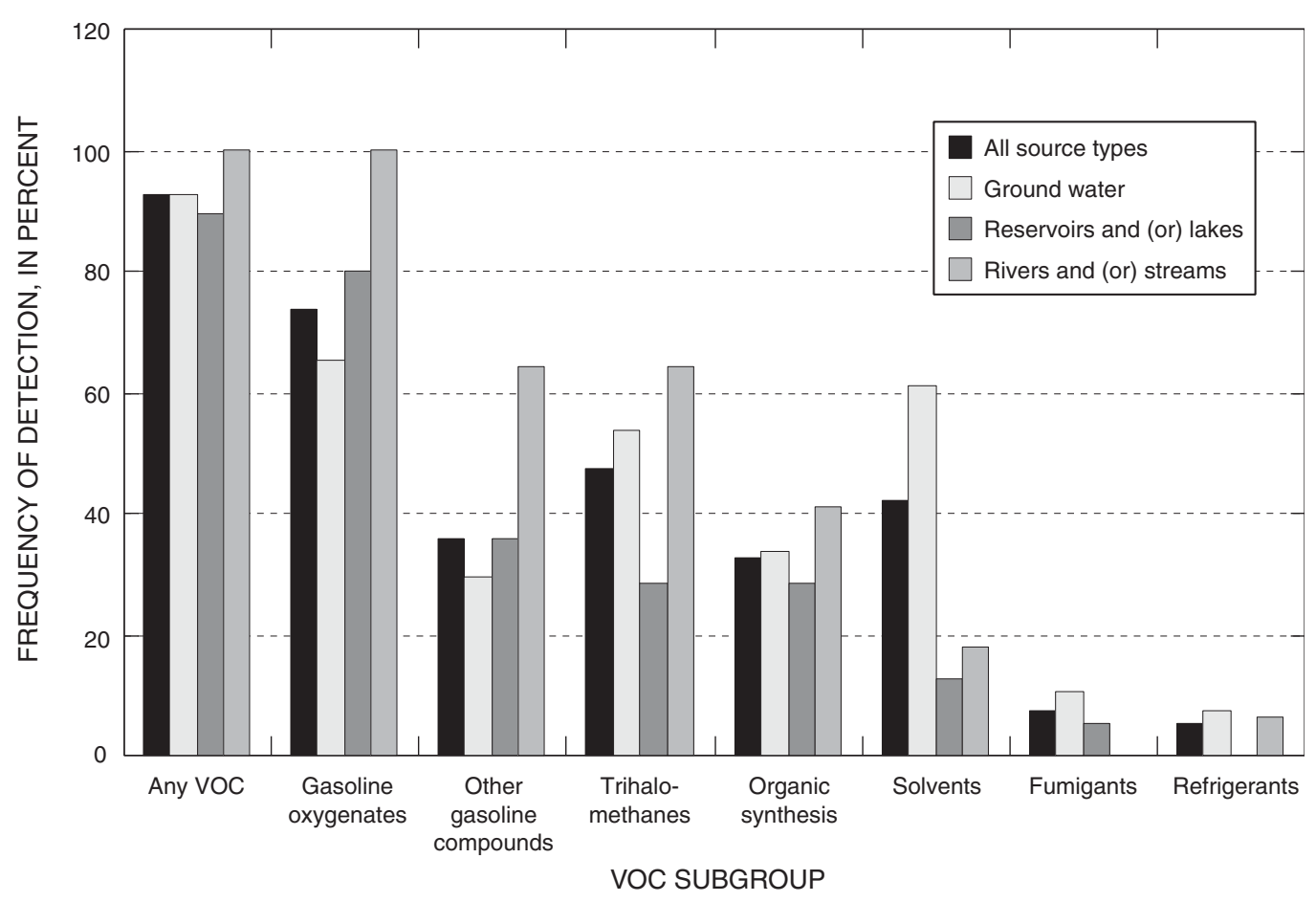

Figure 7. Detection frequency at or above the minimum reporting level of any volatile organic compound (VOC) and by subgroup of VOCs in community water system source waters by source type. 


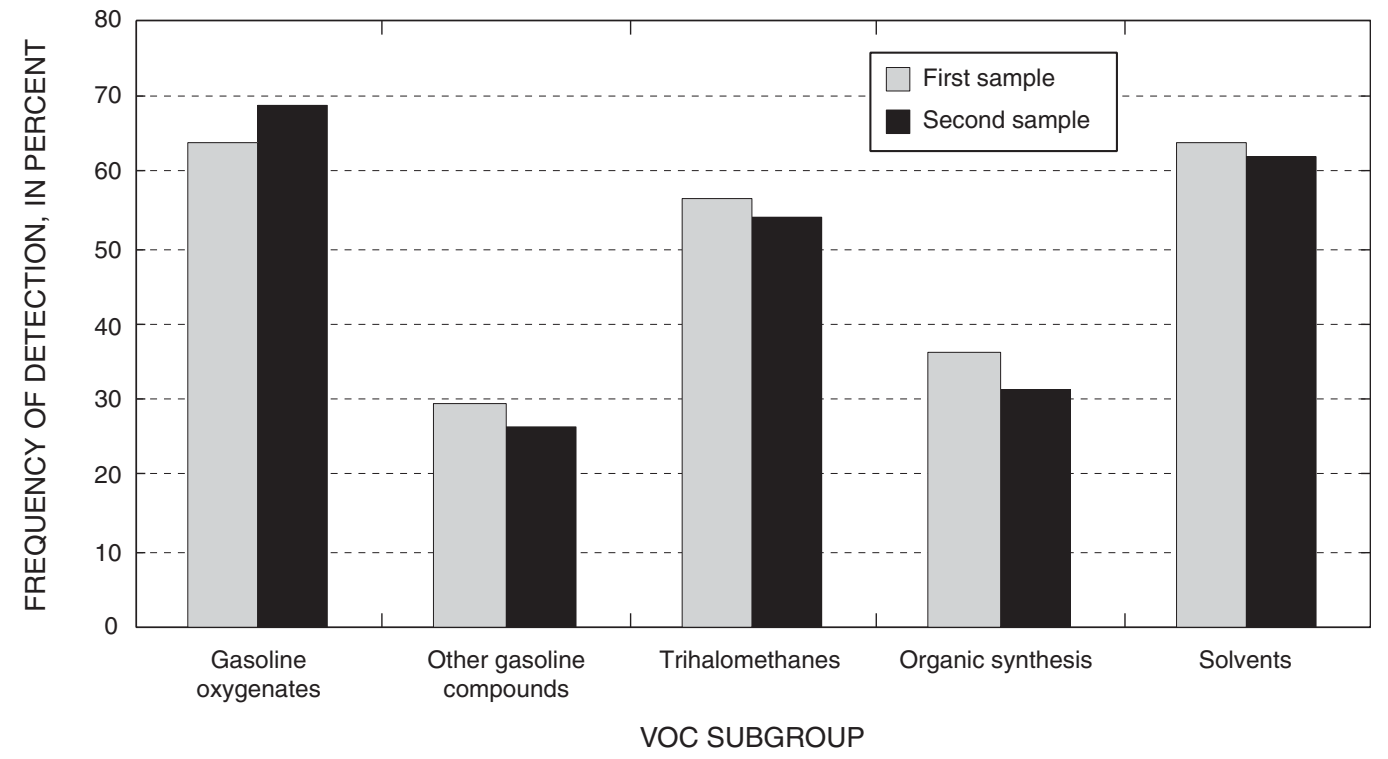

Figure 8. Comparison of the detection frequency of at least one volatile organic compound (VOC) at or above the method detection limit by subgroup of VOCs in the first and second sampling of ground-water source water.

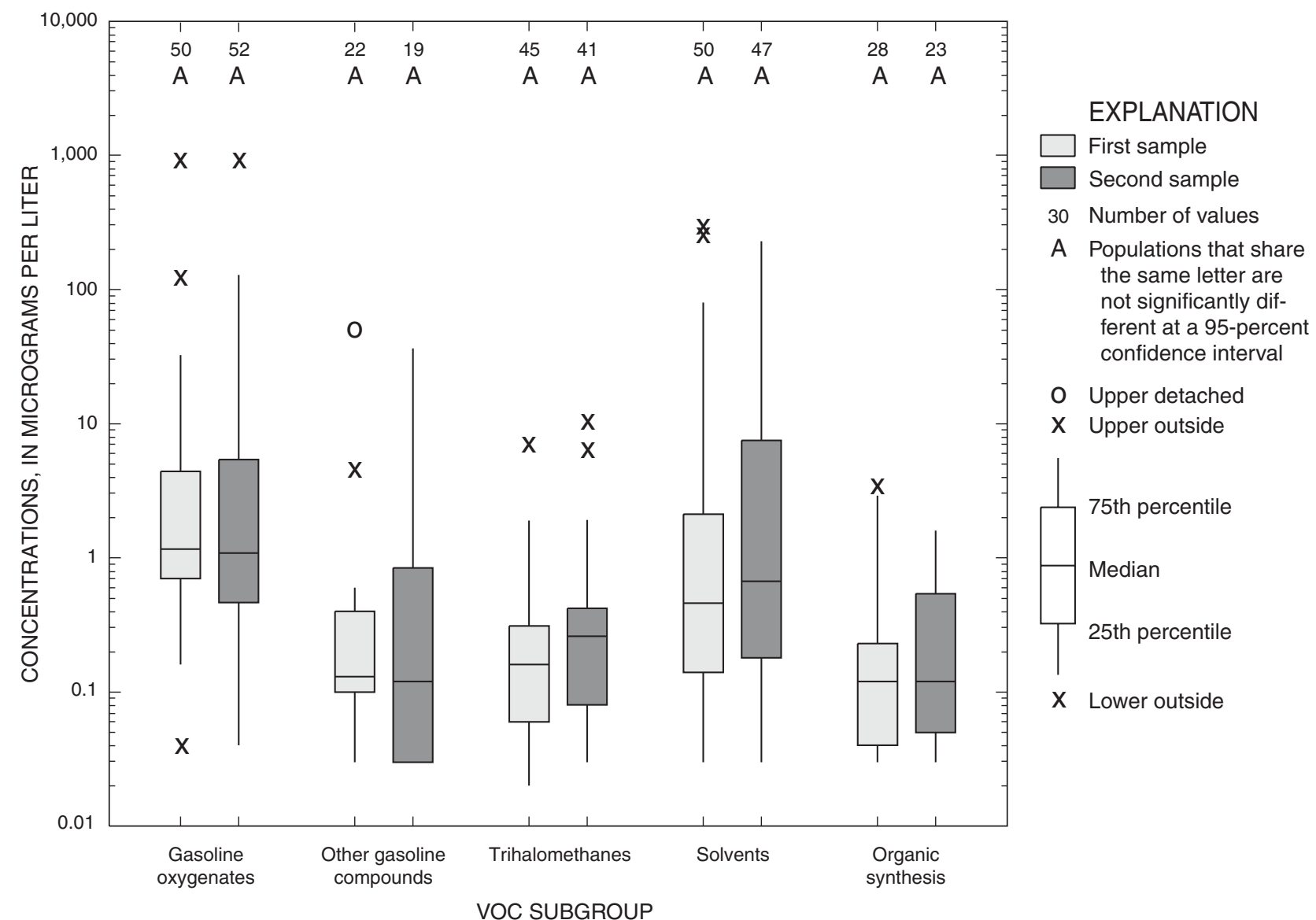

Figure 9. Detected concentrations of volatile organic compound subgroups in ground-water source water collected in the first and second samples. 


\section{Reservoirs and Lakes}

A slight seasonal pattern was evident in the occurrence of gasoline oxygenates and other gasoline compounds (fig. 10) in reservoir and lake source waters. Analyses of data from all 39 reservoirs and (or) lakes sampled quarterly revealed that both of these subgroups of VOCs were detected more frequently in the spring and summer than in the fall and winter. However, these compounds were still fairly prevalent during the fall and winter, when they were detected in at least 27 percent of samples. Thirty-three of the 39 reservoirs sampled allow motorized watercraft. Thus, the greater detection of gasoline-related compounds in the spring and summer is presumed to be related to the increased use of motorized watercraft during these seasons. The continued detection of these compounds during fall and winter may be due, in part, to the continued use of watercraft containing reformulated gasoline during these seasons in areas with warmer climates, and the chemical characteristics of MTBE, which allow it to persist longer in water in comparison to other VOCs.

Trihalomethanes and organic synthesis compounds were detected in about 30 percent of samples collected throughout the year with no significant trend identified. The lack of any substantial, seasonal variability in THMs and organic synthesis compounds indicates the possibility of a common and continuous source of contamination for these compounds.

Concentrations of VOCs detected in reservoir and lake source waters were typically less than $1 \mu \mathrm{g} / \mathrm{L}$, and very few statistically significant differences in seasonal concentrations were identified (fig. 11).

Although gasoline oxygenates and other gasoline compounds were detected more frequently in the spring and summer than in fall and winter, statistically significant differences in detected median concentrations of VOCs typically were not identified by the Wilcoxon rank sum test at an alpha of 0.05 . There were no statistically significant differences between seasonal concentrations of gasoline oxygenates and THMs. Statistically significant differences were found for other gasoline compounds and organic synthesis compounds. For these VOC subgroups, winter and (or) fall concentrations were significantly less than spring and (or) summer concentrations.

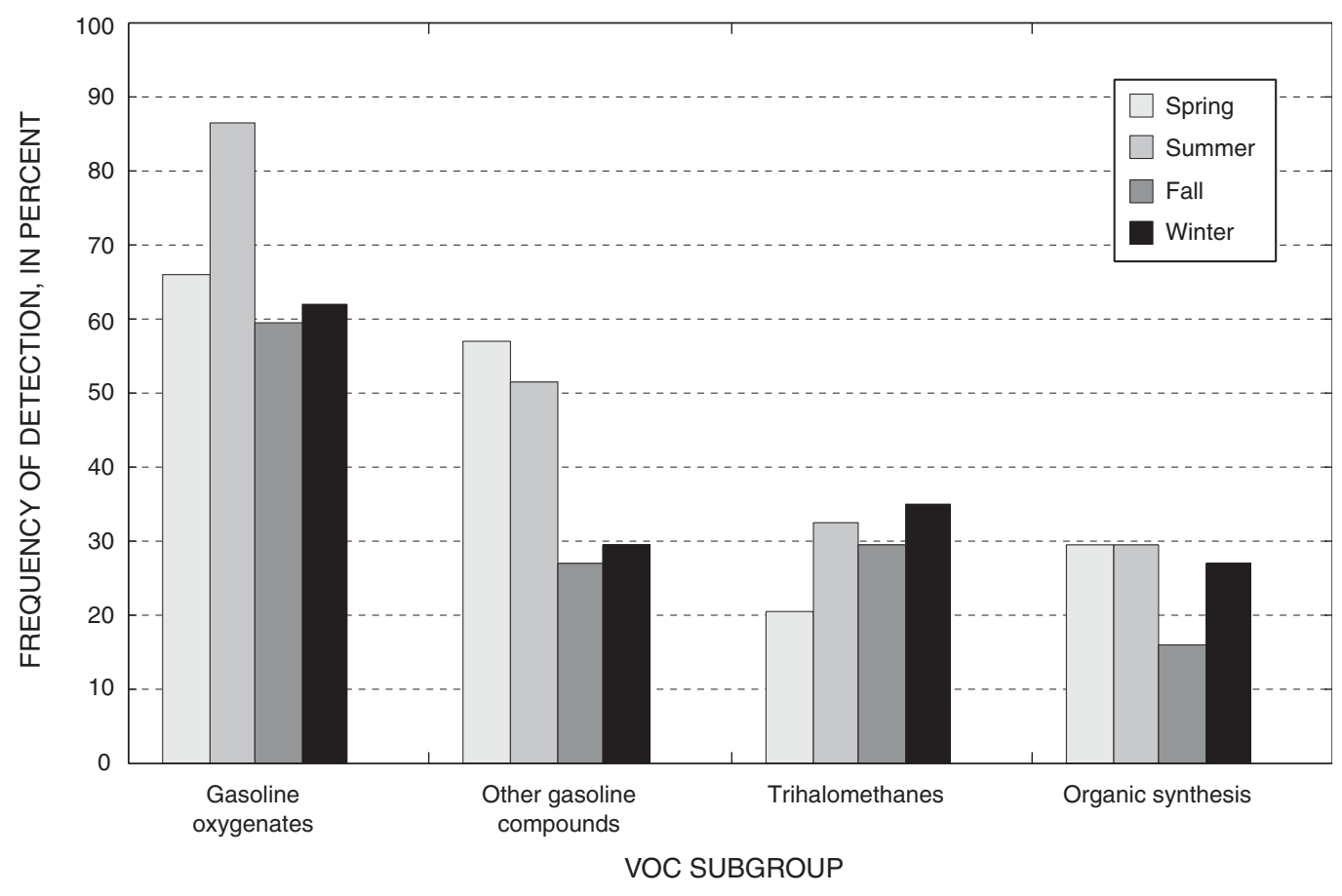

Figure 10. Detection frequency of at least one volatile organic compound (VOC) at or above the method detection limit by subgroup of VOCs in reservoir and lake source waters by season. 


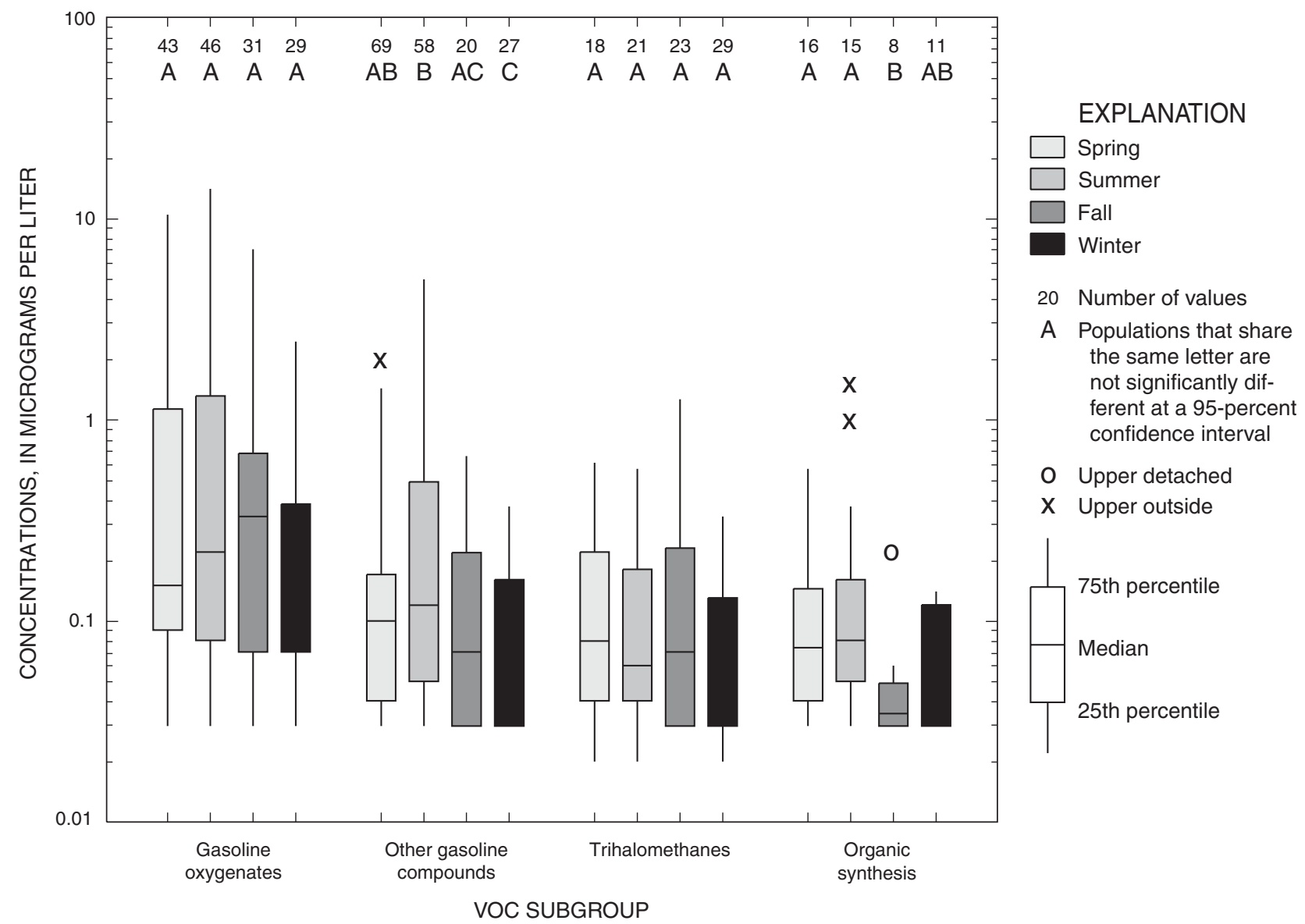

Figure 11. Detected concentrations of volatile organic compound subgroups in reservoir and lake source waters by season.

\section{Rivers and Streams}

No seasonal pattern was evident for any of the more frequently occurring subgroups of VOCs in river and stream source waters (fig. 12). The detection of gasoline oxygenates was found to drop slightly from spring to winter; however, these VOCs were found to be consistently present in the source waters sampled-in at least 78 percent of the samples. This may be indicative of a common source of gasoline oxygenates to the source waters sampled. Other gasoline compounds, THMs, and organic synthesis compounds also were detected at similar frequencies throughout the year. Other gasoline compounds and THMs were detected in more than 50 percent of all samples, and organic synthesis compounds were detected in more than 20 percent of all samples collected throughout the year. Again, the absence of seasonal differences for these subgroups of compounds may indicate an unknown, but common and continuous source of contamination.

Concentrations of the VOCs (subgroups) most frequently detected in river and stream source waters were typically less than $1 \mu \mathrm{g} / \mathrm{L}$, and few statistically significant differences in concentrations were noticed on a seasonal basis (fig. 13). Although these subgroups of VOCs were found frequently year round (fig. 12), the only statistically significant differences in the concentrations of VOCs were within the gasoline oxygenate subgroup, which were found at slightly greater concentrations during the summer than during the winter season. 


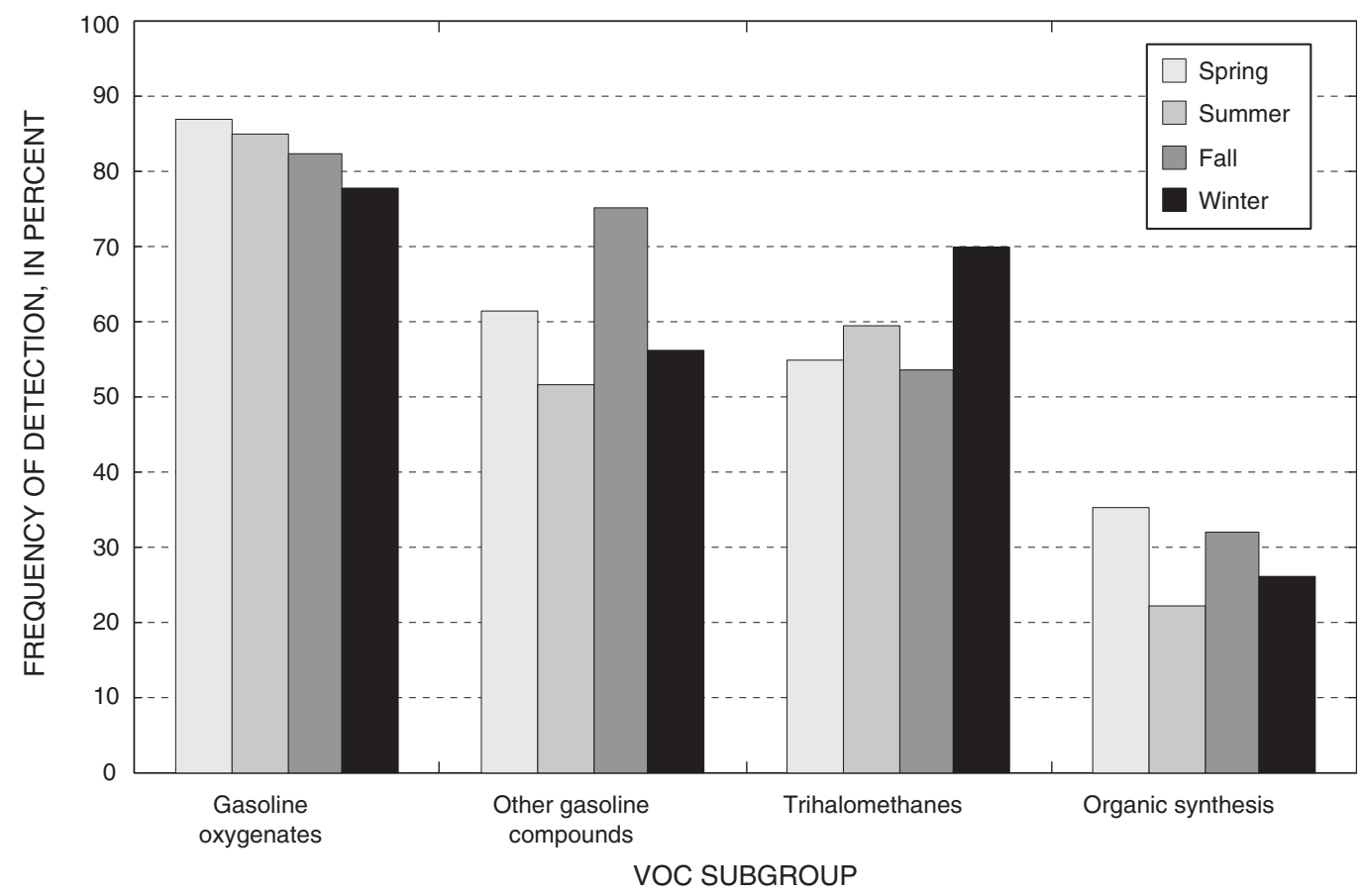

Figure 12. Detection frequency of at least one volatile organic compound (VOC) at or above the method detection limit by subgroup of VOCs in river and stream source waters by season.

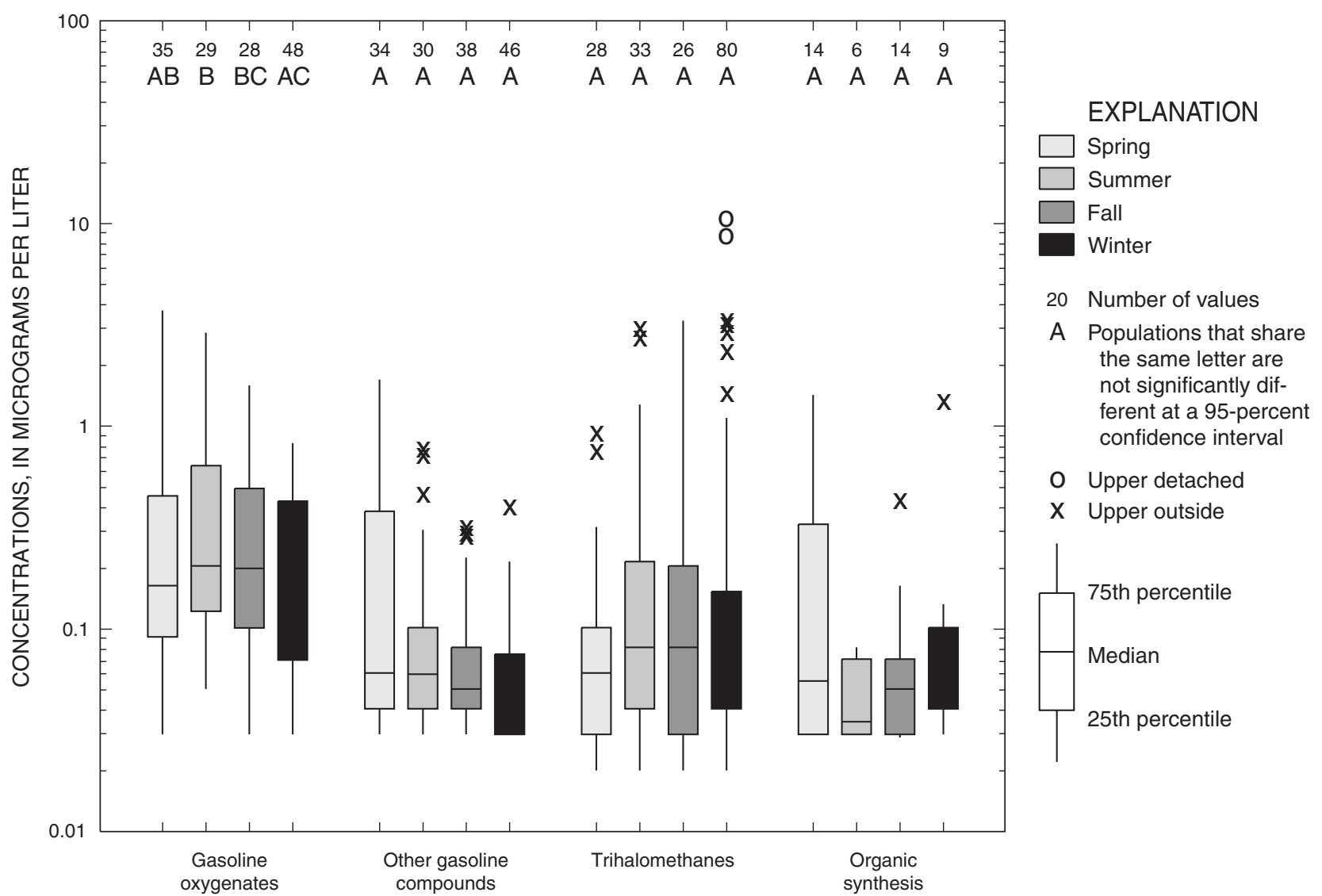

VOC SUBGROUP

Figure 13. Detected concentrations of volatile organic compound subgroups in river and stream source waters by season. 


\section{ANTHROPOGENIC FACTORS ASSOCIATED WITH MTBE, GASOLINE OXYGENATES, AND TRIHALOMETHANES}

Few temporal patterns were found when examining occurrence and concentrations of VOC subgroups in source waters where MTBE was suspected or known to occur. One apparent trend was found in reservoirs and lakes, where gasoline oxygenates and other gasoline compounds were detected more frequently during the spring and summer. This was likely associated with the increased use of motorized watercraft on the reservoirs during these seasons. However, no significant statistical differences were noticed when examining MTBE concentrations alone on a seasonal basis. Although one or two VOCs typically dominate the occurrence within VOC subgroups (table 4), the increased number of potential detections in subgroups should be beneficial in detecting significant trends not otherwise noticed when examining individual VOCs. As such, the most frequently detected VOC (MTBE) and the two most frequently occurring subgroups of VOCs (gasoline oxygenates and THMs) in the Focused Survey were further characterized to evaluate anthropogenic factors that may better explain and (or) to understand their frequent occurrence.

The two most frequently occurring subgroups of VOCs in the Focused Survey were gasoline oxygenates and THMs; these subgroups were detected in 73.9 and 47.8 percent of CWS source waters sampled, respectively (table 4). In CWS source waters, MTBE was the most frequently detected gasoline oxygenate (77.3 percent) followed by TAME (20.3 percent). Chloroform and bromodichloromethane were the two most frequently detected THMs, occurring in 48.4 and 20.9 percent of CWS source waters, respectively.

Anthropogenic factors associated with gasoline oxygenates were evaluated on the basis of MTBE highuse areas for CWSs served by ground-water, reservoir and (or) lake, and river and (or) stream source waters, and on watercraft use on reservoirs and lakes. Anthropogenic factors associated with THMs detected in reservoir source waters were evaluated on the basis of ancillary data provided by CWS personnel. All analyses were performed using data at or above the MDL.

\section{MTBE and Gasoline Oxygenates}

Detected concentrations of MTBE in groundwater source waters inside and outside of MTBE high- use areas were compared. Fifty-five wells were within MTBE high-use areas and 23 were outside of these areas. MTBE was detected more frequently in MTBE low-use areas than in MTBE high-use areas. When both samples collected from individual wells were considered, MTBE was detected in 73.9 percent (34 of 46) of ground-water samples collected in MTBE lowuse areas and in 62.7 percent (69 of 110) of groundwater samples collected in MTBE high-use areas. The differences in occurrence and concentration may be explained, in part, by how these sites were selected. Thirty-eight CWS wells were selected because of the suspected occurrence of MTBE and 37 were selected because of a known occurrence (Appendix A). However, 21 of the 37 sites where MTBE was known to occur were not in areas of MTBE high use. This comparison is then skewed toward those sites outside of MTBE high-use areas and is merely a result of intentionally selecting wells with a known occurrence of MTBE. For this reason, statistical comparisons were not completed.

Concentrations of MTBE in reservoir and (or) lake source waters inside and outside of MTBE highuse areas were compared seasonally (fig. 14). Twentyfive reservoir and (or) lake sources were inside MTBE high-use areas and 14 were outside of these areas. MTBE was detected more frequently and concentrations were greater in MTBE high-use areas than in MTBE low-use areas. This is likely due, in part, to the much larger percentage of MTBE volume/volume present in gasoline in MTBE high-use areas than in other areas. However, because as few as four detections of MTBE were found in reservoir and (or) lake source waters in MTBE low-areas, statistical comparisons were not completed.

Concentrations of MTBE in river and (or) stream source waters inside and outside of MTBE high-use areas also were compared seasonally (fig. 15). Eleven of the river and (or) stream intakes were inside MTBE high-use areas and six were outside of these areas. Similar to reservoir and (or) lake source waters, MTBE was detected more frequently and concentrations were greater in MTBE high-use areas than in MTBE low-use areas. However, because as few as three detections of MTBE were found in river and (or) stream sources in MTBE low-use areas, statistical comparisons were not completed. 


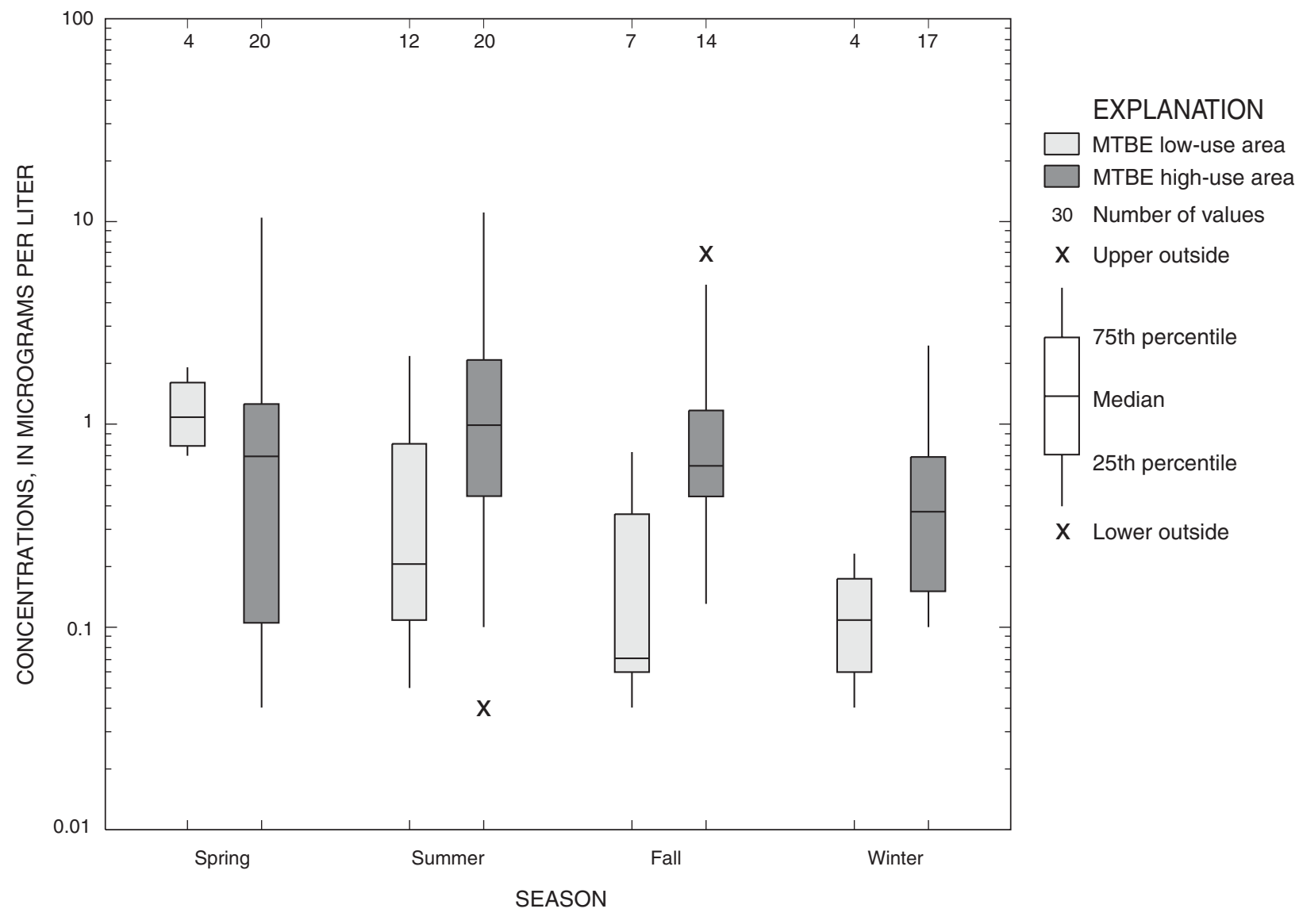

Figure 14. Detected concentrations of methyl tert-butyl ether (MTBE) in reservoir and lake source waters by location in MTBE low- and high-use areas.

Gasoline oxygenates were analyzed in relation to watercraft use as reported in an ancillary data form completed by personnel at each CWS (Ivahnenko and others, 2001). The average number of watercraft per reservoir per year was divided by the surface area (in acres) of each respective reservoir to obtain a watercraft-use factor (number of boats per acre per year). In order to characterize the effect of watercraft on the occurrence and concentration of gasoline oxygenates, the sum of the average detected concentration of all gasoline oxygenates for each reservoir was plotted relative to the watercraft-use factor in MTBE high- and low-use areas (fig. 16).

Linear regression analyses indicated a weak positive trend associated with the average gasoline oxygenate concentration and watercraft use in MTBE high- use areas. The relation between the average gasoline oxygenate concentration and watercraft use in reservoirs inside MTBE high-use areas resulted in an $\mathrm{r}^{2}$ of 0.3783 . However, no relation was observed for reservoirs in MTBE low-use areas $\left(r^{2}=0.0242\right)$. In general, as watercraft use increased in areas of MTBE high-use, the average concentration of gasoline oxygenates also increased.

All watercraft-use values (inside and outside of MTBE high-use areas) were then divided into four quartile categories: (1) 0 to 25 th percentile; (2) 26th to 50th percentile; (3) 51st to 75th percentile; and (4) 76th to 100th percentile. The average gasoline oxygenate concentrations were then plotted per quartile category (fig. 17). Again, the average concentration of gasoline oxygenates increased as watercraft use increased. 


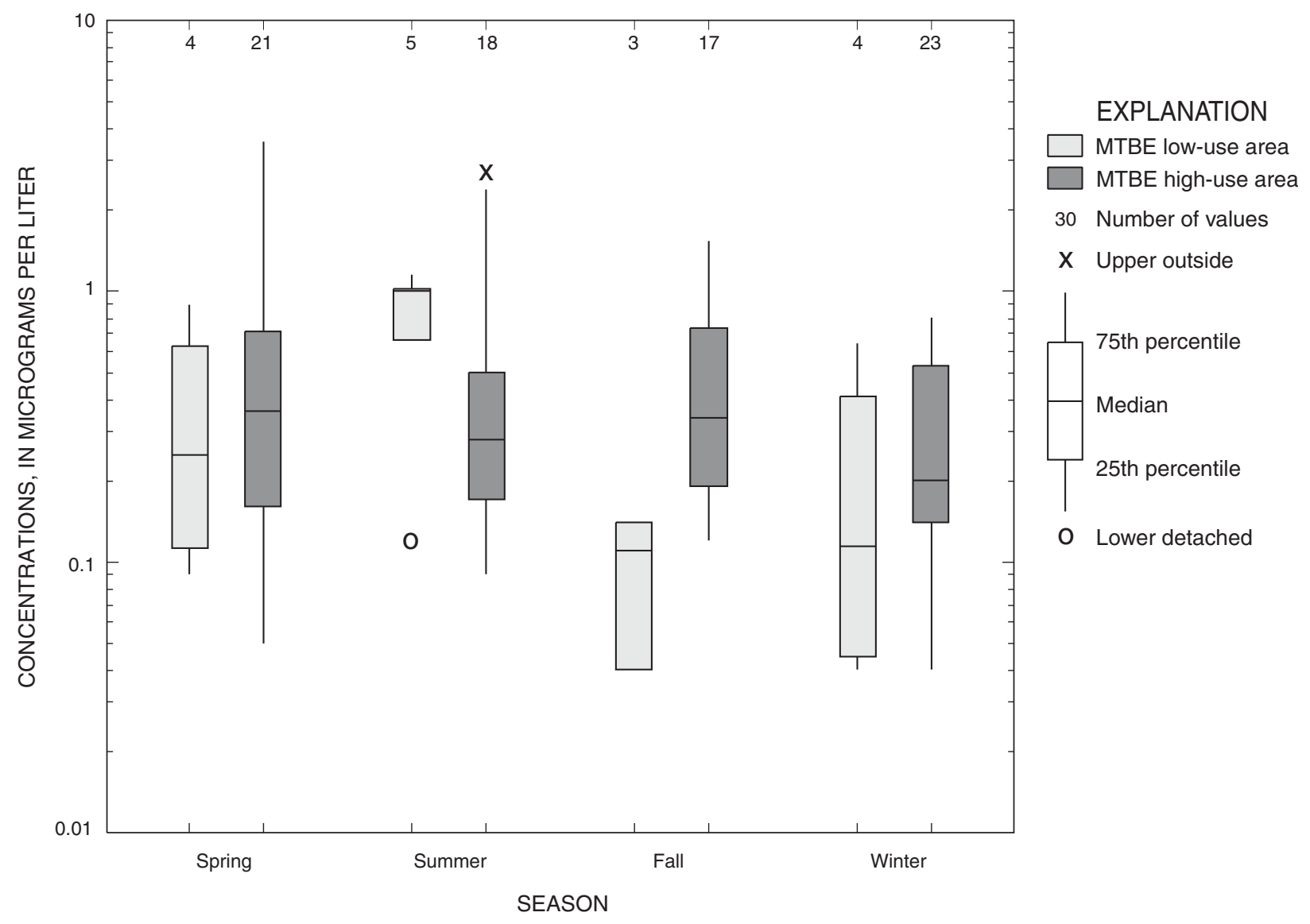

Figure 15. Detected concentrations of methyl tert-butyl ether (MTBE) in river and stream source waters by location in MTBE low- and high-use areas.

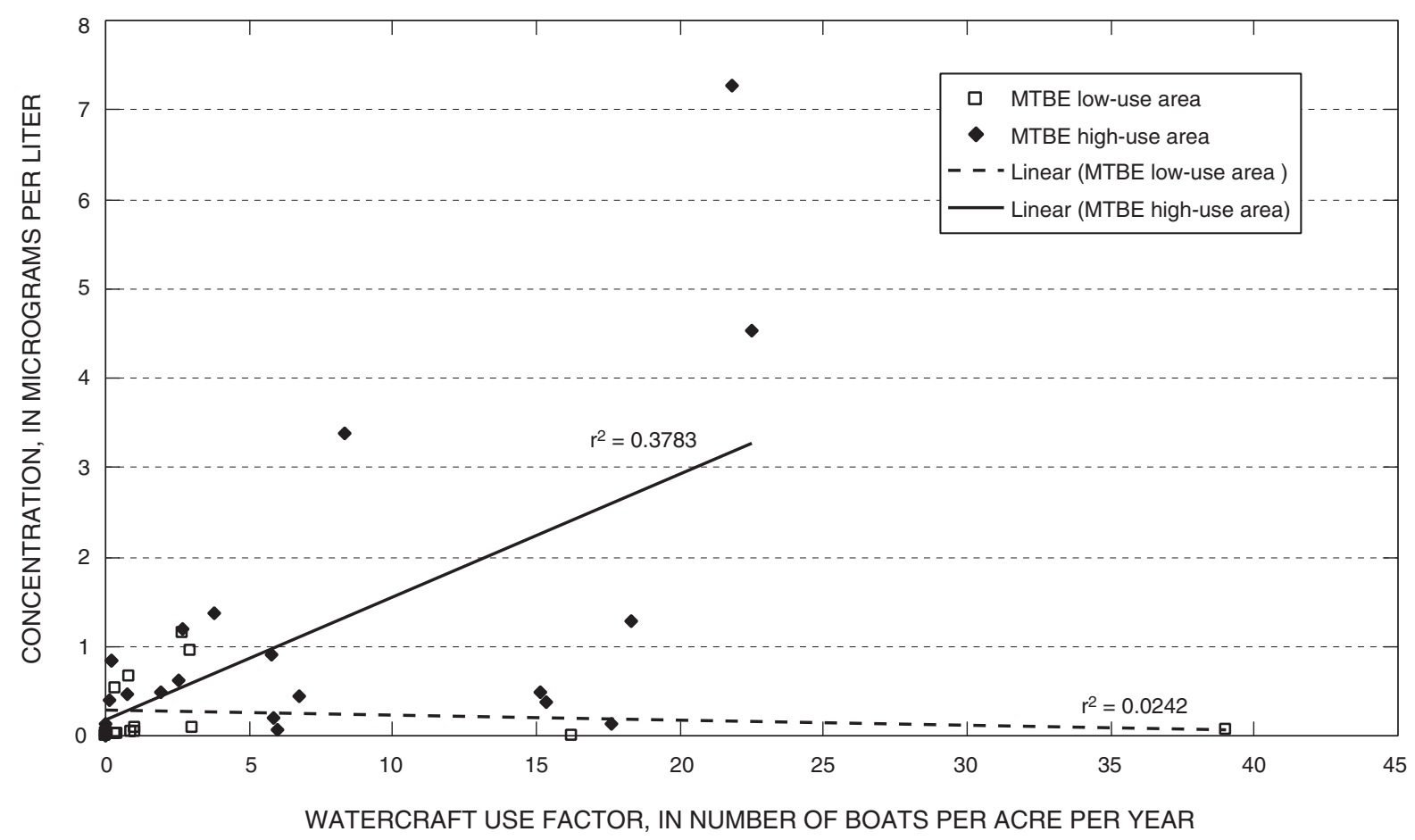

Figure 16. Average sum of gasoline oxygenate concentrations versus watercraft-use factor. 


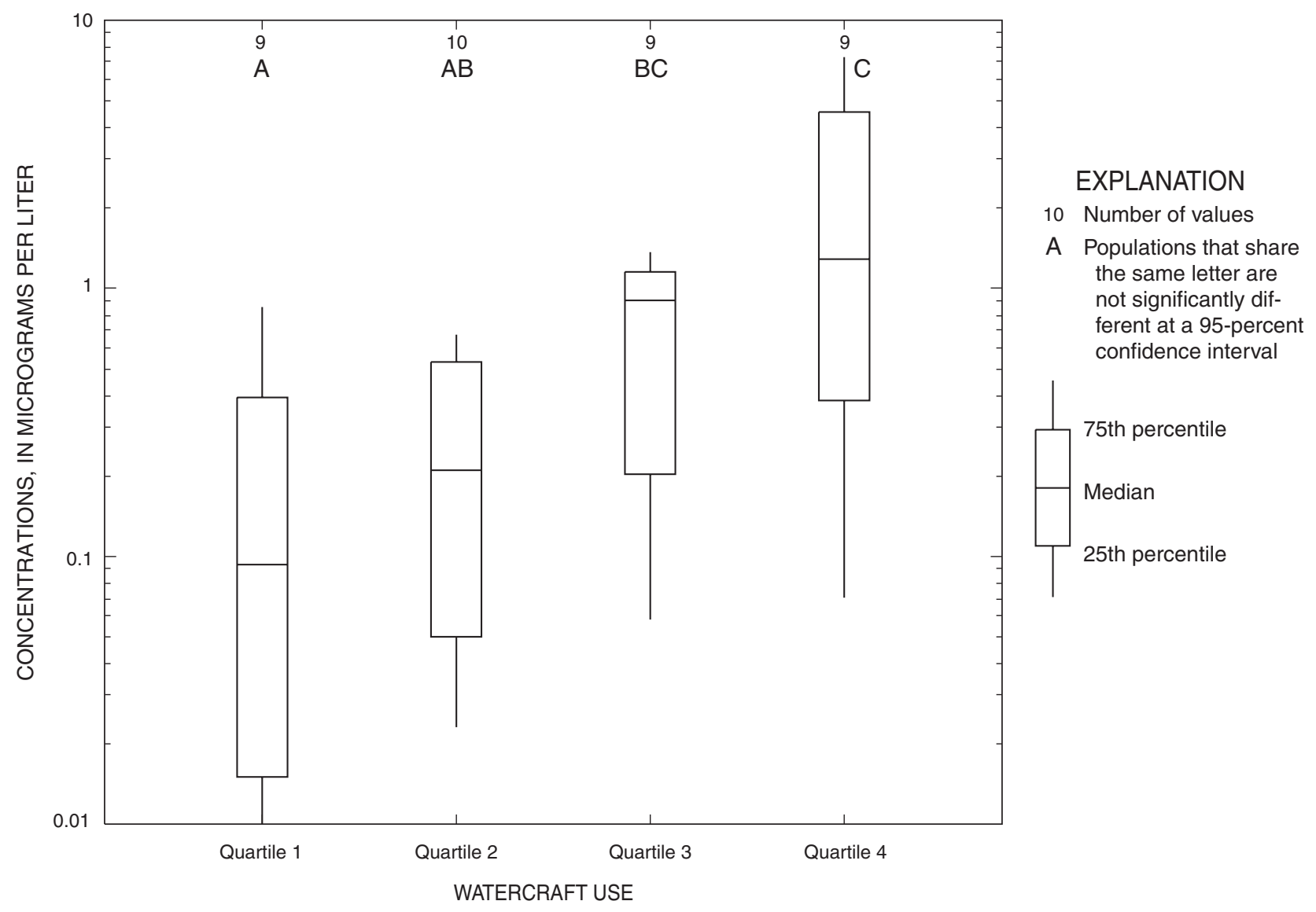

Figure 17. Average concentrations of gasoline oxygenates by watercraft-use quartiles.

\section{Trihalomethanes}

Trihalomethanes were detected in 11 of the reservoirs and (or) lakes sampled in the Focused Survey. The most frequently detected THM was chloroform, which was found in 10 of the 39 reservoirs and (or) lakes (25.6 percent), followed by bromodichloromethane, which was found in 7 of the 39 reservoirs and (or) lakes (17.9 percent). Seven reservoirs and (or) lakes serving CWSs contained detectable concentrations of at least two THMs. THMs commonly are referred to as disinfection by-products because they can occur in drinking water that has been treated with chlorine. Because samples in the Focused Survey were collected directly from the source water-not finished drinking water-each of these seven CWSs were contacted to better understand the occurrence of these compounds, and each provided input to the occurrence and likely source of THMs in their source water.
CWS personnel indicated that THMs were present in their source water as disinfection by-products. Three of the CWSs return filter backwash to the source-water reservoir; one disinfects water from other sources with chlorine and then releases the disinfected water to the reservoir; one CWS adds chlorine upstream of the source reservoir for algae control; one CWS has a powerplant that withdraws water from the reservoir, disinfects the water with chlorine for algal control, uses the water for cooling purposes, and then releases the water back to the reservoir. Lastly, one CWS indicated that the source of THMs in the source water could be due to a wastewater treatment facility discharging upstream of the reservoir.

THMs were detected in 11 of the 17 rivers and (or) streams sampled in the Focused Survey. Chloroform was the most frequently detected THM, occurring in 11 of the 17 rivers and (or) streams (64.7 percent). Nine of these 11 rivers and (or) streams contained at least two THMs. 
The CWSs that obtain their source water from the rivers and (or) streams with more than one detectable concentration of any THM were not contacted for additional information to better understand the occurrence of the THMs. It is presumed, however, that the sources of these compounds may include point-source discharges upstream from the CWS intakes. Discharges could include those from wastewater treatment plants, power plants, and industrial discharge. Nonpoint sources, such as runoff of treated irrigation water from lawns, inflow of ground water containing THMs, and combined sewer overflows that are chlorinated prior to discharge, also could explain the occurrence of these compounds.

\section{SUMMARY AND CONCLUSIONS}

The U.S. Geological Survey National WaterQuality Assessment Program in cooperation with the Metropolitan Water District of Southern California (MWDSC) and the Oregon Health \& Science University completed an investigation of the Nation's drinking-water supplies. The study was sponsored by the American Water Works Association Research Foundation to provide information on the occurrence, concentration, and temporal variability of methyl tertbutyl ether (MTBE) and other volatile organic compounds (VOCs) in source waters used by community water systems (CWSs).

The national investigation was completed in two stages: (1) reviews of available literature, and (2) the collection of new drinking-water data. Two surveys were completed for the collection of new drinkingwater data. The first, termed the Random Survey, employed a statistically stratified design for sampling source waters from 954 randomly selected CWSs based on the total number of systems within five populationserved size categories, source-water type, and the total number of people served by each of the source-size categories used within the United States. The second survey, which is the focus of this report, is termed the Focused Survey, which included samples collected from CWS source waters that are suspected or known to contain MTBE. The intent of the Focused Survey was to provide an improved understanding of the occurrence, concentration, temporal variability, and some anthropogenic factors associated with the frequent occurrence of MTBE and other frequently identified VOCs.
Each sample collected was analyzed for 66 VOCs, including MTBE and three other ether gasoline oxygenates (hereafter termed gasoline oxygenates), at the MWDSC laboratory. The 451 samples were collected at fixed intervals for one year from 78 groundwater, 39 reservoir and (or) lake, and 17 river and (or) stream source waters in select areas of the Nation. Ground-water source waters were sampled biannually, reservoirs and lakes were sampled quarterly, and rivers and streams were sampled eight times per year. In addition, 744 field quality-control (QC) samples, including trip-reagent blanks, field-reagent blanks, field-equipment blanks, and duplicate samples were collected. All data underwent an exhaustive QC review process to accept or reject source-water data for inclusion in the Focused Survey's findings.

Occurrence data from the Focused Survey were compared to results obtained from the Random Survey using a common assessment level of $0.2 \mu \mathrm{g} / \mathrm{L}$. Fortyone and 42 individual VOCs were detected in the Focused Survey and Random Survey, respectively, 37 of which were detected in both surveys. However, the detection frequency of many VOCs was greater in samples collected as part of the Focused Survey than in the Random Survey. Because source waters suspected or known to contain MTBE were sampled in the Focused Survey, MTBE was detected in 55.5 percent of the 134 CWSs sampled in the Focused Survey, whereas MTBE was detected in only 8.7 percent of 954 CWSs sampled in the Random Survey. The increased detection frequency of other VOCs in the Focused Survey may be explained by high-population density, which was one factor associated with the selection of source waters to be sampled as part of the Focused Survey.

The 66 VOCs analyzed were subdivided into seven subgroups of VOCs, based mainly on the primary use of the compounds. Each subgroup of VOCs was found more frequently in the Focused Survey than in the Random Survey. The gasoline oxygenate subgroup, which includes MTBE, was found most frequently and was detected in 53.7 percent of CWSs in the Focused Survey and in 8.5 percent of CWSs sampled in the Random Survey. Again, this difference is due largely to the selection of sites with suspected or known occurrence of MTBE. A large difference in occurrence also was observed in the solvent subgroup; solvents were detected in 21.6 percent and 6.3 percent of CWSs sampled in the Focused and Random Survey, respectively. The two most frequently detected solvents in both surveys were tetrachloroethene and 
trichloroethene; however, these compounds were mainly detected only in CWSs supplied by ground water. Little difference in occurrence was observed for the THM subgroup; these compounds were detected in 16.4 percent of Focused Survey and 14.8 Random Survey CWSs, respectively. This may indicate a pervasive occurrence of THMs in source waters, regardless of CWS size or geographic location.

In contrast to results of the Random Survey, the occurrence of subgroups of VOCs does not appear to be related to the size (based on population served) of CWSs in the Focused Survey supplied by ground water. In the Focused Survey, each subgroup of VOCs was detected at similar frequencies in each CWS size category. However, there were some differences in CWSs supplied by surface water in that the gasoline oxygenate and other gasoline compound subgroups were predominantly detected in the Focused Survey, whereas solvents, THMs, and organic synthesis compounds were detected more frequently in several sizes of CWSs sampled in the Random Survey.

Only two samples were collected from each ground-water source water included in the Focused Survey; thus, temporal variations on a seasonal basis could not be identified. However, comparisons were made between the first sample and the second sample collected from $78 \mathrm{CWSs}$. No apparent differences were observed for any subgroup of VOCs between the first and second ground-water source water samples analyzed. It is presumed that an insufficient amount of time passed between the collection of the first and second ground-water sample, typically 6 months, to observe any significant changes in ground-water quality. The occurrence of each subgroup of VOCs was virtually identical between the two samples, and no statistically significant differences at an alpha of 0.05 were noticed in the detected VOC concentrations. Detected concentrations were small, typically less than $1 \mu \mathrm{g} / \mathrm{L}$. However, the maximum concentrations of MTBE, tetrachloroethene, and trichloroethene in ground-water source waters were 924,290 , and $165 \mu \mathrm{g} / \mathrm{L}$, respectively.

On the basis of data at or above the method detection limit, concentrations of VOCs detected in the Focused Survey in reservoir and (or) lake source waters were typically small (less than $1 \mu \mathrm{g} / \mathrm{L}$ ). Furthermore, very few statistically significant differences in detected concentrations were noticed on a seasonal basis among subgroups of VOCs. However, a slight seasonal pattern was evident for the occurrence of gasoline oxygenates and other gasoline compounds in the 39 reservoirs and lakes sampled. Both of these subgroups of VOCs were detected more frequently during spring and summer than in fall and winter. Thirty-three of the 39 reservoir and (or) lakes sampled allow motorized watercraft. Thus, the greater occurrence of these compounds during spring and summer is presumed to be related to the increased use of watercraft during these seasons. No seasonal pattern was observed for the THMs or organic synthesis subgroups. This indicates the possibility of a common and continuous source of contamination for these VOCs.

As in ground-water and reservoir and (or) lake source waters, concentrations of VOCs in river and (or) stream source waters typically were small (less than $1 \mu \mathrm{g} / \mathrm{L})$, and very few statistically significant differences in detected concentrations were observed on a seasonal basis among subgroups of VOCs. Similarly, a seasonal pattern was not evident for the detection frequency of any subgroup of VOCs in the 17 river and (or) stream source waters sampled. Gasoline oxygenates, other gasoline compounds, THMs, and organic synthesis compounds were detected at similar frequencies within their respective subgroups year-round. The lack of seasonal differences for these subgroups of compounds may indicate a common and continuous source of contamination upstream of the intake location.

The most frequently detected VOC (MTBE) and the two most frequently occurring subgroups of VOCs (gasoline oxygenates and THMs) detected in CWS source waters sampled in the Focused Survey were further characterized to evaluate some anthropogenic factors that may better explain their frequent occurrence. MTBE, gasoline oxygenates, and THMs were detected in 77.3, 73.9, and 47.8 percent of CWS source waters sampled, respectively.

Fifty-five of 78 wells, 25 of 39 reservoirs and (or) lakes, and 11 of 17 rivers and streams were inside MTBE high-use areas. Concentrations of MTBE in reservoir and (or) lake and river and (or) stream source waters inside and outside of MTBE high-use areas were also compared seasonally. MTBE was detected more frequently and concentrations were greater in MTBE high-use areas than in MTBE low-use areas. However, because as few as three detections of MTBE were found in surface-water source waters in MTBE low-use areas, statistical comparisons were not completed. 
The concentration of gasoline oxygenates in reservoirs was slightly correlated with watercraft use (boats/year/acre) on reservoirs inside MTBE high-use areas $\left(r^{2}=0.3783\right)$. As watercraft use increased, the average concentration of gasoline oxygenates also increased. No relation between gasoline oxygenates in reservoirs and watercraft use was observed in reservoirs outside of MTBE high-use areas $\left(\mathrm{r}^{2}=0.0242\right)$.

Trihalomethanes were detected in 11 of the reservoirs and (or) lakes sampled. Seven of these reservoirs contained detectable concentrations of more than one THM. Attempts were made to contact each of the seven CWSs with multiple THM detections. Each CWS provided additional information on reasons why THMs may occur in their source water. In all cases, the presence of THMs were the result of the addition of chlorine to waters that ultimately recycled back to, or upstream of, the reservoir that was sampled.

\section{REFERENCES}

Arizona Department of Environmental Quality, 1999, Report on methyl tertiary butyl ether (MTBE), October 1, 1999: Arizona Department of Environmental Quality, accessed March 1, 2002, at URL http://www.adeq.state.az.us/environ/waste/ust/ mtbe.html

Bourelle, Andy, 1998, MTBE-A real concern for South Lake Tahoe: Tahoe Daily Tribune, August 28, 1998, accessed December 6, 2000, at URL http://www.tahoe.com/tribune/stories.8.28.98/news/ mt28Aug1347.html

Bush, P.W., Ardis, A.F., Fahlquist, Lynne, Ging, P.B., Hornig, C.E., and Lanning-Rush, Jennifer, 2000, Water quality in south-central Texas, 1996-98: U.S. Geological Survey Circular 1212, 32 p.

California Department of Health Services, 2001, MTBE in California drinking water: accessed December 6, 2000, at URL http://www.dhs.cahwnet.gov/ps/ddwem/ chemicals/MTBE/mtbeindex.htm

California Environmental Protection Agency, 1997, MTBE (methyl tertiary butyl ether), Briefing paper prepared by the California Environmental Protection Agency, April 24, 1997 (updated September 3, 1998): accessed February 28, 2002, at URL http://www.arb.ca.gov/cbg/oxy/oxy.htm

California Senate, 1998, Does California need MTBE?, prepared by Kip Wiley, February 1998: accessed February 28, 2002, at URL http://www.sen.ca.gov/ftp/sen/sor/environ/98mtbe.htm
City of Santa Monica, 1999, MTBE issue featured on "60 Minutes": accessed December 6, 2000, at URL http://epwm.santamonica.org/epwm/ watquality/1999report/waterweb/news05.htm

Delzer, G.C., and Ivahnenko, Tamara, 2003, A review of literature for methyl tert-butyl ether in sources of drinking water in the United States: U.S. Geological Survey Open-File Report 01-322, 19 p.

Grady, S.J., 2003, A national survey of methyl tert-butyl ether and other volatile organic compounds in drinking-water sources-Results of the random survey: U.S. Geological Survey Water-Resources Investigations Report 02-4079, $85 \mathrm{p}$

Halde, M.J., Delzer, G.C., and Zogorski, J.S., 1998, Study design and analytical results used to evaluate a surface-water point sampler for volatile organic compounds: U.S. Geological Survey Open-File Report 98-651, $31 \mathrm{p}$.

Hattan, Greg, 2000, MTBE treatment systems in Kansas: Association of State and Territorial Solid Waste Management Officials, MTBE and Fuel Oxygenates Workgroup Newsletter, v. 3, no. 1, 31 p.

Helsel, D.R., and Hirsch, R.M., 1992, Statistical methods in water resources: New York, Elsevier, 529 p

Ivahnenko, Tamara, Grady, S.J., and Delzer, G.C., 2001, Design of a national survey of methyl tert-butyl ether and other volatile organic compounds in drinkingwater sources: U.S. Geological Survey Open-File Report 01-271, $42 \mathrm{p}$.

Johnson, R.L., Pankow, J.F., Bender, D.A., Price, C.V., and Zogorski, J.S., 2000, MTBE-To what extent will past releases contaminate community water supply wells?: Environmental Science \& Technology, v. 34, no. 9, p. 2A-9A.

Koterba, M.T., Wilde, F.D., and Lapham, W.W., 1995, Ground-water data collection protocols and procedures for the National Water-Quality Assessment Program-Collection and documentation of waterquality samples and related data: U.S. Geological Survey Open-File Report 95-399, 113 p.

Lopes, T.J., and Furlong, E.T., 2001, Occurrence and potential adverse effects of semivolatile organic compounds in streambed sediment, United States, 1992-1995: Environmental Toxicology and Chemistry, v. 20, no. 4, p. 727-737.

Reiser, R.G., and O'Brien, A.K., 1998, Occurrence and seasonal variability of volatile organic compounds in seven New Jersey streams: U.S. Geological Survey Water-Resources Investigations Report 98-4074, 11 p.

Rowe, B.L., Grady, S.J., Zogorski, J.S., Koch, Bart, Tratnyek, Paul, 2001, Initial findings-National survey of MTBE, other ether oxygenates, and other VOCs in community drinking-water sources: U.S. Geological Survey Open-File Report 01-399, 1 p. 
Shelton, L.R., 1997, Field guide for collecting samples for analysis of volatile organic compounds in stream water of the National Water-Quality Assessment Program: U.S. Geological Survey Open-File Report 97-401, $14 \mathrm{p}$.

Squillace, P.J., Moran, M.J., Lapham, W.W., Price, C.V., Clawges, R.C., and Zogorski, J.S., 1999, Volatile organic compounds in untreated ambient ground water of the United States, 1985-1995: Environmental Science \& Technology, v. 33, no. 23, p. 41764187.

State of Maine, 1998, The presence of MTBE and other gasoline compounds in Maine's drinking water, preliminary report, October 13, State of Maine, Bureau of Health, Bureau of Waste Management and Remediation, Maine Geological Survey: Augusta, State of Maine, $23 \mathrm{p}$.

U.S. Environmental Protection Agency, 1997, Drinking water advisory-Consumer acceptability advice and health effects analysis on methyl tertiary-butyl ether (MTBE): Office of Water, EPA-822-F-97-009, 4 p.

1998, Announcement of the drinking water contaminant candidate list, notice (March 12, 1998): Federal Register, v. 63, no. 40, p. 10273-10287. 1999a, List of reformulated gasoline program areas: Office of Mobile Sources, accessed April 5, 1999, at

URL http://www.epa.gov/oms/rfgarea.htm

1999b, Winter oxygenated fuels program: Office of Mobile Sources, accessed June 16, 1999, at URL http://www.epa.gov/oms/fuels.htm

2001, National Primary Drinking Water Standards: Office of Water, EPA-816-F-01-007, 4 p.

U.S. Geological Survey, 1990, Digital line graphs from 1:2,000,000-scale maps, data users guide 3: U.S. Geological Survey National Mapping Program Technical Instructions, 70 p., accessed March 25, 2002, at URL ftp://mapping.usgs.gov/pub/ti/DLG/2mdlgguide

Wigglesworth, Terry, 1999, MTBE-A watertight case: Chemistry and Industry, no. 10, p. 408.

Zogorski, J.S., Morduchowitz, A.M., Baehr, A.L., Bauman, B.J., Conrad, D.L., Drew, R.T., Korte, N.E., Lapham, W.W., Pankow, J.F., and Washington, E.R., 1997, Fuel oxygenates and water quality, chapter 2 of the Interagency Assessment of Oxygenated Fuels: Washington, D.C., National Science and Technology Council, Office of Science and Technology Policy, p. 2-1 to 2-80. 
APPENDIXES 



\section{Appendix A - Number of community water system sources sampled per State}


Table A1. Number of community water system source waters sampled that were suspected of having concentrations of methyl tert-butyl ether, by State and source-size category

[GW, ground water; SW, surface water; VSM, very small; SM, small; MED, medium; LRG, large; VLRG, very large]

\begin{tabular}{|c|c|c|c|c|c|c|c|c|c|c|c|}
\hline \multirow[b]{2}{*}{ State $^{1}$} & \multicolumn{10}{|c|}{ Source-size category } & \multirow[b]{2}{*}{ Total } \\
\hline & $\begin{array}{l}\text { GW- } \\
\text { VSM }\end{array}$ & $\begin{array}{l}\text { GW- } \\
\text { SMM }\end{array}$ & $\begin{array}{l}\text { GW- } \\
\text { MED }\end{array}$ & $\begin{array}{l}\text { GW- } \\
\text { LRG }\end{array}$ & $\begin{array}{c}\text { GW- } \\
\text { VLRG }\end{array}$ & $\begin{array}{l}\text { SW- } \\
\text { VSM }\end{array}$ & $\begin{array}{l}\text { SW- } \\
\text { SM }\end{array}$ & $\begin{array}{l}\text { SW- } \\
\text { MED }\end{array}$ & $\begin{array}{l}\text { SW- } \\
\text { LRG }\end{array}$ & $\begin{array}{c}\text { SW- } \\
\text { VLRG }\end{array}$ & \\
\hline $\mathrm{CA}$ & 0 & 0 & 2 & 4 & 6 & 0 & 0 & 0 & 1 & 6 & 19 \\
\hline $\mathrm{CO}$ & 0 & 0 & 0 & 0 & 0 & 0 & 0 & 0 & 0 & 1 & 1 \\
\hline CT & 0 & 0 & 0 & 2 & 1 & 0 & 1 & 0 & 0 & 0 & 4 \\
\hline $\mathrm{DE}$ & 2 & 2 & 3 & 1 & 1 & 0 & 0 & 0 & 0 & 2 & 11 \\
\hline GA & 0 & 0 & 0 & 1 & 0 & 0 & 0 & 0 & 0 & 2 & 3 \\
\hline IN & 0 & 0 & 0 & 0 & 0 & 0 & 0 & 0 & 0 & 1 & 1 \\
\hline KY & 0 & 0 & 0 & 2 & 0 & 0 & 0 & 0 & 0 & 1 & 3 \\
\hline LA & 0 & 0 & 0 & 0 & 0 & 0 & 0 & 0 & 0 & 1 & 1 \\
\hline MA & 0 & 0 & 0 & 0 & 0 & 0 & 0 & 0 & 0 & 2 & 2 \\
\hline MD & 0 & 0 & 0 & 0 & 0 & 0 & 0 & 0 & 0 & 1 & 1 \\
\hline MS & 0 & 0 & 0 & 0 & 0 & 0 & 0 & 0 & 0 & 1 & 1 \\
\hline $\mathrm{NJ}$ & 0 & 0 & 0 & 0 & 0 & 0 & 0 & 0 & 0 & 1 & 1 \\
\hline NV & 0 & 0 & 0 & 0 & 0 & 0 & 0 & 0 & 0 & 1 & 1 \\
\hline NY & 0 & 0 & 0 & 0 & 4 & 0 & 0 & 0 & 0 & 0 & 4 \\
\hline OK & 0 & 0 & 0 & 0 & 0 & 0 & 0 & 0 & 0 & 2 & 2 \\
\hline OR & 0 & 0 & 1 & 3 & 0 & 0 & 1 & 1 & 0 & 0 & 6 \\
\hline PA & 0 & 0 & 0 & 0 & 0 & 0 & 0 & 0 & 0 & 3 & 3 \\
\hline RI & 0 & 0 & 0 & 0 & 0 & 0 & 0 & 0 & 0 & 1 & 1 \\
\hline TX & 0 & 1 & 0 & 0 & 2 & 0 & 0 & 0 & 0 & 3 & 6 \\
\hline VA & 0 & 0 & 0 & 0 & 1 & 0 & 0 & 0 & 0 & 3 & 4 \\
\hline VT & 0 & 0 & 0 & 0 & 0 & 0 & 0 & 0 & 0 & 1 & 1 \\
\hline WV & 0 & 0 & 2 & 0 & 0 & 0 & 0 & 0 & 0 & 0 & 2 \\
\hline Total & 2 & 3 & 8 & 13 & 15 & 0 & 2 & 1 & 1 & 33 & 78 \\
\hline
\end{tabular}

${ }^{1}$ Postal Service State abbreviation. 
Table A2. Number of community water system source waters sampled with known concentrations of methyl tert-butyl ether, by State and source-size category

[GW, ground water; SW, surface water; VSM, very small; SM, small; MED, medium; LRG, large; VLRG, very large]

\begin{tabular}{|c|c|c|c|c|c|c|c|c|c|c|c|}
\hline \multirow[b]{2}{*}{ State $^{1}$} & \multicolumn{10}{|c|}{ Source-size category } & \multirow[b]{2}{*}{ Total } \\
\hline & $\begin{array}{l}\text { GW- } \\
\text { VSM }\end{array}$ & $\begin{array}{l}\text { GW- } \\
\text { SM }\end{array}$ & $\begin{array}{l}\text { GW- } \\
\text { MED }\end{array}$ & $\begin{array}{l}\text { GW- } \\
\text { LRG }\end{array}$ & $\begin{array}{c}\text { GW- } \\
\text { VLRG }\end{array}$ & $\begin{array}{l}\text { SW- } \\
\text { VSM }\end{array}$ & $\begin{array}{l}\text { SW- } \\
\text { SM }\end{array}$ & $\begin{array}{l}\text { SW- } \\
\text { MED }\end{array}$ & $\begin{array}{l}\text { SW- } \\
\text { LRG }\end{array}$ & $\begin{array}{l}\text { SW- } \\
\text { VLRG }\end{array}$ & \\
\hline $\mathrm{AZ}$ & 0 & 0 & 0 & 1 & 0 & 0 & 0 & 0 & 0 & 1 & 2 \\
\hline $\mathrm{CA}$ & 0 & 0 & 0 & 0 & 0 & 0 & 1 & 0 & 0 & 8 & 9 \\
\hline CT & 1 & 0 & 0 & 0 & 0 & 0 & 0 & 0 & 0 & 0 & 1 \\
\hline FL & 0 & 0 & 0 & 0 & 2 & 0 & 0 & 0 & 0 & 1 & 3 \\
\hline IA & 0 & 2 & 0 & 0 & 0 & 0 & 0 & 0 & 0 & 0 & 2 \\
\hline IL & 0 & 2 & 2 & 0 & 0 & 0 & 0 & 0 & 0 & 0 & 4 \\
\hline KY & 1 & 0 & 0 & 0 & 0 & 0 & 0 & 0 & 0 & 0 & 1 \\
\hline KS & 0 & 2 & 1 & 1 & 0 & 0 & 0 & 0 & 0 & 0 & 4 \\
\hline MA & 1 & 0 & 0 & 1 & 0 & 0 & 0 & 0 & 0 & 0 & 2 \\
\hline MD & 0 & 1 & 1 & 1 & 0 & 0 & 0 & 0 & 0 & 0 & 3 \\
\hline $\mathrm{ME}$ & 0 & 1 & 2 & 1 & 0 & 0 & 0 & 0 & 0 & 0 & 4 \\
\hline $\mathrm{NC}$ & 0 & 0 & 1 & 0 & 0 & 0 & 0 & 0 & 0 & 1 & 2 \\
\hline $\mathrm{NH}$ & 0 & 0 & 1 & 1 & 0 & 0 & 0 & 0 & 1 & 1 & 4 \\
\hline NJ & 0 & 0 & 0 & 2 & 2 & 0 & 0 & 0 & 0 & 0 & 4 \\
\hline NY & 0 & 0 & 0 & 0 & 1 & 0 & 0 & 0 & 0 & 0 & 1 \\
\hline $\mathrm{OH}$ & 0 & 1 & 0 & 0 & 0 & 0 & 0 & 0 & 0 & 0 & 1 \\
\hline OR & 2 & 0 & 0 & 0 & 0 & 0 & 0 & 0 & 0 & 0 & 2 \\
\hline PA & 1 & 0 & 0 & 0 & 0 & 0 & 0 & 0 & 0 & 1 & 2 \\
\hline $\mathrm{TN}$ & 0 & 0 & 0 & 0 & 0 & 0 & 0 & 0 & 1 & 0 & 1 \\
\hline TX & 0 & 0 & 0 & 0 & 0 & 0 & 1 & 0 & 0 & 2 & 3 \\
\hline VA & 0 & 1 & 0 & 0 & 0 & 0 & 0 & 0 & 0 & 0 & 1 \\
\hline Total & 6 & 10 & 8 & 8 & 5 & 0 & 2 & 0 & 2 & 15 & 56 \\
\hline
\end{tabular}

${ }^{1}$ Postal Service State abbreviation.

Table A3. Number of community water system source waters sampled as control sites where methyl tert-butyl ether would likely not be present, by State and source-size category

[GW, ground water; SW, surface water; VSM, very small; SM, small; MED, medium; LRG, large; VLRG, very large]

\begin{tabular}{|c|c|c|c|c|c|c|c|c|c|c|c|}
\hline \multirow[b]{2}{*}{ State $^{1}$} & \multicolumn{10}{|c|}{ Source-size category } & \multirow[b]{2}{*}{ Tota } \\
\hline & $\begin{array}{l}\text { GW- } \\
\text { VSM }\end{array}$ & $\begin{array}{l}\text { GW- } \\
\text { SM }\end{array}$ & $\begin{array}{l}\text { GW- } \\
\text { MED }\end{array}$ & $\begin{array}{l}\text { GW- } \\
\text { LRG }\end{array}$ & $\begin{array}{c}\text { GW- } \\
\text { VLRG }\end{array}$ & $\begin{array}{l}\text { SW- } \\
\text { VSM }\end{array}$ & $\begin{array}{l}\text { SW- } \\
\text { SM }\end{array}$ & $\begin{array}{l}\text { SW- } \\
\text { MED }\end{array}$ & $\begin{array}{l}\text { SW- } \\
\text { LRG }\end{array}$ & $\begin{array}{c}\text { SW- } \\
\text { VLRG }\end{array}$ & \\
\hline SD & 0 & 0 & 0 & 0 & 0 & 0 & 0 & 0 & 0 & 1 & 1 \\
\hline MN & 0 & 0 & 0 & 1 & 1 & 0 & 0 & 0 & 0 & 1 & 3 \\
\hline
\end{tabular}

${ }^{1}$ Postal Service State abbreviation. 

Appendix B - Detailed review of field quality-control data 


\section{SUMMARY OF QUALITY-CONTROL SAMPLES}

A review of the field quality-control (QC) data collected in the Focused Survey has been conducted with parallel protocols as those of the Random Survey. Field-reagent blank (FRB) and trip-reagent blank (TRB) samples were collected in both surveys; however, duplicate samples and field-equipment blank (FEB) samples also were collected in the Focused Survey. FEB samples were collected only for surfacewater samples.

As in the Random Survey, FRB samples were used to measure contamination from the environment around the sampling site and during sample shipment. In the Focused Survey, a bottle containing VOC-free water was provided to U.S. Geological Survey (USGS) field personnel with each sample kit. FRB samples were prepared by directly filling VOC $40 \mathrm{~mL}$ (milliliters) vials labeled "Field Blank" at each sampling site with VOC-free water immediately prior to or following the collection of the source-water sample. USGS field personnel preserved the FRB sample with a 1:1 hydrochloric acid solution to a $\mathrm{pH}$ of 2 . It is important to note that FRB samples are used extensively to accept or reject detected concentrations of volatile organic compounds (VOCs) in source-water samples in the following appendix (Appendix C). TRB samples, however, were prepared at the laboratory by filling vials with VOC-free water. TRB samples were placed in each sample kit and traveled along with the sourcewater samples back to the Metropolitan Water District of Southern California (MWDSC) laboratory. TRB samples were never opened and were intended to measure any contamination associated with samples during shipment. Because ground-water samples were collected from permanently installed pumps, FEB samples were collected only for surface-water source waters. FEBs were intended to represent all contamination associated with the surface-water sampling process, sampling equipment, processing, transportation, and laboratory handling/analysis. FEB samples were collected by passing VOC-free water through the USGS VOC hand sampler and filling the vials accordingly. FEB sample collection procedures for the VOC hand sampler are described by Shelton (1997). Field duplicate source-water samples were collected at about 15 percent of the surface- and ground-water sites to characterize variability associated with sampling, processing, transportation, and analysis. Ground-water duplicates were collected sequentially, and surfacewater duplicates were collected concurrently with their respective source-water sample.

\section{Field-Reagent Blank Samples}

In addition to data for 467 (451 source-water samples plus 16 from control sites) source-water samples analyzed as part of the Focused Survey, the MWDSC laboratory reported VOC analysis for 321 FRB samples. For the first three months of sampling, FRB samples were not collected with 100 percent of the source-water samples. Subsequently, a FRB accompanied all source-water samples. Forty-six VOCs were detected in one or more of the 321 FRB samples (table B1) with a concentration range of 0.03 to $17.0 \mu \mathrm{g} / \mathrm{L}$ for all VOCs detected. Detection frequencies ranged from 0.31 percent for several VOCs to 75.4 percent for toluene.

As in the Random Survey, toluene and methylene chloride were the most frequently detected compounds, reported in nearly two-thirds of the FRB samples. Seven other VOCs, including MTBE, ethylbenzene, $m, p$-xylene, $o$-xylene, chloroform, styrene, and 1,2,4trimethylbenzene were reported in 10 percent of the FRB samples (table B1). Up to 67 percent of the detections in the FRBs were less than $0.2 \mu \mathrm{g} / \mathrm{L}$.

\section{Trip-Reagent Blank Samples}

TRB samples were sent with 100 percent of the source-water samples; however, TRB samples were analyzed only when a VOC was detected in the sourcewater sample. The MWDSC laboratory analyzed 304 TRB samples. There were 163 source-water samples with no VOCs detected in the source-water sample, thus the accompanying TRB sample was not analyzed.

Concentrations of the detected VOCs in the TRB samples ranged from 0.03 to $2.56 \mu \mathrm{g} / \mathrm{L}$ (table B1). Detection frequencies ranged from 0.3 percent for several VOCs to 58.9 percent for toluene. Thirty-five of the 66 VOC compounds analyzed were detected in the 304 TRB samples.

As with the FRB samples in both the Focused and Random Surveys, methylene chloride (58.0 percent) and toluene (58.9 percent) were the most frequently detected compounds, reported in nearly two-thirds of the TRB samples. Similarly, six (MTBE, ethylbenzene, $m, p$-xylene, $o$-xylene, styrene, and 1,2,4trimethylbenzene) of the seven VOCs detected in FRB samples also were detected in TRB samples. Up to 54.7 percent of the detected concentrations in the TRBs were less than $0.2 \mu \mathrm{g} / \mathrm{L}$. 
Table B1. Summary of volatile organic compounds detected in field-equipment blanks, field-reagent blanks, and trip-reagent blanks

[FEB, field-equipment blank; FRB, field-reagent blank; TRB, trip-reagent blank; ND, not detected; --, not applicable]

\begin{tabular}{|c|c|c|c|c|c|}
\hline Volatile organic compound & $\begin{array}{l}\text { Type of } \\
\text { blank }\end{array}$ & $\begin{array}{l}\text { Number of } \\
\text { samples }\end{array}$ & $\begin{array}{l}\text { Number of } \\
\text { detections }\end{array}$ & $\begin{array}{c}\text { Range in } \\
\text { concentration } \\
\text { (micrograms per liter) }\end{array}$ & $\begin{array}{l}\text { Detection frequency } \\
\text { (percent) }\end{array}$ \\
\hline \multicolumn{6}{|c|}{ Gasoline Oxygenates } \\
\hline \multirow[t]{3}{*}{ tert-Amyl methyl ether (TAME) } & FRB & 321 & 7 & $0.04-0.42$ & 2.2 \\
\hline & TRB & 304 & 4 & $0.04-0.05$ & 1.3 \\
\hline & FEB & 50 & ND & -- & -- \\
\hline \multirow[t]{3}{*}{ Diisopropyl ether (DIPE) } & FRB & 321 & ND & -- & -- \\
\hline & TRB & 304 & ND & -- & -- \\
\hline & FEB & 50 & ND & -- & -- \\
\hline \multirow[t]{3}{*}{ Ethyl tert-butyl ether (ETBE) } & FRB & 321 & ND & -- & -- \\
\hline & TRB & 304 & ND & -- & -- \\
\hline & FEB & 50 & ND & -- & -- \\
\hline \multirow[t]{3}{*}{ Methyl tert-butyl ether (MTBE) } & FRB & 321 & 143 & $0.04-17.02$ & 44.6 \\
\hline & TRB & 304 & 153 & $0.04-1.62$ & 50.3 \\
\hline & FEB & 50 & 9 & $0.04-1.74$ & 18.0 \\
\hline \multicolumn{6}{|c|}{ Other Gasoline Compounds } \\
\hline \multirow[t]{3}{*}{ Benzene } & FRB & 321 & 11 & $0.03-9.46$ & 3.4 \\
\hline & TRB & 304 & 5 & $0.03-0.08$ & 1.6 \\
\hline & FEB & 50 & 2 & $0.05-2.01$ & 4.0 \\
\hline \multirow[t]{3}{*}{$n$-Butylbenzene } & FRB & 321 & 1 & 0.07 & 0.3 \\
\hline & TRB & 304 & ND & -- & -- \\
\hline & FEB & 50 & 1 & 0.07 & 2.0 \\
\hline \multirow[t]{3}{*}{ sec-Butylbenzene } & FRB & 321 & 1 & 0.05 & 0.3 \\
\hline & TRB & 304 & ND & -- & -- \\
\hline & FEB & 50 & ND & -- & -- \\
\hline \multirow[t]{3}{*}{ tert-Butylbenzene } & FRB & 321 & 1 & 0.04 & 0.3 \\
\hline & TRB & 304 & ND & -- & -- \\
\hline & FEB & 50 & ND & -- & -- \\
\hline \multirow[t]{3}{*}{ Ethylbenzene } & FRB & 321 & 125 & $0.04-0.79$ & 38.9 \\
\hline & TRB & 304 & 50 & $0.04-0.3$ & 16.4 \\
\hline & FEB & 50 & 9 & $0.04-0.88$ & 18.0 \\
\hline \multirow[t]{3}{*}{ Naphthalene } & FRB & 321 & 22 & $0.06-0.15$ & 6.9 \\
\hline & TRB & 304 & 15 & $0.06-0.13$ & 4.9 \\
\hline & FEB & 50 & 7 & $0.06-0.38$ & 14.0 \\
\hline \multirow[t]{3}{*}{ Toluene } & FRB & 321 & 242 & $0.03-6.95$ & 75.4 \\
\hline & TRB & 304 & 179 & $0.03-0.62$ & 58.9 \\
\hline & FEB & 50 & 17 & $0.03-6.01$ & 34.0 \\
\hline
\end{tabular}


Table B1. Summary of volatile organic compounds detected in field-equipment blanks, field-reagent blanks, and trip-reagent blanks-Continued

[FEB, field-equipment blank; FRB, field-reagent blank; TRB, trip-reagent blank; ND, not detected; --, not applicable]

\begin{tabular}{|c|c|c|c|c|c|}
\hline Volatile organic compound & $\begin{array}{l}\text { Type of } \\
\text { blank }\end{array}$ & $\begin{array}{l}\text { Number of } \\
\text { samples }\end{array}$ & $\begin{array}{l}\text { Number of } \\
\text { detections }\end{array}$ & $\begin{array}{c}\text { Range in } \\
\text { concentration } \\
\text { (micrograms per liter) }\end{array}$ & $\begin{array}{l}\text { Detection frequency } \\
\text { (percent) }\end{array}$ \\
\hline \multicolumn{6}{|c|}{ Other Gasoline Compounds-Continued } \\
\hline \multirow[t]{3}{*}{ 1,3,5-Trimethylbenzene } & FRB & 321 & 2 & $0.05-0.18$ & 0.6 \\
\hline & TRB & 304 & ND & -- & -- \\
\hline & FEB & 50 & 2 & $0.03-0.29$ & 4.0 \\
\hline \multirow[t]{3}{*}{$m, p$-Xylene } & FRB & 321 & 123 & $0.07-1.49$ & 38.3 \\
\hline & $\mathrm{TRB}$ & 304 & 57 & $0.07-0.76$ & 18.8 \\
\hline & FEB & 50 & 7 & $0.07-3.73$ & 14.0 \\
\hline \multirow[t]{3}{*}{$o$-Xylene } & FRB & 321 & 103 & $0.03-0.88$ & 32.1 \\
\hline & $\mathrm{TRB}$ & 304 & 37 & $0.03-0.23$ & 12.2 \\
\hline & FEB & 50 & 6 & $0.03-1.68$ & 12.0 \\
\hline \multicolumn{6}{|c|}{ Trihalomethanes } \\
\hline \multirow[t]{3}{*}{ Bromodichloromethane } & FRB & 321 & 2 & $0.02-0.03$ & 0.6 \\
\hline & TRB & 304 & ND & -- & -- \\
\hline & FEB & 50 & ND & -- & -- \\
\hline \multirow[t]{3}{*}{ Bromoform } & FRB & 321 & ND & -- & -- \\
\hline & $\mathrm{TRB}$ & 304 & ND & -- & -- \\
\hline & FEB & 50 & ND & -- & -- \\
\hline \multirow[t]{3}{*}{ Chlorodibromomethane } & FRB & 321 & 2 & $0.02-0.03$ & 0.6 \\
\hline & TRB & 304 & ND & -- & -- \\
\hline & FEB & 50 & ND & -- & -- \\
\hline \multirow[t]{3}{*}{ Chloroform } & FRB & 321 & 45 & $0.03-5.7$ & 14.0 \\
\hline & TRB & 304 & 13 & $0.03-0.06$ & 4.3 \\
\hline & FEB & 50 & 4 & $0.03-0.18$ & 8.0 \\
\hline \multicolumn{6}{|c|}{ Solvents } \\
\hline \multirow[t]{3}{*}{ Bromobenzene } & FRB & 321 & 1 & 0.03 & 0.3 \\
\hline & TRB & 304 & 1 & 0.03 & 0.3 \\
\hline & FEB & 50 & ND & -- & -- \\
\hline \multirow[t]{3}{*}{ Carbon tetrachloride } & FRB & 321 & 1 & 0.28 & 0.3 \\
\hline & TRB & 304 & $\mathrm{ND}$ & -- & -- \\
\hline & FEB & 50 & ND & -- & -- \\
\hline \multirow[t]{3}{*}{ Chlorobenzene } & FRB & 321 & ND & -- & -- \\
\hline & TRB & 304 & ND & -- & -- \\
\hline & FEB & 50 & ND & -- & -- \\
\hline \multirow[t]{3}{*}{ Chloroethane } & FRB & 321 & 2 & $0.34-0.84$ & 0.6 \\
\hline & $\mathrm{TRB}$ & 304 & ND & -- & -- \\
\hline & FEB & 50 & ND & -- & -- \\
\hline
\end{tabular}


Table B1. Summary of volatile organic compounds detected in field-equipment blanks, field-reagent blanks, and trip-reagent blanks-Continued

[FEB, field-equipment blank; FRB, field-reagent blank; TRB, trip-reagent blank; ND, not detected; --, not applicable]

\begin{tabular}{|c|c|c|c|c|c|}
\hline Volatile organic compound & $\begin{array}{l}\text { Type of } \\
\text { blank }\end{array}$ & $\begin{array}{l}\text { Number of } \\
\text { samples }\end{array}$ & $\begin{array}{l}\text { Number of } \\
\text { detections }\end{array}$ & $\begin{array}{c}\text { Range in } \\
\text { concentration } \\
\text { (micrograms per liter) }\end{array}$ & $\begin{array}{l}\text { Detection frequency } \\
\text { (percent) }\end{array}$ \\
\hline \multicolumn{6}{|c|}{ Solvents-Continued } \\
\hline \multirow[t]{3}{*}{ 2-Chlorotoluene } & FRB & 321 & ND & -- & -- \\
\hline & TRB & 304 & ND & -- & -- \\
\hline & FEB & 50 & 1 & 0.14 & 2.0 \\
\hline \multirow[t]{3}{*}{ 4-Chlorotoluene } & FRB & 321 & 1 & 0.03 & 0.3 \\
\hline & TRB & 304 & ND & -- & -- \\
\hline & FEB & 50 & 1 & 0.04 & 2.0 \\
\hline \multirow[t]{3}{*}{ Dibromomethane } & FRB & 321 & ND & -- & -- \\
\hline & TRB & 304 & ND & -- & -- \\
\hline & FEB & 50 & ND & -- & -- \\
\hline \multirow[t]{3}{*}{ 1,2-Dichlorobenzene } & FRB & 321 & ND & -- & -- \\
\hline & TRB & 304 & ND & -- & -- \\
\hline & FEB & 50 & ND & -- & -- \\
\hline \multirow[t]{3}{*}{ 1,3-Dichlorobenzene } & FRB & 321 & ND & -- & -- \\
\hline & $\mathrm{TRB}$ & 304 & ND & -- & -- \\
\hline & FEB & 50 & ND & -- & -- \\
\hline \multirow[t]{3}{*}{ 1,1-Dichloroethane } & FRB & 321 & 3 & $0.04-0.08$ & 0.9 \\
\hline & TRB & 304 & 1 & 0.04 & 0.3 \\
\hline & FEB & 50 & ND & -- & -- \\
\hline \multirow[t]{3}{*}{ 1,2-Dichloroethane } & FRB & 321 & 1 & 0.32 & 0.3 \\
\hline & TRB & 304 & ND & -- & -- \\
\hline & FEB & 50 & ND & -- & -- \\
\hline \multirow[t]{3}{*}{ 1,1-Dichloroethene } & FRB & 321 & 1 & 0.1 & 0.3 \\
\hline & TRB & 304 & ND & -- & -- \\
\hline & FEB & 50 & ND & -- & -- \\
\hline \multirow[t]{3}{*}{ cis-1,2-Dichloroethene } & FRB & 321 & 3 & $0.03-0.09$ & 0.9 \\
\hline & TRB & 304 & ND & -- & -- \\
\hline & FEB & 50 & ND & -- & -- \\
\hline \multirow[t]{3}{*}{ trans-1,2-Dichloroethene } & FRB & 321 & ND & -- & -- \\
\hline & $\mathrm{TRB}$ & 304 & ND & -- & -- \\
\hline & FEB & 50 & ND & -- & -- \\
\hline \multirow[t]{3}{*}{ 1,2-Dichloropropane } & FRB & 321 & 1 & 0.03 & 0.3 \\
\hline & $\mathrm{TRB}$ & 304 & ND & -- & -- \\
\hline & FEB & 50 & ND & -- & -- \\
\hline
\end{tabular}


Table B1. Summary of volatile organic compounds detected in field-equipment blanks, field-reagent blanks, and trip-reagent blanks-Continued

[FEB, field-equipment blank; FRB, field-reagent blank; TRB, trip-reagent blank; ND, not detected; --, not applicable]

\begin{tabular}{|c|c|c|c|c|c|}
\hline Volatile organic compound & $\begin{array}{l}\text { Type of } \\
\text { blank }\end{array}$ & $\begin{array}{l}\text { Number of } \\
\text { samples }\end{array}$ & $\begin{array}{l}\text { Number of } \\
\text { detections }\end{array}$ & $\begin{array}{c}\text { Range in } \\
\text { concentration } \\
\text { (micrograms per liter) }\end{array}$ & $\begin{array}{l}\text { Detection frequency } \\
\text { (percent) }\end{array}$ \\
\hline \multicolumn{6}{|c|}{ Solvents-Continued } \\
\hline \multirow[t]{3}{*}{ Hexachloroethane } & FRB & 321 & ND & -- & -- \\
\hline & $\mathrm{TRB}$ & 304 & ND & -- & -- \\
\hline & FEB & 50 & ND & -- & -- \\
\hline \multirow[t]{3}{*}{ Methylene chloride } & FRB & 318 & 191 & $0.03-1.18$ & 60.1 \\
\hline & $\mathrm{TRB}$ & 300 & 174 & $0.03-0.71$ & 58.0 \\
\hline & FEB & 50 & 31 & $0.03-0.54$ & 62.0 \\
\hline \multirow[t]{3}{*}{ Methyl ethyl ketone } & FRB & 321 & 13 & $0.8-2.87$ & 4.0 \\
\hline & $\mathrm{TRB}$ & 304 & 11 & $0.71-1.09$ & 3.6 \\
\hline & FEB & 50 & 1 & 0.85 & 2.0 \\
\hline \multirow[t]{3}{*}{$n$-Propylbenzene } & FRB & 321 & 20 & $0.05-0.26$ & 6.2 \\
\hline & $\mathrm{TRB}$ & 304 & 8 & $0.05-0.11$ & 2.6 \\
\hline & FEB & 50 & 2 & $0.14-0.17$ & 4.0 \\
\hline \multirow[t]{3}{*}{ 1,1,1,2-Tetrachloroethane } & FRB & 321 & 1 & 0.02 & 0.3 \\
\hline & TRB & 304 & ND & -- & -- \\
\hline & FEB & 50 & ND & -- & -- \\
\hline \multirow[t]{3}{*}{ 1,1,2,2-Tetrachloroethane } & FRB & 321 & 1 & 0.1 & 0.3 \\
\hline & $\mathrm{TRB}$ & 304 & ND & -- & -- \\
\hline & FEB & 50 & ND & -- & -- \\
\hline \multirow[t]{3}{*}{ Tetrachloroethene } & FRB & 321 & 6 & $0.05-1.1$ & 1.9 \\
\hline & $\mathrm{TRB}$ & 304 & 1 & 0.05 & 0.3 \\
\hline & FEB & 50 & ND & -- & -- \\
\hline \multirow[t]{3}{*}{ 1,2,4-Trichlorobenzene } & FRB & 321 & 10 & $0.05-0.13$ & 3.1 \\
\hline & TRB & 304 & 1 & 0.05 & 0.3 \\
\hline & FEB & 50 & 4 & $0.05-0.14$ & 8.0 \\
\hline \multirow[t]{3}{*}{ 1,1,1-Trichloroethane } & FRB & 321 & 1 & 0.4 & 0.3 \\
\hline & $\mathrm{TRB}$ & 304 & ND & -- & -- \\
\hline & FEB & 50 & ND & -- & -- \\
\hline \multirow[t]{3}{*}{ 1,1,2-Trichloroethane } & FRB & 321 & ND & -- & -- \\
\hline & $\mathrm{TRB}$ & 304 & ND & -- & -- \\
\hline & FEB & 50 & ND & -- & -- \\
\hline \multirow[t]{3}{*}{ Trichloroethene } & FRB & 321 & 1 & 0.25 & 0.3 \\
\hline & $\mathrm{TRB}$ & 304 & ND & -- & -- \\
\hline & FEB & 50 & ND & -- & -- \\
\hline
\end{tabular}


Table B1. Summary of volatile organic compounds detected in field-equipment blanks, field-reagent blanks, and trip-reagent blanks-Continued

[FEB, field-equipment blank; FRB, field-reagent blank; TRB, trip-reagent blank; ND, not detected; --, not applicable]

\begin{tabular}{|c|c|c|c|c|c|}
\hline Volatile organic compound & $\begin{array}{l}\text { Type of } \\
\text { blank }\end{array}$ & $\begin{array}{l}\text { Number of } \\
\text { samples }\end{array}$ & $\begin{array}{l}\text { Number of } \\
\text { detections }\end{array}$ & $\begin{array}{c}\text { Range in } \\
\text { concentration } \\
\text { (micrograms per liter) }\end{array}$ & $\begin{array}{l}\text { Detection frequency } \\
\text { (percent) }\end{array}$ \\
\hline \multicolumn{6}{|c|}{ Solvents-Continued } \\
\hline \multirow[t]{3}{*}{ 1,2,3-Trichloropropane } & FRB & 321 & 7 & $0.03-0.1$ & 2.2 \\
\hline & TRB & 304 & ND & -- & -- \\
\hline & FEB & 50 & 4 & 0.03-0.09 & 8.0 \\
\hline \multicolumn{6}{|c|}{ Organic Synthesis } \\
\hline \multirow[t]{3}{*}{ Acrylonitrile } & FRB & 321 & 1 & 0.31 & 0.3 \\
\hline & TRB & 304 & ND & -- & -- \\
\hline & FEB & 50 & ND & -- & -- \\
\hline \multirow[t]{3}{*}{ Bromochloromethane } & FRB & 321 & 1 & 0.04 & 0.3 \\
\hline & TRB & 304 & ND & -- & -- \\
\hline & FEB & 50 & ND & -- & -- \\
\hline \multirow[t]{3}{*}{ 1,3-Dichloropropane } & FRB & 321 & 3 & $0.04-0.15$ & 0.9 \\
\hline & TRB & 304 & 6 & $0.03-0.23$ & 2.0 \\
\hline & FEB & 50 & 1 & 0.03 & 2.0 \\
\hline \multirow[t]{3}{*}{ 2,2-Dichloropropane } & FRB & 321 & 1 & 0.07 & 0.3 \\
\hline & TRB & 304 & 1 & 0.29 & 0.3 \\
\hline & FEB & 50 & ND & -- & -- \\
\hline \multirow[t]{3}{*}{ 1,1-Dichloropropene } & FRB & 321 & ND & -- & -- \\
\hline & TRB & 304 & ND & -- & -- \\
\hline & FEB & 50 & ND & -- & -- \\
\hline \multirow[t]{3}{*}{ Hexachlorobutadiene } & FRB & 321 & 1 & 0.11 & 0.3 \\
\hline & TRB & 304 & ND & -- & -- \\
\hline & FEB & 50 & ND & -- & -- \\
\hline \multirow[t]{3}{*}{ Isopropylbenzene } & FRB & 321 & 29 & $0.04-0.34$ & 9.0 \\
\hline & TRB & 304 & 9 & $0.04-0.12$ & 2.6 \\
\hline & FEB & 50 & 2 & $0.04-0.31$ & 4.0 \\
\hline \multirow[t]{3}{*}{$p$-Isopropyltoluene } & FRB & 321 & ND & -- & -- \\
\hline & TRB & 304 & 8 & $0.04-0.1$ & 3.0 \\
\hline & FEB & 50 & ND & -- & -- \\
\hline \multirow[t]{3}{*}{ Styrene } & FRB & 321 & 230 & $0.03-8.61$ & 71.7 \\
\hline & $\mathrm{TRB}$ & 304 & 154 & $0.03-2.56$ & 50.7 \\
\hline & FEB & 50 & 20 & $0.03-0.87$ & 40.0 \\
\hline \multirow[t]{3}{*}{ 1,2,3-Trichlorobenzene } & FRB & 321 & 11 & $0.05-0.11$ & 3.4 \\
\hline & TRB & 304 & 7 & $0.05-0.1$ & 2.3 \\
\hline & FEB & 50 & 3 & $0.06-0.1$ & 6.0 \\
\hline
\end{tabular}


Table B1. Summary of volatile organic compounds detected in field-equipment blanks, field-reagent blanks, and trip-reagent blanks-Continued

[FEB, field-equipment blank; FRB, field-reagent blank; TRB, trip-reagent blank; ND, not detected; --, not applicable]

\begin{tabular}{|c|c|c|c|c|c|}
\hline Volatile organic compound & $\begin{array}{c}\text { Type of } \\
\text { blank }\end{array}$ & $\begin{array}{l}\text { Number of } \\
\text { samples }\end{array}$ & $\begin{array}{l}\text { Number of } \\
\text { detections }\end{array}$ & $\begin{array}{c}\text { Range in } \\
\text { concentration } \\
\text { (micrograms per liter) }\end{array}$ & $\begin{array}{l}\text { Detection frequency } \\
\text { (percent) }\end{array}$ \\
\hline \multicolumn{6}{|c|}{ Organic Synthesis-Continued } \\
\hline \multirow[t]{3}{*}{ 1,2,4-Trimethylbenzene } & FRB & 321 & 49 & $0.03-0.58$ & 15.3 \\
\hline & TRB & 304 & 31 & $0.03-0.06$ & 10.2 \\
\hline & FEB & 50 & 6 & $0.03-1.34$ & 12.0 \\
\hline \multirow[t]{3}{*}{ Vinyl bromide } & FRB & 321 & ND & -- & -- \\
\hline & TRB & 304 & ND & -- & -- \\
\hline & FEB & 50 & ND & -- & -- \\
\hline \multirow[t]{3}{*}{ Vinyl chloride } & FRB & 321 & ND & -- & -- \\
\hline & TRB & 304 & ND & -- & -- \\
\hline & FEB & 50 & ND & -- & -- \\
\hline \multicolumn{6}{|c|}{ Fumigants } \\
\hline \multirow[t]{3}{*}{ Bromomethane } & FRB & 319 & 6 & $0.1-0.18$ & 1.9 \\
\hline & TRB & 299 & 5 & $0.09-0.13$ & 1.7 \\
\hline & FEB & 50 & ND & -- & -- \\
\hline \multirow[t]{3}{*}{ 1,4-Dichlorobenzene } & FRB & 321 & 4 & $0.04-0.11$ & 1.3 \\
\hline & TRB & 304 & 1 & 0.06 & 0.3 \\
\hline & FEB & 50 & ND & -- & -- \\
\hline \multirow[t]{3}{*}{ cis-1,3-Dichloropropene } & FRB & 321 & ND & -- & -- \\
\hline & TRB & 304 & ND & -- & -- \\
\hline & FEB & 50 & ND & -- & -- \\
\hline \multirow[t]{3}{*}{ trans-1,3-Dichloropropene } & FRB & 321 & ND & -- & -- \\
\hline & TRB & 304 & ND & -- & -- \\
\hline & FEB & 50 & ND & -- & -- \\
\hline \multicolumn{6}{|c|}{ Refrigerants } \\
\hline \multirow[t]{3}{*}{ Chloromethane } & FRB & 321 & 8 & $0.13-1.53$ & 2.5 \\
\hline & TRB & 304 & ND & -- & -- \\
\hline & FEB & 50 & 2 & $0.13-0.18$ & 4.0 \\
\hline \multirow[t]{3}{*}{ Dichlorodifluoromethane } & FRB & 321 & ND & -- & -- \\
\hline & TRB & 304 & ND & -- & -- \\
\hline & FEB & 50 & ND & -- & -- \\
\hline \multirow[t]{3}{*}{ Trichlorofluoromethane } & FRB & 321 & ND & -- & -- \\
\hline & TRB & 304 & ND & -- & -- \\
\hline & FEB & 50 & ND & -- & -- \\
\hline \multirow[t]{3}{*}{ 1,1,2-Trichloro-1,2,2-trifluoroethane } & FRB & 321 & ND & -- & -- \\
\hline & TRB & 304 & ND & -- & -- \\
\hline & FEB & 50 & ND & -- & -- \\
\hline
\end{tabular}




\section{FIELD-EQUIPMENT BLANK SAMPLES}

FEB samples were collected only for equipment used to collect samples at surface-water sites by passing VOC-free water through the USGS VOC hand sampler and filling the vials accordingly. Fifty FEB samples were collected. Twenty-three VOCs were reported in one or more of the FEB samples. Concentrations of these VOCs ranged from 0.03 to $6.01 \mu \mathrm{g} / \mathrm{L}$. Detection frequencies (table B1) ranged from 2 percent for several VOCs to 62 percent for methylene chloride.

\section{Duplicate Samples}

In addition to the FEBs, FRBs, and TRBs, duplicate samples were collected sequentially at groundwater sampling sites and concurrently at surface-water sampling sites. Duplicate samples were processed in the same manner as the source-water sample and provide an indication of sampling and analytical reproducibility. Sixty-nine source-water samples were collected with field duplicates. Detected concentrations of MTBE in field duplicate samples and corresponding source-water samples are shown in figure B1. Most of the points fall directly on or near the 1:1 line with an $\mathrm{r}^{2}$ value of 0.999 , indicating very little variation in the concentrations of duplicates and source-water samples.

\section{STATISTICAL COMPARISON OF QUALITY- CONTROL SAMPLES}

The low-level (less than $0.2 \mu \mathrm{g} / \mathrm{L}$ ) contamination evident in the field quality-control data required further analysis to determine the level of uncertainty associated with VOC detections. Similarities between detected concentrations in different blank types may indicate a common source of contamination, whereas differences may indicate more of a random source. The statistical analyses described below include comparisons between FRB, TRB, and FEB samples. In addition, duplicate source-water samples are further analyzed.

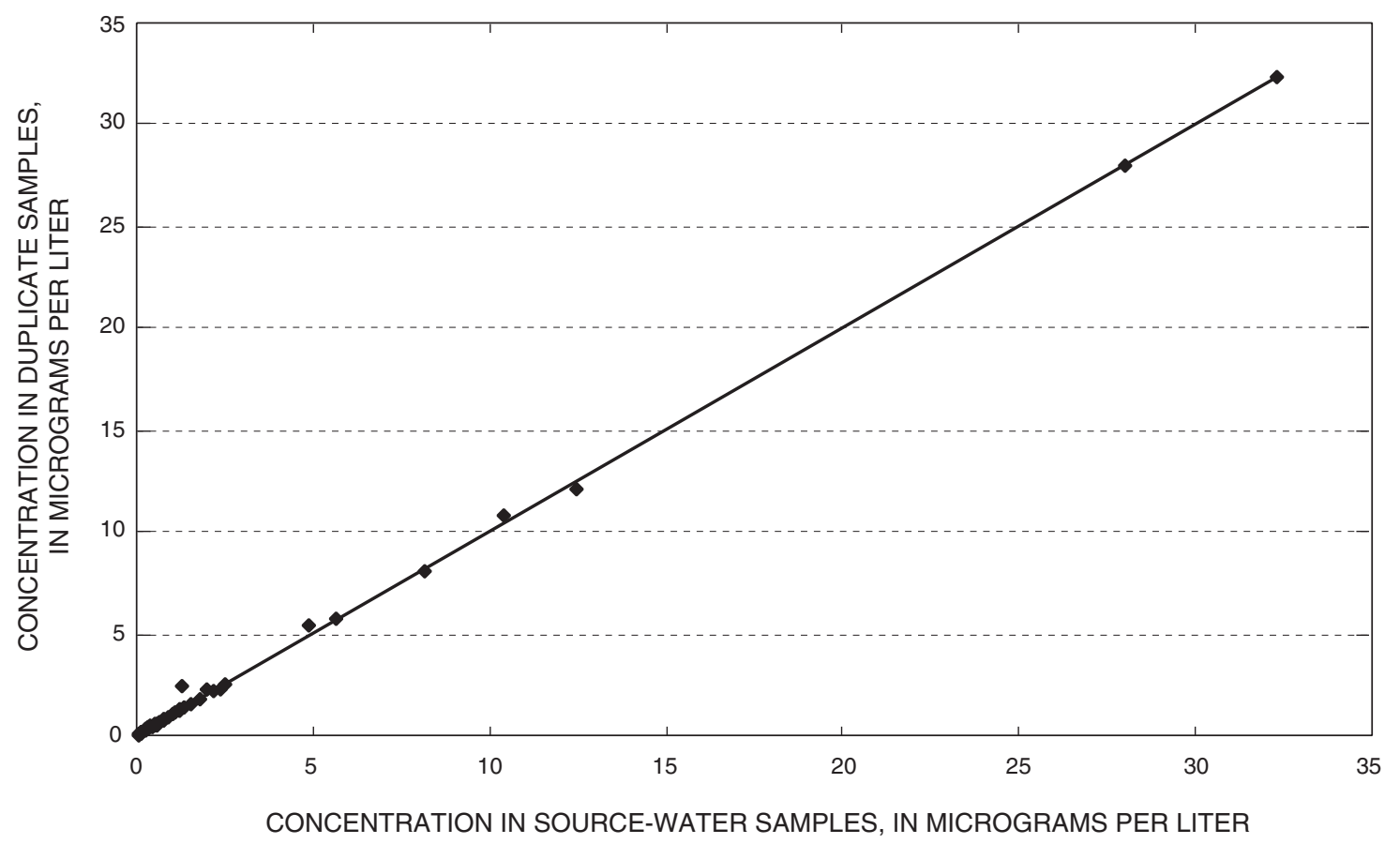

Figure B1. Concentration of methyl tert-butyl ether in field duplicate and source-water samples. 


\section{Field-Reagent Blank Samples Versus Trip- Reagent Blank Samples}

A review of the FRB and TRB sample data was completed to determine if there was a relation between the frequency and concentration of VOC detections in these samples for sites where both quality-control samples were collected. Of the 304 TRB samples collected, 292 had a companion FRB sample.

A Wilcoxon signed-rank test (Helsel and Hirsch, 1992), was used to statistically determine the relation between concentrations in FRB and TRB samples. VOCs detected in either blank type were used in the statistical analysis. Results for all 292 pairs of samples indicated that the concentrations of seven of the VOCs detected in both blanks were statistically different at the 95-percent confidence level (table B2). These seven VOCs include chloromethane, methylene chloride, MTBE, $n$-propylbenzene, styrene, TAME, and toluene. Concentrations of six of these VOCs were found to be statistically greater in the FRB samples than in the TRB samples. This may indicate that the detections of VOCs might be due to greater exposure of the source water for the FRB samples to conditions in the field than the TRB samples, which were unopened during field operations. Concentrations of chloromethane were found to be statistically greater in the TRB samples than in the FRB samples, but this compound was detected in only 16 source-water samples.

Table B2. Relation between concentrations of volatile organic compounds in 292 companion field-blank samples and tripblank samples

[Statistically different results are the 95-percent confidence interval are given in boldface; $\mathrm{H}_{\mathrm{o}}$, null hypothesis; FRB, field-reagent blank; TRB, trip-reagent blank; <, less than; >, greater than]

\begin{tabular}{|c|c|c|c|c|c|}
\hline \multirow{2}{*}{$\begin{array}{l}\text { Volatile organic } \\
\text { compound }\end{array}$} & \multirow{2}{*}{$\begin{array}{l}\text { Number of } \\
\text { detections in } \\
\text { FRB samples }\end{array}$} & \multirow{2}{*}{$\begin{array}{l}\text { Number of } \\
\text { detections in } \\
\text { TRB samples }\end{array}$} & \multicolumn{3}{|c|}{ Null hypothesis tested and p-value } \\
\hline & & & $H_{0}: F R B=T R B^{1}$ & $H_{o}: F R B<T R B^{2}$ & $H_{o}: F R B>T R B^{2}$ \\
\hline tert-Amyl methyl ether (TAME) & 5 & 3 & 0.0457 & 0.0228 & 0.9773 \\
\hline Benzene & 8 & 4 & 0.5394 & 0.7310 & 0.2697 \\
\hline Bromomethane & 6 & 5 & 0.7679 & 0.3839 & 0.6169 \\
\hline Chloroform & 37 & 12 & 0.4377 & 0.7815 & 0.2189 \\
\hline Chloromethane & 8 & 0 & 0.0347 & 0.9827 & 0.0174 \\
\hline 1,4-Dichlorobenzene & 4 & 1 & 0.3190 & 0.0904 & 0.8413 \\
\hline 1,1-Dichloroethane & 3 & 1 & 0.9989 & 0.5021 & 0.4993 \\
\hline Ethylbenzene & 115 & 46 & 0.3452 & 0.1726 & 0.8276 \\
\hline Isopropylbenzene & 23 & 7 & 0.5298 & 0.2649 & 0.7356 \\
\hline$p$-Isopropyltoluene & 0 & 8 & 0.1577 & 0.0788 & 0.9215 \\
\hline Methyl ethyl ketone & 11 & 10 & 0.2224 & 0.1112 & 0.8891 \\
\hline Methylene chloride & 172 & 166 & 0.0427 & 0.0214 & 0.9787 \\
\hline Methyl tert-butyl ether (MTBE) & 131 & 145 & $<0.0001$ & $<0.0001$ & 1.0000 \\
\hline Naphthalene & 19 & 13 & 0.5981 & 0.7016 & 0.2990 \\
\hline$n$-Propylbenzene & 16 & 7 & 0.0605 & 0.0303 & 0.9699 \\
\hline Styrene & 213 & 148 & $<0.0001$ & $<0.0001$ & 1.0000 \\
\hline Toluene & 222 & 171 & $<0.0001$ & $<0.0001$ & 1.0000 \\
\hline 1,2,3-Trichloropropane & 5 & 0 & 0.4215 & 0.7901 & 0.2108 \\
\hline 1,2,4-Trimethylbenzene & 42 & 29 & 0.8231 & 0.4116 & 0.5890 \\
\hline$m, p$-Xylene & 112 & 53 & 0.2678 & 0.1339 & 0.8663 \\
\hline$o$-Xylene & 91 & 32 & 0.4475 & 0.2238 & 0.7765 \\
\hline
\end{tabular}

${ }^{1}$ Two-sided p-values $<0.1$ significant at 95 -percent confidence level.

${ }^{2}$ One-sided p-values $<0.05$ significant at 95 -percent confidence level. 


\section{Field-Reagent Blank Samples Versus Field- Equipment Blank Samples}

Concentrations of VOCs were statistically compared using the Wilcoxon signed-rank test for FEBs and FRBs in 27 paired sets of blank samples. As in the test comparing FRB samples to TRB samples, VOCs detected in either blank type were used in the statistical analysis. Concentrations of MTBE and styrene were found to be statistically different at the 95-percent confidence level (table B3). Concentrations of MTBE were determined to be statistically higher in FEB samples than in FRB samples. Conversely, concentrations of styrene were found to be statistically higher at the 95-percent confidence level in the FRB samples than in the FEB samples. Concentration differences between FRB samples and FEB samples for all other compounds analyzed were not found to be statistically different.

\section{Trip-Reagent Blank Samples Versus Field- Equipment Blank Samples}

Concentrations of FEB samples and TRB samples were also compared for 27 sets of paired blanks. For all compounds analyzed, none were statistically different, nor were any concentrations of compounds statistically higher or lower for any of the blanks (table B4).

\section{Duplicate Samples}

A Wilcoxon signed-rank test for the VOCs was used to test whether there were significant differences between the samples and the duplicates. Results of the test indicated that for the 69 pairs of source-water samples and duplicates, the concentrations of three compounds (naphthalene, trichloroethene, and 1,3,5trimethylbenzene) were significantly different at the 95-percent confidence level (table B5).

Table B3. Relation between concentrations of volatile organic compounds in 27 companion field-equipment blank samples and field-reagent blank samples

[Statistically different results at the 95-percent confidence interval are given in boldface; $\mathrm{H}_{\mathrm{o}}$, null hypothesis; FEB, field-equipment blank; FRB, fieldreagent blank; <, less than; >, greater than]

\begin{tabular}{|c|c|c|c|c|c|}
\hline \multirow{2}{*}{$\begin{array}{l}\text { Volatile organic } \\
\text { compounds }\end{array}$} & \multirow{2}{*}{$\begin{array}{c}\text { Number of } \\
\text { detections in FEB } \\
\text { samples }\end{array}$} & \multirow{2}{*}{$\begin{array}{c}\text { Number of } \\
\text { detections in FRB } \\
\text { samples }\end{array}$} & \multicolumn{3}{|c|}{ Null hypothesis tested and p-value } \\
\hline & & & $H_{0}: F E B=F R B^{1}$ & $H_{o}: F E B<F R B^{2}$ & $H_{0}: F E B>F^{2} B^{2}$ \\
\hline Benzene & 1 & 0 & 0.3356 & 0.1678 & 0.8501 \\
\hline Chloroform & 2 & 5 & 0.1920 & 0.0960 & 0.9100 \\
\hline Chloromethane & 2 & 1 & 0.3356 & 0.8501 & 0.1678 \\
\hline Ethylbenzene & 3 & 12 & 0.9675 & 0.5270 & 0.4838 \\
\hline Isopropylbenzene & 1 & 0 & 0.3356 & 0.8501 & 0.1678 \\
\hline Methylene chloride & 16 & 17 & 0.9796 & 0.4898 & 0.5204 \\
\hline Methyl tert-butyl ether (MTBE) & 4 & 9 & 0.0155 & 0.0078 & 0.9928 \\
\hline Naphthalene & 4 & 0 & 0.9844 & 0.4922 & 0.5234 \\
\hline$n$-Propylbenzene & 1 & 0 & 0.3356 & 0.1678 & 0.8501 \\
\hline Styrene & 9 & 20 & 0.0013 & 0.9994 & 0.0006 \\
\hline Toluene & 8 & 19 & 0.9802 & 0.5198 & 0.4901 \\
\hline 1,2,4-Trichlorobenzene & 2 & 0 & 1.0000 & 0.5000 & 0.5213 \\
\hline 1,2,3-Trichloropropane & 2 & 2 & 0.3356 & 0.8501 & 0.1678 \\
\hline 1,2,4-Trimethylbenzene & 4 & 5 & 0.5790 & 0.2895 & 0.7255 \\
\hline$m, p$-Xylene & 2 & 12 & 0.2093 & 0.1047 & 0.8367 \\
\hline$o$-Xylene & 2 & 8 & 0.1267 & 0.0633 & 0.9402 \\
\hline
\end{tabular}

${ }^{1}$ Two-sided p-values $<0.1$ significant at 95 -percent confidence level.

${ }^{2}$ One-sided p-values $<0.05$ significant at 95 -percent confidence level. 
Table B4. Relation between concentrations of volatile organic compounds in 27 companion field-equipment blank samples and trip-reagent blank samples

[ $\mathrm{H}_{\mathrm{o}}$, null hypothesis; FEB, field-equipment blank; TRB, trip-reagent blank; <, less than; >, greater than]

\begin{tabular}{|c|c|c|c|c|c|}
\hline \multirow{2}{*}{$\begin{array}{l}\text { Volatile organic } \\
\text { compound }\end{array}$} & \multirow{2}{*}{$\begin{array}{c}\text { Number of } \\
\text { detections in FEB } \\
\text { samples }\end{array}$} & \multirow{2}{*}{$\begin{array}{l}\text { Number of } \\
\text { detections in } \\
\text { TRB samples }\end{array}$} & \multicolumn{3}{|c|}{ Null hypothesis tested and $p$-value } \\
\hline & & & $H_{0}: F E B=T R B^{1}$ & $H_{0}: F E B<T_{R B}^{2}$ & $H_{0}:$ FEB $>T^{2} B^{2}$ \\
\hline Benzene & 1 & 0 & 0.3356 & 0.1678 & 0.8501 \\
\hline Chloroform & 2 & 2 & 0.9844 & 0.5234 & 0.4922 \\
\hline Chloromethane & 2 & 0 & 0.1654 & 0.9252 & 0.0827 \\
\hline Ethylbenzene & 3 & 6 & 0.4346 & 0.2173 & 0.7923 \\
\hline Isopropylbenzene & 1 & 1 & 1.0000 & 0.5213 & 0.5000 \\
\hline$p$-Isopropyltoluene & 0 & 2 & 0.1654 & 0.0827 & 0.9252 \\
\hline Methylene chloride & 15 & 19 & 0.2060 & 0.1030 & 0.9014 \\
\hline Methyl tert-butyl ether (MTBE) & 4 & 13 & 0.5280 & 0.2640 & 0.7442 \\
\hline Naphthalene & 4 & 0 & 0.9687 & 0.4844 & 0.5312 \\
\hline$n$-Propylbenzene & 1 & 0 & 0.3356 & 0.1678 & 0.8501 \\
\hline Styrene & 10 & 15 & 0.1375 & 0.9345 & 0.0688 \\
\hline Toluene & 8 & 14 & 0.7010 & 0.3505 & 0.6590 \\
\hline 1,2,3-Trichlorobenzene & 3 & 0 & 0.6097 & 0.3049 & 0.7105 \\
\hline 1,2,3-Trichloropropane & 2 & 0 & 0.1654 & 0.9252 & 0.0827 \\
\hline 1,2,4-Trimethylbenzene & 4 & 6 & 0.6097 & 0.7105 & 0.3049 \\
\hline$m, p$-Xylene & 2 & 7 & 0.1548 & 0.0774 & 0.9268 \\
\hline$o$-Xylene & 2 & 3 & 1.0000 & 0.5000 & 0.5156 \\
\hline
\end{tabular}

\footnotetext{
${ }^{1}$ Two-sided p-values $<0.1$ significant at 95 -percent confidence level.
}

${ }^{2}$ One-sided p-values $<0.05$ significant at 95 -percent confidence level. 
Table B5. Statistical comparison of concentrations of volatile organic compounds in source-water and duplicate samples

[Statistically different results at the 95-percent confidence interval are given in boldface; $\mathrm{H}_{\mathrm{o}}$, null hypothesis; ENV, source-water sample; DUP, duplicate sample]

\begin{tabular}{|c|c|}
\hline \multirow[t]{2}{*}{ Volatile organic compound } & $\begin{array}{l}\text { Null hypothesis tested } \\
\text { and } p \text {-value }{ }^{1}\end{array}$ \\
\hline & $H_{0}: E N V=D U P$ \\
\hline tert-Amyl methyl ether (TAME) & 0.9772 \\
\hline Benzene & 0.5970 \\
\hline Bromodichloromethane & 0.7101 \\
\hline Bromomethane & 0.1604 \\
\hline Carbon tetrachloride & 1.0000 \\
\hline Chlorodibromomethane & 0.9706 \\
\hline Chloroform & 0.3490 \\
\hline Chloromethane & 0.3174 \\
\hline 1,1-Dichloroethane & 0.9820 \\
\hline 1,2-Dichloroethane & 0.9940 \\
\hline cis-1,2-Dichloroethene & 0.2406 \\
\hline 1,3-Dichloropropane & 0.1604 \\
\hline Ethylbenzene & 0.4321 \\
\hline Isopropylbenzene & 0.3245 \\
\hline Methylene chloride & 0.5811 \\
\hline Methyl tert-butyl ether (MTBE) & 0.5230 \\
\hline Naphthalene & 0.0620 \\
\hline$n$-Propylbenzene & 0.5754 \\
\hline Styrene & 0.5923 \\
\hline 1,1,1-Trichloroethane & 0.9820 \\
\hline Tetrachloroethene & 0.9883 \\
\hline Toluene & 0.4417 \\
\hline Trichloroethene & 0.0354 \\
\hline 1,2,4-Trimethylbenzene & 0.6894 \\
\hline 1,3,5-Trimethybenzene & 0.0848 \\
\hline$m, p$-Xylene & 1.0000 \\
\hline$o$-Xylene & 0.8334 \\
\hline
\end{tabular}

${ }^{1}$ Two-sided p-values $<0.1$ significant at 95 -percent confidence level shown in bold. 



\section{Appendix C - Data acceptance criteria using quality-control data}




\section{SOURCE-WATER DATA ACCEPTANCE CRITERIA}

Two objectives of the Focused Survey include: (1) to determine the temporal variability, and (2) characterize sampling sites that had frequent occurrence of MTBE and other VOCs in source water. In order to accomplish these two objectives, data analyses will involve the use of concentration values to determine temporal trends as well as a presence/absence approach for site characterizations. The strength of these types of comparisons relies on the amount of data (detections) available for data analyses. That is, if a compound is determined to be present, it may be used in statistical tests to determine if the VOC is associated with some environmental risk factor. However, if the concentration of a compound detected below the minimum reporting level (MRL) is censored, low-level temporal trends and explanatory factors could be missed. It is important to note that data below the MRL can only be used in these analyses if the QC screening process supports those activities.

\section{Source-Water Data Screening Process}

As with the Random Survey, an analysis of source-water data and field QC data can identify potential contamination of individual VOCs in source-water samples. Subsequently, the frequency of detection can be adjusted to account for possible contamination. The source-water samples were subdivided into seven conditions that relate to the level of uncertainty associated with source-water VOC detections. These conditions are described in table $\mathrm{C} 1$.

Table C1. Schematic diagram for adjusting the frequency of detection of volatile organic compounds in source-water samples to reflect possible random sample contamination

[VOCs, volatile organic compounds; <, less than; >=, greater than or equal to]

\begin{tabular}{|c|c|}
\hline Condition & $\begin{array}{l}\text { Possibility of random contamination of } \\
\text { source-water samples }\end{array}$ \\
\hline $\begin{array}{l}\text { Condition A: } \\
\text { Source water = no VOCs detected } \\
\text { Field blank = no VOCs detected }\end{array}$ & None \\
\hline $\begin{array}{l}\text { Condition B: } \\
\text { Source water }=\text { no VOCs detected } \\
\text { Field blank = VOCs detected }\end{array}$ & None \\
\hline $\begin{array}{l}\text { Condition C: } \\
\text { Source water = no VOCs detected } \\
\text { Field blank = not analyzed }\end{array}$ & None \\
\hline $\begin{array}{l}\text { Condition D: } \\
\text { Source water = VOCs detected } \\
\text { Field blank = no VOCs detected }\end{array}$ & None \\
\hline $\begin{array}{l}\text { Condition E1: } \\
\text { Source water = VOCs detected } \\
\text { Field blank = same VOCs detected, however, source water } \\
\quad \text { concentrations }>=5 \text { times the field blank concentrations }\end{array}$ & None \\
\hline $\begin{array}{l}\text { Condition E2: } \\
\text { Source water = VOCs detected } \\
\text { Field blank = same VOCs detected, however, source water } \\
\quad \text { concentrations }<5 \text { times the field blank concentrations }\end{array}$ & Random contamination suspected \\
\hline $\begin{array}{l}\text { Condition F: } \\
\text { Source water = VOCs detected } \\
\text { Field blank = not analyzed }\end{array}$ & $\begin{array}{l}\text { Undetermined-Possibility of random sample } \\
\text { contamination }\end{array}$ \\
\hline
\end{tabular}


Conditions A, B, C, and D all indicate that random sample contamination of source-water samples above the method detection limit (MDL) is not likely. As presented in table $\mathrm{C} 2$, the majority of source-water samples had no detections (conditions A, B, and C), thus, random contamination was not measurable. For example, many source-water samples did not have a detected VOC in the source-water sample or FRB sample (condition A). There also were many sourcewater samples with no VOC detections, but with detections in the corresponding FRB samples

(condition B) - methylene chloride, styrene, and toluene were detected in 179, 118, and 111 FRB samples, respectively, but were not detected in the corresponding source-water samples. Concentrations for methylene chloride, styrene, and toluene in FRB samples ranged from $0.03 \mu \mathrm{g} / \mathrm{L}$ for all three compounds to $1.18,8.61$, and $6.95 \mu \mathrm{g} / \mathrm{L}$, respectively. This may be an indication that the VOC-free water used in the collection of these FRBs was contaminated with those compounds when the FRB sample was collected. Condition C VOCs were not detected in source-water samples, thus they are not considered contaminated and, as stated in the protocol, the FRB samples were not analyzed unless compounds were detected in the source-water samples. Also, chloroform and MTBE were detected in 146 and 134 source-water samples, respectively, but with no detections in the corresponding FRB samples (condition D). This further indicates contamination associated with those compounds under that specific condition is unlikely.

The validity of only two categories of data remain in question: (1) the samples that have the same VOCs in the source-water sample as well as the associated FRB sample (conditions E1 and E2); and (2) those source-water samples with VOC detections that do not have an associated FRB sample (condition F). Samples classified into category E1 and E2 have detections of the same VOCs in both the source-water sample and associated FRB sample (table C2). Samples classified as E1 have VOC concentrations 5 times greater than the concentrations in the accompanying FRB sample. Samples classified as E2 have VOC concentrations less than 5 times the concentrations in the accompanying FRB sample. The source-water samples that were classified as E1 were judged to have essentially no possibility that the source-water concentration was an artifact of random contamination. These samples were few, except for MTBE, which had 82 samples in this category. In addition, toluene and ethylbenzene had 18 and 3 samples in condition E1, respectively (table $\mathrm{C} 2$ ).
For samples with VOCs at concentrations less than five times the FRB sample concentration there was a clear possibility that the source-water detection was due to random contamination, especially when concentrations approached a 1:1 ratio for one or more compound. Accordingly, 487 source-water VOC detections that fall under condition E2 (223 of these detections were due to styrene and toluene) were censored from the source-water data and not included in the analyses of VOCs subsequently reported for source water. As in the QC analysis for the Random Survey, this is a conservative approach to reporting VOC occurrence data, and it is recognized that the detection of the same VOC in both the FRB and source-water samples does not definitively indicate that random contamination of the source-water sample has occurred, but indicates that it may have occurred or cannot be ruled out.

Source-water samples classified as condition F had a detected VOC in the source-water sample but an associated FRB sample was not available. This condition is considered to have some uncertainty associated with the detection, however, as in the Random Survey, these concentrations were not censored from the source-water data. Thus, only E2 samples were censored from the data set and are not included in any analyses subsequently reported for source water.

\section{Volatile Organic Compound Detection Frequencies}

The total number of samples collected, the original detection frequency before adjusting for E2 conditions, and the adjusted detection frequency after adjusting for E2 conditions for data at the MDL are listed in table C3. As in the Random Survey analyses, the adjusted detection frequency is equal to the total number of times a VOC was detected minus the number of condition E2 samples divided by the total number of samples minus the number of condition E2 samples. Table C4 illustrates an example of calculating the adjusted detection frequency for MTBE at the MDL.

The detection frequency in source-water samples was adjusted downward for 32 of the 58 detected VOCs due to possible random contamination. Only the adjusted samples (those not affected by condition E2) were used in data analyses presented in this report. 
Table C2. Number of source-water samples that meet specified conditions at the method detection limit, with respect to the possibility of random contamination

\begin{tabular}{|c|c|c|c|c|c|c|c|}
\hline \multirow{2}{*}{$\begin{array}{l}\text { Possible volatile organic compound } \\
\text { contaminant }\end{array}$} & \multicolumn{7}{|c|}{ Number of samples per condition ${ }^{1}$} \\
\hline & A & B & C & $\mathbf{D}$ & E1 & E2 & $\mathbf{F}$ \\
\hline Acrylonitrile & 315 & 1 & 145 & 6 & 0 & 0 & 0 \\
\hline tert-Amyl methyl ether (TAME) & 227 & 4 & 126 & 88 & 0 & 3 & 19 \\
\hline Benzene & 213 & 6 & 125 & 98 & 1 & 4 & 20 \\
\hline Bromobenzene & 319 & 1 & 145 & 2 & 0 & 0 & 0 \\
\hline Bromochloromethane & 312 & 1 & 144 & 9 & 0 & 0 & 1 \\
\hline Bromodichloromethane & 262 & 2 & 141 & 52 & 0 & 6 & 4 \\
\hline Bromoform & 306 & 0 & 137 & 15 & 0 & 0 & 8 \\
\hline Bromomethane & 306 & 5 & 138 & 10 & 0 & 1 & 5 \\
\hline$n$-Butylbenzene & 313 & 1 & 141 & 8 & 0 & 0 & 1 \\
\hline sec-Butylbenzene & 320 & 0 & 145 & 1 & 0 & 1 & 0 \\
\hline tert-Butylbenzene & 320 & 1 & 145 & 1 & 0 & 0 & 0 \\
\hline Carbon tetrachloride & 313 & 1 & 143 & 8 & 0 & 0 & 2 \\
\hline Chlorobenzene & 311 & 0 & 141 & 10 & 0 & 0 & 4 \\
\hline Chlorodibromomethane & 274 & 1 & 129 & 46 & 0 & 1 & 16 \\
\hline Chloroethane & 318 & 0 & 145 & 2 & 0 & 2 & 0 \\
\hline Chloroform & 136 & 20 & 88 & 146 & 6 & 14 & 57 \\
\hline Chloromethane & 306 & 3 & 142 & 8 & 0 & 5 & 3 \\
\hline 2-Chlorotoluene & 321 & 0 & 145 & 0 & 0 & 0 & 0 \\
\hline 4-Chlorotoluene & 319 & 1 & 145 & 2 & 0 & 0 & 0 \\
\hline Dibromomethane & 319 & 0 & 145 & 3 & 0 & 0 & 0 \\
\hline 1,2-Dichlorobenzene & 316 & 0 & 145 & 5 & 0 & 0 & 1 \\
\hline 1,3-Dichlorobenzene & 321 & 0 & 145 & 13 & 1 & 0 & 2 \\
\hline 1,4-Dichlorobenzene & 309 & 3 & 142 & 9 & 0 & 1 & 3 \\
\hline Dichlorodifluoromethane & 320 & 0 & 144 & 2 & 0 & 0 & 1 \\
\hline 1,1-Dichloroethane & 294 & 0 & 130 & 26 & 0 & 2 & 15 \\
\hline 1,2-Dichloroethane & 291 & 1 & 137 & 30 & 0 & 0 & 8 \\
\hline 1,1-Dichloroethene & 307 & 0 & 145 & 13 & 1 & 0 & 2 \\
\hline cis-1,2-Dichloroethene & 287 & 0 & 138 & 32 & 1 & 2 & 7 \\
\hline trans-1,2-Dichloroethene & 312 & 0 & 144 & 10 & 0 & 0 & 1 \\
\hline 1,2-Dichloropropane & 313 & 1 & 144 & 8 & 0 & 0 & 1 \\
\hline 1,3-Dichloropropane & 313 & 3 & 141 & 6 & 0 & 0 & 4 \\
\hline 2,2-Dichloropropane & 321 & 1 & 145 & 0 & 0 & 0 & 0 \\
\hline 1,1-Dichloropropene & 321 & 0 & 145 & 0 & 0 & 0 & 0 \\
\hline cis-1,3-Dichloropropene & 321 & 0 & 145 & 0 & 0 & 0 & 0 \\
\hline trans-1,3-Dichloropropene & 321 & 0 & 145 & 0 & 0 & 0 & 0 \\
\hline
\end{tabular}


Table C2. Number of source-water samples that meet specified conditions at the method detection limit, with respect to the possibility of random contamination-Continued

\begin{tabular}{|c|c|c|c|c|c|c|c|}
\hline \multirow{2}{*}{$\begin{array}{l}\text { Possible volatile organic compound } \\
\text { contaminant }\end{array}$} & \multicolumn{7}{|c|}{ Number of samples per condition ${ }^{1}$} \\
\hline & A & B & C & D & E1 & E2 & $\mathbf{F}$ \\
\hline Diisopropyl ether (DIPE) & 307 & 0 & 142 & 15 & 0 & 0 & 3 \\
\hline Ethylbenzene & 176 & 95 & 140 & 19 & 3 & 29 & 5 \\
\hline Ethyl tert-butyl ether (ETBE) & 318 & 0 & 144 & 4 & 0 & 0 & 1 \\
\hline Hexachlorobutadiene & 320 & 0 & 145 & 1 & 0 & 1 & 0 \\
\hline Hexachloroethane & 321 & 0 & 145 & 0 & 0 & 0 & 0 \\
\hline Isopropylbenzene & 282 & 25 & 144 & 11 & 0 & 4 & 1 \\
\hline$p$-Isopropyltoluene & 321 & 0 & 145 & 1 & 0 & 0 & 0 \\
\hline Methyl ethyl ketone & 302 & 12 & 141 & 7 & 0 & 1 & 4 \\
\hline Methylene chloride & 124 & 179 & 138 & 3 & 1 & 12 & 7 \\
\hline Methyl tert-butyl ether (MTBE) & 43 & 17 & 41 & 134 & 82 & 46 & 104 \\
\hline Naphthalene & 280 & 10 & 129 & 23 & 0 & 9 & 16 \\
\hline$n$-Propylbenzene & 292 & 16 & 143 & 10 & 0 & 4 & 2 \\
\hline Styrene & 78 & 118 & 102 & 11 & 1 & 114 & 43 \\
\hline 1,1,1,2-Tetrachloroethane & 318 & 1 & 145 & 3 & 0 & 0 & 0 \\
\hline 1,1,2,2-Tetrachloroethane & 321 & 1 & 145 & 0 & 0 & 0 & 0 \\
\hline Tetrachloroethene & 266 & 4 & 131 & 50 & 1 & 1 & 14 \\
\hline Toluene & 52 & 111 & 93 & 32 & 18 & 109 & 52 \\
\hline 1,2,3-Trichlorobenzene & 301 & 8 & 143 & 10 & 0 & 3 & 4 \\
\hline 1,2,4-Trichlorobenzene & 302 & 8 & 136 & 10 & 0 & 2 & 9 \\
\hline 1,1,1-Trichloroethane & 287 & 0 & 141 & 33 & 0 & 1 & 6 \\
\hline 1,1,2-Trichloroethane & 317 & 0 & 145 & 5 & 0 & 0 & 0 \\
\hline Trichloroethene & 273 & 0 & 128 & 48 & 0 & 1 & 17 \\
\hline Trichlorofluoromethane & 315 & 0 & 141 & 7 & 0 & 0 & 4 \\
\hline 1,2,3-Trichloropropane & 307 & 3 & 139 & 8 & 0 & 4 & 6 \\
\hline 1,1,2-Trichloro-1,2,2-trifluoromethane & 320 & 0 & 144 & 2 & 0 & 0 & 1 \\
\hline 1,2,4-Trimethylbenzene & 239 & 12 & 140 & 36 & 0 & 35 & 5 \\
\hline 1,3,5-Trimethylbenzene & 298 & 1 & 143 & 22 & 0 & 1 & 2 \\
\hline Vinyl bromide & 321 & 0 & 145 & 0 & 0 & 0 & 0 \\
\hline Vinyl chloride & 317 & 0 & 143 & 5 & 0 & 0 & 2 \\
\hline$m, p$-Xylene & 168 & 91 & 136 & 31 & 3 & 29 & 9 \\
\hline$o$-Xylene & 176 & 65 & 132 & 42 & 0 & 39 & 13 \\
\hline
\end{tabular}

\footnotetext{
${ }^{1}$ Described in table C1.
} 
Table C3. Detection frequency of volatile organic compounds detected at or above the method detection level in source water before and after applying the quality-control screening process

[--, not applicable]

\begin{tabular}{|c|c|c|c|c|c|c|}
\hline Volatile organic compound & $\begin{array}{c}\text { Number of } \\
\text { samples }\end{array}$ & $\begin{array}{l}\text { Number of } \\
\text { original } \\
\text { detections }\end{array}$ & $\begin{array}{l}\text { Unadjusted } \\
\text { detection } \\
\text { frequency } \\
\text { (percent) }\end{array}$ & $\begin{array}{l}\text { Number of } \\
\text { samples after } \\
\text { screening } \\
\text { process }\end{array}$ & $\begin{array}{c}\text { Number of } \\
\text { detections after } \\
\text { screening } \\
\text { process }\end{array}$ & $\begin{array}{r}\text { Adjusted } \\
\text { detection } \\
\text { frequency } \\
\text { (percent) }\end{array}$ \\
\hline Acrylonitrile & 467 & 6 & 1.3 & 467 & 6 & 1.3 \\
\hline tert-Amyl methyl ether (TAME) & 467 & 110 & 23.6 & 464 & 107 & 23.1 \\
\hline Benzene & 467 & 123 & 26.3 & 463 & 119 & 25.7 \\
\hline Bromobenzene & 467 & 2 & 0.4 & 467 & 2 & 0.4 \\
\hline Bromochloromethane & 467 & 10 & 2.1 & 467 & 10 & 2.1 \\
\hline Bromodichloromethane & 467 & 62 & 13.3 & 461 & 56 & 12.1 \\
\hline Bromoform & 467 & 23 & 4.9 & 467 & 23 & 4.9 \\
\hline Bromomethane & 465 & 16 & 3.4 & 464 & 15 & 3.2 \\
\hline$n$-Butylbenzene & 467 & 9 & 1.5 & 467 & 9 & 1.5 \\
\hline sec-Butylbenzene & 467 & 2 & 0.4 & 466 & 1 & 0.2 \\
\hline tert-Butylbenzene & 467 & 1 & 0.2 & 467 & 1 & 0.2 \\
\hline Carbon tetrachloride & 467 & 10 & 2.1 & 467 & 10 & 2.1 \\
\hline Chlorobenzene & 467 & 14 & 3.0 & 467 & 14 & 3.0 \\
\hline Chlorodibromomethane & 467 & 63 & 13.5 & 466 & 62 & 13.3 \\
\hline Chloroethane & 467 & 4 & 0.9 & 465 & 2 & 0.4 \\
\hline Chloroform & 467 & 223 & 47.8 & 453 & 209 & 46.1 \\
\hline Chloromethane & 467 & 16 & 3.4 & 462 & 11 & 2.4 \\
\hline 4-Chlorotoluene & 467 & 2 & 0.4 & 467 & 2 & 0.4 \\
\hline Dibromomethane & 467 & 3 & 0.6 & 467 & 3 & 0.6 \\
\hline 1,2-Dichlorobenzene & 467 & 6 & 1.3 & 467 & 6 & 1.3 \\
\hline 1,3-Dichlrobenzene & 467 & 6 & 1.3 & 467 & 6 & 1.3 \\
\hline 1,4-Dichlorobenzene & 467 & 13 & 2.8 & 466 & 12 & 2.6 \\
\hline Dichlorodifluoromethane & 467 & 3 & 0.6 & 467 & 3 & 0.6 \\
\hline 1,1-Dichloroethane & 467 & 43 & 9.2 & 465 & 41 & 8.8 \\
\hline 1,2-Dichloroethane & 467 & 38 & 8.1 & 467 & 38 & 8.1 \\
\hline 1,1-Dichloroethene & 467 & 16 & 3.4 & 467 & 16 & 3.4 \\
\hline cis-1,2-Dichloroethene & 467 & 42 & 9.0 & 465 & 40 & 8.6 \\
\hline trans-1,2-Dichloroethene & 467 & 11 & 2.4 & 467 & 11 & 2.4 \\
\hline 1,2-Dichloropropane & 467 & 9 & 1.9 & 467 & 9 & 1.9 \\
\hline 1,3-Dichloropropane & 464 & 10 & 2.2 & 464 & 10 & 2.2 \\
\hline Diisopropyl ether (DIPE) & 467 & 19 & 4.1 & 467 & 19 & 4.1 \\
\hline Ethylbenzene & 467 & 56 & 12.0 & 438 & 27 & 6.2 \\
\hline Ethyl tert-butyl ether (ETBE) & 467 & 5 & 1.1 & 467 & 5 & 1.1 \\
\hline Hexachlorobutadiene & 467 & 2 & 0.4 & 466 & 1 & 0.2 \\
\hline
\end{tabular}


Table C3. Detection frequency of volatile organic compounds detected at or above the method detection level in source water before and after applying the quality-control screening process-Continued

[--, not applicable]

\begin{tabular}{|c|c|c|c|c|c|c|}
\hline Volatile organic compound & $\begin{array}{l}\text { Number of } \\
\text { samples }\end{array}$ & $\begin{array}{l}\text { Number of } \\
\text { original } \\
\text { detections }\end{array}$ & $\begin{array}{l}\text { Unadjusted } \\
\text { detection } \\
\text { frequency } \\
\text { (percent) }\end{array}$ & $\begin{array}{l}\text { Number of } \\
\text { samples after } \\
\text { screening } \\
\text { process }\end{array}$ & $\begin{array}{c}\text { Number of } \\
\text { detections after } \\
\text { screening } \\
\text { process }\end{array}$ & $\begin{array}{l}\text { Adjusted } \\
\text { detection } \\
\text { frequency } \\
\text { (percent) }\end{array}$ \\
\hline Isopropylbenzene & 467 & 16 & 3.4 & 463 & 12 & 2.6 \\
\hline$p$-Isopropyltoluene & 467 & 1 & 0.2 & 467 & 1 & 0.2 \\
\hline Methyl ethyl ketone & 467 & 12 & 2.6 & 466 & 11 & 2.4 \\
\hline Methylene chloride & 464 & 23 & 5.0 & 452 & 11 & 2.4 \\
\hline Methyl tert-butyl ether (MTBE) & 467 & 366 & 78.4 & 421 & 320 & 76.0 \\
\hline Naphthalene & 467 & 48 & 10.3 & 458 & 39 & 8.5 \\
\hline$n$-Propylbenzene & 467 & 16 & 3.4 & 463 & 12 & 2.6 \\
\hline Styrene & 467 & 169 & 36.2 & 353 & 55 & 15.6 \\
\hline 1,1,1,2-Tetrachloroethane & 467 & 3 & 0.6 & 467 & 3 & 0.6 \\
\hline 1,1,2,2-Tetrachloroethane & 467 & 1 & 0.2 & 467 & 1 & 0.2 \\
\hline Tetrachloroethene & 467 & 66 & 14.1 & 466 & 65 & 13.9 \\
\hline Toluene & 467 & 211 & 45.2 & 358 & 102 & 28.5 \\
\hline 1,2,3-Trichlorobenzene & 467 & 17 & 3.6 & 464 & 14 & 3.0 \\
\hline 1,2,4-Trichlorobenzene & 467 & 21 & 4.5 & 465 & 19 & 4.1 \\
\hline 1,1,1-Trichloroethane & 467 & 40 & 8.6 & 466 & 39 & 8.4 \\
\hline 1,1,2-Trichloroethane & 467 & 5 & 1.1 & 467 & 5 & 1.1 \\
\hline Trichloroethene & 467 & 66 & 14.1 & 466 & 65 & 13.9 \\
\hline Trichlorofluoromethane & 467 & 11 & 2.4 & 467 & 11 & 2.4 \\
\hline 1,2,3-Trichloropropane & 467 & 18 & 3.9 & 463 & 14 & 3.0 \\
\hline $\begin{array}{l}\text { 1,1,2-Trichloro-1,2,2-trifluoro- } \\
\text { ethane }\end{array}$ & 467 & 3 & 0.6 & 467 & 3 & 0.6 \\
\hline 1,2,4-Trimethylbenzene & 467 & 76 & 16.3 & 432 & 41 & 9.5 \\
\hline 1,3,5-Trimethylbenzene & 467 & 25 & 5.4 & 466 & 24 & 5.2 \\
\hline Vinyl chloride & 467 & 7 & 1.5 & 467 & 7 & 1.5 \\
\hline$m, p$-Xylene & 467 & 72 & 15.4 & 438 & 43 & 9.8 \\
\hline$o$-Xylene & 467 & 94 & 20.1 & 428 & 55 & 12.9 \\
\hline
\end{tabular}


Table C4. Schematic diagram for adjusting the frequency of detection of methyl tert-butyl ether in source-water samples to reflect possible random sample contamination ${ }^{1}$

[VOCs, volatile organic compounds; MTBE, methyl tert-butyl ether; <, less than; >=, greater than or equal to]

\section{Possibility of random contamination} of source-water samples

No random sample contamination

No random sample contamination

No random sample contamination

No random sample contamination

No random sample contamination

Random contamination suspected

Undetermined-Possibility of random sample contamination

\section{Condition}

Condition A: Source water $=$ no VOCs detected Field blank $=$ no VOCs detected

For MTBE $=43$ samples

Condition B: Source water $=$ no VOCs detected Field blank = VOCs detected

For MTBE $=17$ samples

Condition C: Source water $=$ no VOCs detected Field blank $=$ not analyzed

For MTBE $=41$ samples

Condition D: Source water $=$ VOCs detected Field blank $=$ no VOCs detected

For MTBE $=134$ samples

Condition E1: Source water $=$ VOCs detected

Field blank = same VOCs detected, and source water concentrations $>=5$ times the field blank concentrations

For MTBE $=82$ samples

Condition E2: Source water $=$ VOCs detected

Field blank $=$ same VOCs detected, and source water concentrations $<5$ times the field blank concentrations

For MTBE $=46$ samples

Condition F: Source water $=$ VOCs detected Field blank $=$ not analyzed

For MTBE $=104$ samples

Frequency of detection, unadjusted $=(\mathrm{D}+\mathrm{E} 1+\mathrm{E} 2+\mathrm{F}) /(\mathrm{A}+\mathrm{B}+\mathrm{C}+\mathrm{D}+\mathrm{E} 1+\mathrm{E} 2+\mathrm{F})$

For MTBE $=(134+82+46+104) /(43+17+41+134+82+46+104)=366 / 467=78.4$ percent

Frequency of detection, adjusted $=(\mathrm{D}+\mathrm{E} 1+\mathrm{F}) /(\mathrm{A}+\mathrm{B}+\mathrm{C}+\mathrm{D}+\mathrm{E} 1+\mathrm{F})$

For MTBE $=(134+82+104) /(43+17+41+134+82+104)=320 / 421=76.0$ percent

Estimated frequency of detection that may be attributed to random contamination of source-water samples $=$ frequency of detection, unadjusted - frequency of detection, adjusted For MTBE $=78.4$ percent -76.0 percent $=2.4$ percent

\footnotetext{
${ }^{1}$ Based on all detections greater than or equal to the method detection limit.
} 


\section{Appendix D - Summary of VOC concentrations in the Focused Survey}


Table D1. Statistical summary of volatile organic compounds in source-water samples in the Focused Survey

[Values in micrograms per liter; N, number of sources sampled; ND, not detected]

\begin{tabular}{|c|c|c|c|c|c|c|c|c|c|c|}
\hline \multirow{2}{*}{$\begin{array}{l}\text { Volatile organic } \\
\text { compounds }\end{array}$} & \multicolumn{5}{|c|}{ All community water systems $(\mathrm{N}=134)$} & \multicolumn{5}{|c|}{ Ground Water $(\mathrm{N}=78)$} \\
\hline & $\begin{array}{l}\text { Mini- } \\
\text { mum }\end{array}$ & 25th & Median & 75th & $\begin{array}{l}\text { Maxi- } \\
\text { mum }\end{array}$ & $\begin{array}{l}\text { Mini- } \\
\text { mum }\end{array}$ & 25th & Median & 75th & $\begin{array}{l}\text { Maxi- } \\
\text { mum }\end{array}$ \\
\hline \multicolumn{11}{|l|}{ Gasoline oxygenates } \\
\hline Diisopropyl ether & 0.10 & 0.14 & 0.27 & 0.74 & 3.93 & 0.10 & 0.14 & 0.27 & 0.74 & 3.93 \\
\hline Ethyl tert-butyl ether & 0.16 & 0.17 & 0.18 & 0.19 & 0.20 & 0.16 & 0.17 & 0.18 & 0.19 & 0.20 \\
\hline Methyl tert-butyl ether & 0.04 & 0.18 & 0.68 & 1.63 & 924.00 & 0.04 & 0.57 & 0.95 & 4.73 & 924.00 \\
\hline tert-Amyl methyl ether & 0.03 & 0.04 & 0.11 & 0.18 & 1.27 & 0.03 & 0.06 & 0.11 & 0.23 & 1.27 \\
\hline \multicolumn{11}{|l|}{ Other gasoline compounds } \\
\hline 1,3,5-Trimethylbenzene & 0.03 & 0.06 & 0.20 & 0.33 & 0.49 & 0.32 & 0.32 & 0.32 & 0.32 & 0.32 \\
\hline Benzene & 0.03 & 0.04 & 0.10 & 0.30 & 37.90 & 0.03 & 0.09 & 0.14 & 0.86 & 37.90 \\
\hline Ethylbenzene & 0.05 & 0.05 & 0.07 & 0.54 & 2.69 & 0.05 & 0.06 & 0.06 & 1.38 & 2.69 \\
\hline$m, p$-Xylene & 0.07 & 0.08 & 0.09 & 0.72 & 3.26 & 0.07 & 0.09 & 0.10 & 0.89 & 3.26 \\
\hline Naphthalene & 0.06 & 0.06 & 0.12 & 0.17 & 0.98 & 0.06 & 0.11 & 0.15 & 0.21 & 0.98 \\
\hline$n$-Butylbenzene & 0.05 & 0.09 & 0.12 & 0.16 & 0.19 & 0.19 & 0.19 & 0.19 & 0.19 & 0.19 \\
\hline$o$-Xylene & 0.03 & 0.03 & 0.04 & 0.20 & 1.16 & 0.03 & 0.03 & 0.04 & 0.09 & 0.93 \\
\hline sec-Butylbenzene & 0.05 & 0.06 & 0.06 & 0.07 & 0.07 & 0.05 & 0.06 & 0.06 & 0.07 & 0.07 \\
\hline tert-Butylbenzene & ND & ND & ND & ND & ND & ND & ND & ND & ND & ND \\
\hline Toluene & 0.03 & 0.05 & 0.09 & 0.32 & 4.98 & 0.03 & 0.03 & 0.05 & 0.18 & 4.42 \\
\hline \multicolumn{11}{|l|}{ Trihalomethanes } \\
\hline Bromodichloromethane & 0.02 & 0.02 & 0.04 & 0.08 & 1.27 & 0.02 & 0.02 & 0.03 & 0.04 & 1.27 \\
\hline Bromoform & 0.03 & 0.09 & 0.20 & 0.28 & 2.61 & 0.19 & 0.21 & 0.26 & 0.88 & 2.61 \\
\hline Chlorodibromomethane & 0.02 & 0.03 & 0.04 & 0.07 & 2.43 & 0.02 & 0.03 & 0.04 & 0.15 & 2.43 \\
\hline Chloroform & 0.03 & 0.05 & 0.12 & 0.29 & 5.00 & 0.03 & 0.06 & 0.13 & 0.30 & 5.00 \\
\hline \multicolumn{11}{|l|}{ Organic synthesis } \\
\hline 1,1-Dichloropropene & ND & ND & ND & ND & ND & $\mathrm{ND}$ & ND & ND & ND & ND \\
\hline 1,2,3-Trichlorobenzene & 0.05 & 0.07 & 0.08 & 0.13 & 0.17 & 0.05 & 0.07 & 0.11 & 0.14 & 0.17 \\
\hline 1,2,4-Trimethylbenzene & 0.03 & 0.07 & 0.09 & 0.15 & 2.42 & 2.42 & 2.42 & 2.42 & 2.42 & 2.42 \\
\hline 1,3-Dichloropropane & 0.05 & 0.06 & 0.10 & 0.16 & 0.21 & 0.05 & 0.09 & 0.13 & 0.17 & 0.21 \\
\hline 2,2-Dichloropropane & ND & ND & ND & ND & ND & $\mathrm{ND}$ & ND & ND & $\mathrm{ND}$ & ND \\
\hline Acrylonitrile & 0.75 & 0.75 & 0.75 & 0.75 & 0.75 & 0.75 & 0.75 & 0.75 & 0.75 & 0.75 \\
\hline Bromochloromethane & 0.04 & 0.04 & 0.04 & 0.05 & 0.08 & 0.04 & 0.04 & 0.04 & 0.06 & 0.08 \\
\hline Hexachlorobutadiene & ND & ND & ND & ND & ND & $\mathrm{ND}$ & ND & ND & ND & ND \\
\hline Isopropylbenzene & 0.04 & 0.05 & 0.05 & 0.09 & 0.24 & 0.04 & 0.05 & 0.05 & 0.10 & 0.24 \\
\hline$p$-Isopropyltoluene & 0.04 & 0.04 & 0.04 & 0.04 & 0.04 & ND & ND & ND & ND & ND \\
\hline Styrene & 0.03 & 0.04 & 0.07 & 0.12 & 1.10 & 0.03 & 0.04 & 0.08 & 0.21 & 1.10 \\
\hline Vinyl bromide & $\mathrm{ND}$ & $\mathrm{ND}$ & $\mathrm{ND}$ & $\mathrm{ND}$ & ND & $\mathrm{ND}$ & $\mathrm{ND}$ & $\mathrm{ND}$ & ND & ND \\
\hline Vinyl chloride & 0.61 & 0.86 & 1.10 & 1.18 & 1.25 & 0.61 & 0.86 & 1.10 & 1.18 & 1.25 \\
\hline \multicolumn{11}{|l|}{ Solvents } \\
\hline 1,1,1,2-Tetrachloroethane & 0.02 & 0.02 & 0.02 & 0.02 & 0.02 & 0.02 & 0.02 & 0.02 & 0.02 & 0.02 \\
\hline 1,1,1-Trichloroethane & 0.06 & 0.13 & 0.23 & 0.67 & 6.84 & 0.06 & 0.13 & 0.23 & 0.67 & 6.84 \\
\hline
\end{tabular}




\begin{tabular}{|c|c|c|c|c|c|c|c|c|c|c|c|c|c|c|}
\hline \multicolumn{5}{|c|}{ Reservoir (N=39) } & \multicolumn{5}{|c|}{ Rivers ( $=17)$} & \multicolumn{5}{|c|}{ All surface water $(\mathrm{N}=56)$} \\
\hline $\begin{array}{l}\text { Mini- } \\
\text { mum }\end{array}$ & 25th & Median & 75th & $\begin{array}{l}\text { Maxi- } \\
\text { mum }\end{array}$ & $\begin{array}{l}\text { Mini- } \\
\text { mum }\end{array}$ & 25th & Median & 75th & $\begin{array}{l}\text { Maxi- } \\
\text { mum }\end{array}$ & $\begin{array}{l}\text { Mini- } \\
\text { mum }\end{array}$ & 25th & Median & 75th & $\begin{array}{l}\text { Maxi- } \\
\text { mum }\end{array}$ \\
\hline ND & ND & ND & ND & ND & ND & ND & ND & ND & ND & ND & ND & ND & ND & ND \\
\hline ND & ND & ND & ND & ND & ND & ND & ND & ND & ND & ND & ND & ND & ND & ND \\
\hline 0.04 & 0.10 & 0.40 & 1.18 & 14.00 & 0.09 & 0.14 & 0.20 & 0.64 & 1.65 & 0.04 & 0.11 & 0.26 & 0.85 & 14.00 \\
\hline 0.03 & 0.05 & 0.12 & 0.12 & 0.35 & 0.03 & 0.04 & 0.05 & 0.08 & 0.11 & 0.03 & 0.04 & 0.11 & 0.12 & 0.35 \\
\hline 0.33 & 0.37 & 0.41 & 0.45 & 0.49 & 0.03 & 0.05 & 0.06 & 0.07 & 0.07 & 0.03 & 0.06 & 0.07 & 0.33 & 0.49 \\
\hline 0.03 & 0.04 & 0.06 & 0.26 & 1.83 & 0.03 & 0.03 & 0.05 & 0.05 & 0.30 & 0.03 & 0.03 & 0.05 & 0.22 & 1.83 \\
\hline 0.05 & 0.06 & 0.07 & 0.39 & 0.70 & ND & ND & ND & ND & ND & 0.05 & 0.06 & 0.07 & 0.39 & 0.70 \\
\hline 0.07 & 0.07 & 0.33 & 0.79 & 2.63 & 0.08 & 0.08 & 0.08 & 0.08 & 0.08 & 0.07 & 0.08 & 0.08 & 0.72 & 2.63 \\
\hline 0.07 & 0.09 & 0.07 & 0.12 & 0.16 & 0.06 & 0.06 & 0.06 & 0.06 & 0.06 & 0.06 & 0.06 & 0.06 & 0.07 & 0.16 \\
\hline ND & ND & ND & ND & ND & 0.05 & 0.05 & 0.05 & 0.05 & 0.05 & 0.05 & 0.05 & 0.05 & 0.05 & 0.05 \\
\hline 0.03 & 0.04 & 0.15 & 0.37 & 1.16 & 0.03 & 0.03 & 0.04 & 0.08 & 0.21 & 0.03 & 0.03 & 0.04 & 0.25 & 1.16 \\
\hline ND & ND & ND & ND & ND & ND & ND & ND & ND & ND & ND & ND & ND & ND & ND \\
\hline ND & ND & ND & ND & ND & ND & ND & ND & ND & ND & ND & ND & ND & ND & ND \\
\hline 0.10 & 0.19 & 0.35 & 1.99 & 4.98 & 0.03 & 0.05 & 0.07 & 0.11 & 0.70 & 0.03 & 0.06 & 0.10 & 0.35 & 4.98 \\
\hline 0.02 & 0.03 & 0.04 & 0.09 & 0.21 & 0.02 & 0.03 & 0.06 & 0.10 & 0.16 & 0.02 & 0.03 & 0.06 & 0.10 & 0.21 \\
\hline 0.06 & 0.06 & 0.06 & 0.06 & 0.06 & 0.03 & 0.03 & 0.03 & 0.03 & 0.03 & 0.03 & 0.04 & 0.05 & 0.05 & 0.06 \\
\hline 0.02 & 0.03 & 0.05 & 0.10 & 0.15 & 0.02 & 0.03 & 0.03 & 0.04 & 0.07 & 0.02 & 0.03 & 0.03 & 0.07 & 0.15 \\
\hline 0.03 & 0.05 & 0.07 & 0.08 & 0.33 & 0.03 & 0.05 & 0.10 & 0.25 & 0.90 & 0.03 & 0.05 & 0.08 & 0.13 & 0.90 \\
\hline ND & ND & ND & ND & ND & ND & ND & ND & ND & ND & ND & ND & ND & ND & ND \\
\hline 0.07 & 0.07 & 0.08 & 0.08 & 0.07 & 0.08 & 0.08 & ND & ND & 0.08 & 0.07 & 0.07 & 0.08 & 0.08 & 0.08 \\
\hline 0.03 & 0.06 & 0.09 & 0.14 & 0.99 & 0.06 & 0.07 & 0.08 & 0.11 & 0.13 & 0.03 & 0.06 & 0.08 & 0.13 & 0.99 \\
\hline 0.06 & 0.08 & 0.10 & 0.12 & 0.14 & ND & ND & ND & ND & ND & 0.06 & 0.08 & 0.10 & 0.12 & 0.14 \\
\hline ND & ND & ND & ND & ND & ND & ND & ND & ND & ND & ND & ND & ND & ND & ND \\
\hline ND & ND & ND & ND & ND & ND & ND & ND & ND & ND & ND & ND & ND & ND & ND \\
\hline ND & ND & ND & ND & ND & 0.04 & 0.04 & 0.04 & 0.04 & 0.04 & 0.04 & 0.04 & 0.04 & 0.04 & 0.04 \\
\hline ND & ND & ND & ND & ND & ND & ND & ND & ND & ND & ND & ND & ND & ND & ND \\
\hline 0.09 & 0.09 & 0.09 & 0.09 & 0.09 & ND & ND & ND & ND & ND & 0.09 & 0.09 & 0.09 & 0.09 & 0.09 \\
\hline 0.04 & 0.04 & 0.04 & 0.04 & 0.04 & ND & ND & ND & ND & ND & 0.04 & 0.04 & 0.04 & 0.04 & 0.04 \\
\hline 0.03 & 0.03 & 0.04 & 0.04 & 0.04 & 0.04 & 0.04 & 0.04 & 0.04 & 0.04 & 0.03 & 0.04 & 0.04 & 0.04 & 0.04 \\
\hline ND & ND & ND & ND & ND & ND & ND & ND & ND & ND & ND & ND & ND & ND & ND \\
\hline ND & ND & ND & ND & ND & ND & ND & ND & ND & ND & ND & ND & ND & ND & ND \\
\hline ND & ND & ND & ND & ND & ND & ND & ND & ND & ND & ND & ND & ND & ND & ND \\
\hline ND & ND & ND & ND & ND & ND & ND & ND & ND & ND & ND & ND & ND & ND & ND \\
\hline
\end{tabular}


Table D1. Statistical summary of volatile organic compounds in source-water samples in the Focused Survey-Continued [Values in micrograms per liter; $\mathrm{N}$, number of sources sampled; ND, not detected]

\begin{tabular}{|c|c|c|c|c|c|c|c|c|c|c|}
\hline \multirow{2}{*}{$\begin{array}{c}\text { Volatile organic } \\
\text { compounds }\end{array}$} & \multicolumn{5}{|c|}{ All community water systems $(\mathrm{N}=134)$} & \multicolumn{5}{|c|}{ Ground Water $(\mathrm{N}=78)$} \\
\hline & $\begin{array}{l}\text { Mini- } \\
\text { mum }\end{array}$ & 25th & Median & 75th & $\begin{array}{l}\text { Maxi- } \\
\text { mum }\end{array}$ & $\begin{array}{l}\text { Mini- } \\
\text { mum }\end{array}$ & 25th & Median & 75th & $\begin{array}{l}\text { Maxi- } \\
\text { mum }\end{array}$ \\
\hline \multicolumn{11}{|l|}{ Solvents-Continued } \\
\hline $1,1,2,2$-Tetrachloroethane & ND & ND & ND & ND & ND & ND & ND & ND & ND & ND \\
\hline 1,1,2-Trichloroethane & 0.04 & 0.07 & 0.10 & 0.12 & 0.15 & 0.04 & 0.07 & 0.10 & 0.12 & 0.15 \\
\hline 1,1-Dichloroethane & 0.04 & 0.05 & 0.09 & 0.33 & 3.85 & 0.04 & 0.07 & 0.10 & 0.36 & 3.85 \\
\hline 1,1-Dichloroethene & 0.10 & 0.14 & 0.64 & 1.53 & 9.78 & 0.10 & 0.14 & 0.64 & 1.53 & 9.78 \\
\hline 1,2,3-Trichloropropane & 0.03 & 0.04 & 0.05 & 0.08 & 0.09 & 0.03 & 0.04 & 0.05 & 0.07 & 0.08 \\
\hline 1,2,4-Trichlorobenzene & 0.06 & 0.06 & 0.06 & 0.08 & 0.14 & 0.06 & 0.08 & 0.10 & 0.12 & 0.14 \\
\hline 1,2-Dichlorobenzene & 0.18 & 0.19 & 0.20 & 0.21 & 0.22 & 0.18 & 0.19 & 0.20 & 0.21 & 0.22 \\
\hline 1,2-Dichloroethane & 0.03 & 0.06 & 0.14 & 0.39 & 2.14 & 0.03 & 0.06 & 0.14 & 0.39 & 2.14 \\
\hline 1,2-Dichloropropane & 0.04 & 0.09 & 0.11 & 0.17 & 1.04 & 0.04 & 0.09 & 0.11 & 0.17 & 1.04 \\
\hline 1,3-Dichlorobenzene & 0.04 & 0.05 & 0.05 & 0.11 & 0.17 & 0.04 & 0.05 & 0.05 & 0.11 & 0.17 \\
\hline 2-Chlorotoluene & ND & ND & ND & ND & ND & ND & ND & ND & ND & ND \\
\hline 4-Chlorotoluene & 0.03 & 0.03 & 0.03 & 0.03 & 0.03 & 0.03 & 0.03 & 0.03 & 0.03 & 0.03 \\
\hline Bromobenzene & ND & ND & ND & ND & ND & ND & ND & ND & ND & ND \\
\hline Carbon tetrachloride & 0.06 & 0.41 & 0.75 & 0.95 & 1.15 & 0.06 & 0.41 & 0.75 & 0.95 & 1.15 \\
\hline Chlorobenzene & 0.05 & 0.07 & 0.08 & 0.56 & 0.81 & 0.07 & 0.08 & 0.32 & 0.62 & 0.81 \\
\hline Chloroethane & 0.15 & 0.15 & 0.15 & 0.15 & 0.15 & 0.15 & 0.15 & 0.15 & 0.15 & 0.15 \\
\hline cis-1,2-Dichloroethene & 0.03 & 0.06 & 0.27 & 1.38 & 10.35 & 0.03 & 0.06 & 0.27 & 1.38 & 10.35 \\
\hline Dibromomethane & 0.30 & 0.30 & 0.30 & 0.30 & 0.30 & 0.30 & 0.30 & 0.30 & 0.30 & 0.30 \\
\hline Hexachloroethane & ND & ND & ND & ND & ND & ND & ND & ND & ND & ND \\
\hline Methyl ethyl ketone & 1.84 & 1.84 & 1.84 & 1.84 & 1.84 & 1.84 & 1.84 & 1.84 & 1.84 & 1.84 \\
\hline Methylene chloride & 0.31 & 0.31 & 0.31 & 0.31 & 0.31 & 0.31 & 0.31 & 0.31 & 0.31 & 0.31 \\
\hline$n$-Propylbenzene & 0.05 & 0.06 & 0.13 & 0.26 & 0.47 & 0.47 & 0.47 & 0.47 & 0.47 & 0.47 \\
\hline Tetrachloroethene & 0.05 & 0.10 & 0.39 & 4.24 & 290.00 & 0.05 & 0.10 & 0.39 & 4.24 & 290.00 \\
\hline trans-1,2-Dichloroethene & 0.05 & 0.07 & 0.19 & 0.29 & 0.45 & 0.05 & 0.07 & 0.19 & 0.29 & 0.45 \\
\hline Trichloroethene & 0.04 & 0.17 & 0.43 & 2.18 & 165.00 & 0.04 & 0.17 & 0.43 & 2.18 & 165.00 \\
\hline \multicolumn{11}{|l|}{ Fumigants } \\
\hline 1,4-Dichlorobenzene & 0.04 & 0.04 & 0.06 & 0.15 & 0.46 & 0.04 & 0.04 & 0.05 & 0.18 & 0.46 \\
\hline Bromomethane & 0.09 & 0.09 & 0.09 & 0.10 & 0.11 & 0.09 & 0.09 & 0.09 & 0.10 & 0.11 \\
\hline cis-1,3-Dichloropropene & ND & ND & ND & ND & ND & ND & ND & ND & ND & ND \\
\hline trans-1,3-Dichloropropene & ND & ND & ND & ND & ND & ND & ND & ND & ND & ND \\
\hline \multicolumn{11}{|l|}{ Refrigerants } \\
\hline $\begin{array}{l}\text { 1,1,2-Trichloro-1,2,2-trifluo- } \\
\text { roethane }\end{array}$ & 2.27 & 2.27 & 2.27 & 2.27 & 2.27 & 2.27 & 2.27 & 2.27 & 2.27 & 2.27 \\
\hline Chloromethane & 0.11 & 0.13 & 0.15 & 0.78 & 2.63 & 0.13 & 0.15 & 0.16 & 1.40 & 2.63 \\
\hline Dichlorodifluoromethane & 0.40 & 0.40 & 0.40 & 0.40 & 0.40 & 0.40 & 0.40 & 0.40 & 0.40 & 0.40 \\
\hline Trichlorofluoromethane & 0.23 & 0.35 & 0.46 & 0.48 & 0.50 & 0.23 & 0.35 & 0.46 & 0.48 & 0.50 \\
\hline
\end{tabular}




\begin{tabular}{|c|c|c|c|c|c|c|c|c|c|c|c|c|c|c|}
\hline \multicolumn{5}{|c|}{ Reservoir (N=39) } & \multicolumn{5}{|c|}{ Rivers $(\mathrm{N}=17)$} & \multicolumn{5}{|c|}{ All surface water $(\mathrm{N}=56)$} \\
\hline $\begin{array}{l}\text { Mini- } \\
\text { mum }\end{array}$ & 25th & Median & 75th & $\begin{array}{l}\text { Maxi- } \\
\text { mum }\end{array}$ & $\begin{array}{l}\text { Mini- } \\
\text { mum }\end{array}$ & 25th & Median & 75th & $\begin{array}{l}\text { Maxi- } \\
\text { mum }\end{array}$ & $\begin{array}{l}\text { Mini- } \\
\text { mum }\end{array}$ & 25th & Median & 75th & $\begin{array}{l}\text { Maxi- } \\
\text { mum }\end{array}$ \\
\hline ND & ND & ND & ND & ND & ND & ND & ND & ND & ND & ND & ND & ND & ND & ND \\
\hline ND & ND & ND & ND & ND & ND & ND & ND & ND & ND & ND & ND & ND & ND & ND \\
\hline ND & ND & ND & ND & ND & 0.04 & 0.04 & 0.04 & 0.04 & 0.04 & 0.04 & 0.04 & 0.04 & 0.04 & 0.04 \\
\hline ND & ND & ND & ND & ND & ND & ND & ND & ND & ND & ND & ND & ND & ND & ND \\
\hline 0.04 & 0.05 & 0.07 & 0.08 & 0.09 & ND & ND & ND & ND & ND & 0.04 & 0.05 & 0.07 & 0.08 & 0.09 \\
\hline 0.06 & 0.06 & 0.06 & 0.06 & 0.06 & 0.06 & 0.06 & ND & ND & 0.06 & 0.06 & 0.06 & 0.06 & 0.06 & 0.06 \\
\hline ND & ND & ND & ND & ND & ND & ND & ND & ND & ND & ND & ND & ND & ND & ND \\
\hline ND & ND & ND & ND & ND & ND & ND & ND & ND & ND & ND & ND & ND & ND & ND \\
\hline ND & ND & ND & ND & ND & ND & ND & ND & ND & ND & ND & ND & ND & ND & ND \\
\hline ND & ND & ND & ND & ND & ND & ND & ND & ND & ND & ND & ND & ND & ND & ND \\
\hline ND & ND & ND & ND & ND & ND & ND & ND & ND & ND & ND & ND & ND & ND & ND \\
\hline ND & ND & ND & ND & ND & ND & ND & ND & ND & ND & ND & ND & ND & ND & ND \\
\hline ND & ND & ND & ND & ND & ND & ND & ND & ND & ND & ND & ND & ND & ND & ND \\
\hline ND & ND & ND & ND & ND & ND & ND & ND & ND & ND & ND & ND & ND & ND & ND \\
\hline ND & ND & ND & ND & ND & 0.05 & 0.05 & 0.05 & 0.05 & 0.05 & 0.05 & 0.05 & 0.05 & 0.05 & 0.05 \\
\hline ND & ND & ND & ND & ND & ND & ND & ND & ND & ND & ND & ND & ND & ND & ND \\
\hline ND & ND & ND & ND & ND & ND & ND & ND & ND & ND & ND & ND & ND & ND & ND \\
\hline ND & ND & ND & ND & ND & ND & ND & ND & ND & ND & ND & ND & ND & ND & ND \\
\hline ND & ND & ND & ND & ND & ND & ND & ND & ND & ND & ND & ND & $\mathrm{ND}$ & ND & ND \\
\hline ND & ND & ND & ND & ND & ND & ND & ND & ND & ND & ND & ND & ND & ND & ND \\
\hline ND & ND & ND & ND & ND & ND & ND & ND & ND & ND & ND & ND & ND & ND & ND \\
\hline 0.05 & 0.09 & 0.12 & 0.16 & 0.19 & 0.06 & 0.06 & 0.06 & 0.06 & 0.06 & 0.05 & 0.06 & 0.06 & 0.13 & 0.19 \\
\hline ND & ND & ND & ND & ND & ND & ND & ND & ND & ND & ND & ND & ND & ND & ND \\
\hline ND & ND & ND & ND & ND & ND & ND & ND & ND & ND & ND & ND & ND & ND & ND \\
\hline ND & ND & ND & ND & ND & ND & ND & ND & ND & ND & ND & ND & ND & ND & ND \\
\hline 0.06 & 0.06 & 0.06 & 0.06 & 0.06 & ND & ND & ND & ND & ND & 0.06 & 0.06 & 0.06 & 0.06 & 0.06 \\
\hline 0.09 & 0.09 & 0.09 & 0.09 & 0.09 & ND & ND & ND & ND & ND & 0.09 & 0.09 & 0.09 & 0.09 & 0.09 \\
\hline ND & ND & ND & ND & ND & ND & ND & ND & ND & ND & ND & ND & ND & ND & ND \\
\hline ND & ND & ND & ND & ND & ND & ND & ND & ND & ND & ND & ND & ND & ND & ND \\
\hline ND & ND & ND & ND & ND & ND & ND & ND & ND & ND & ND & ND & ND & ND & ND \\
\hline ND & ND & ND & ND & ND & 0.11 & 0.11 & 0.11 & 0.11 & 0.11 & 0.11 & 0.11 & 0.11 & 0.11 & 0.11 \\
\hline ND & ND & ND & ND & ND & ND & ND & ND & ND & ND & ND & ND & ND & ND & ND \\
\hline ND & ND & ND & ND & ND & ND & ND & ND & ND & ND & ND & ND & ND & ND & ND \\
\hline
\end{tabular}

